NBER WORKING PAPER SERIES

\title{
BANKING ON DEPOSITS: \\ MATURITY TRANSFORMATION WITHOUT INTEREST RATE RISK
}

\author{
Itamar Drechsler \\ Alexi Savov \\ Philipp Schnabl \\ Working Paper 24582 \\ http://www.nber.org/papers/w24582 \\ NATIONAL BUREAU OF ECONOMIC RESEARCH \\ 1050 Massachusetts Avenue \\ Cambridge, MA 02138 \\ May 2018
}

We thank Markus Brunnermeier, Eduardo Davila, John Driscoll, Mark Egan, Mark Flannery, Raj Iyer, Arvind Krishnamurthy, Yueran Ma, Gregor Matvos, Monika Piazzesi, Anthony Saunders, David Scharfstein, Andrei Shleifer, Philip Strahan, Adi Sunderam, Bruce Tuckman, James Vickery, and seminar participants at the American Economic Association Meeting, BIS Research Meeting, Brandeis University, Carnegie Mellon, Chinese University in Hong Kong, ECB Monetary Policy Forum, FDIC, FRB Chicago, FRB New York, FRB Philadelphia, FRB San Francisco, Federal Reserve Board, Hong Kong University of Science and Technology, International Research Forum on Monetary Policy, LBS Summer Symposium, MIT Macroeconomics Seminar, NBER Summer Institute Corporate Finance, NBER Monetary Economics, Northwestern Macroeconomics Seminar, Ohio State University, Office of Financial Research, Princeton University, Purdue University, SITE, University of Amsterdam, University of Michigan, University of Pittsburgh, University of Rochester, and Yale University for their comments. We also thank Patrick Farrell, Manasa Gopal, and Pauline Liang for excellent research assistance. The views expressed herein are those of the authors and do not necessarily reflect the views of the National Bureau of Economic Research.

NBER working papers are circulated for discussion and comment purposes. They have not been peerreviewed or been subject to the review by the NBER Board of Directors that accompanies official NBER publications.

(C) 2018 by Itamar Drechsler, Alexi Savov, and Philipp Schnabl. All rights reserved. Short sections of text, not to exceed two paragraphs, may be quoted without explicit permission provided that full credit, including $\odot$ notice, is given to the source. 
Banking on Deposits: Maturity Transformation without Interest Rate Risk

Itamar Drechsler, Alexi Savov, and Philipp Schnabl

NBER Working Paper No. 24582

May 2018, Revised January 2020

JEL No. E43,E52,G21,G31

\begin{abstract}
$\underline{\text { ABSTRACT }}$
We show that maturity transformation does not expose banks to significant interest rate risk/it hedges it. This is due to banks' deposit franchise. The deposit franchise gives banks substantial market power over deposits, allowing them to pay deposit rates that are low and insensitive to market interest rates. Maintaining this power requires banks to incur large, interest-insensitive operating costs, so that the total costs of deposits are similar to fixed-rate, long-term debt. Hedging these costs therefore requires banks to lend long term|i.e., to do maturity transformation. As predicted by this theory, we document that banks' net interest margins have been highly stable and insensitive to interest rates, and banks' net worth is largely insulated from monetary policy shocks. We further show that banks match the interest-rate sensitivities of their expenses and income one-for-one, so that banks with less interest-sensitive deposits (more market power) hold assets with substantially longer duration. Our results show that deposits are special because they are short-term and yet have interest-insensitive costs, which explains why banks are able to supply long-term credit.
\end{abstract}

Itamar Drechsler

Wharton School

University of Pennsylvania

3620 Locust Walk

Philadelphia, PA 19104

and NBER

idrechsl@wharton.upenn.edu
Philipp Schnabl

Stern School of Business

New York University

44 West Fourth Street

New York, NY 10012

and NBER

schnabl@stern.nyu.edu

Alexi Savov

Stern School of Business

New York University

44 West Fourth Street, Suite 9-80

New York, NY 10012

and NBER

asavov@stern.nyu.edu 


\section{Introduction}

A defining function of banks is maturity transformation-borrowing short term and lending long term. This function is important because it supplies firms with long-term credit and households with short-term, liquid deposits. In textbook models, banks engage in maturity transformation to earn the average difference between the long- and short-term rates - the term premium - but this exposes them to interest rate risk. An unexpected increase in the short rate makes banks' interest expenses rise relative to interest income, pushing down net interest margins and depleting banks' capital. Interest rate risk is therefore viewed as fundamental to the economic model of banking, and it underlies discussion of how monetary policy impacts the banking sector. ${ }^{1}$

In this paper, we show that in fact banks do not take on interest rate risk, despite having a large maturity mismatch. The reason for this is the deposit franchise. Because of the deposit franchise, maturity transformation actually reduces the amount of risk banks take on. The deposit franchise has two essential properties that drive this result. The first is that it gives banks market power over retail deposits, which allows them to borrow at rates that are both low and insensitive to the market short rate. The second is that running a deposit franchise incurs high costs (branches, salaries, marketing), but these costs are largely fixed and hence also insensitive to the short rate. Therefore, even though deposits are short-term, funding via a deposit franchise resembles funding with long-term fixed-rate debt.

This makes it natural for banks to hedge their deposit franchise by holding long-term fixed-rate assets. And since deposits are very large, so too are banks' long-term asset holdings. Thus, a big maturity mismatch actually insulates banks' profits from interest rate risk. We show empirically that this is true in the aggregate: bank profits are insensitive to even large fluctuations in interest rates. It is also true in the cross section: banks that have a stronger deposit franchise - and hence less sensitive interest expenses - hold more long-term assets. Moreover, there is a close quantitative match: banks with less sensitive interest expenses have one-for-one less sensitive interest income, which makes their profits fully hedged

\footnotetext{
${ }^{1}$ In 2010, Federal Reserve Vice Chairman Donald Kohn argued that "Intermediaries need to be sure that as the economy recovers, they aren't also hit by the interest rate risk that often accompanies this sort of mismatch in asset and liability maturities" (Kohn 2010). See also Boivin, Kiley, and Mishkin (2010).
} 
with respect to interest rates.

Our findings have several important implications. First, they explain why deposit taking and long-term lending take place within the same institution, thereby providing a new answer to one of the fundamental questions in banking (e.g., Kashyap, Rajan, and Stein 2002). This question underlies the renewed debate surrounding narrow banking, which argues for separating deposit taking from long-term lending (Friedman 1960, Cochrane 2014). Our results suggest that narrow banking could make banks more exposed to interest rate risk and reduce the supply of long-term credit. ${ }^{2}$ Second, our findings have implications for the transmission of monetary policy. In particular, they imply that banks are largely insulated from the balance sheet channel of monetary policy, the idea that interest rate changes influence bank lending by shocking their net worth (Bernanke and Gertler 1989, Bernanke, Gertler, and Gilchrist 1999). ${ }^{3}$ More broadly, our results show that, in a world where interest rates fluctuate widely, the deposit franchise is the reason why banks can provide long-term loans without taking on interest rate risk.

We begin the analysis by documenting that banks do in fact engage in significant maturity transformation. Aggregate bank assets have an average estimated duration of 4.2 years, versus only 0.4 years for liabilities. This mismatch of about 4 years is large and stable over time. It implies that if banks paid market rates on their liabilities (as assumed in the textbook model), then a 100-bps level shock to interest rates would cause a cumulative 400bps reduction in net interest margins (interest income minus interest expenses, divided by assets) over the following years. This loss in profits would lead to a $4 \%$ decline in the book value of assets relative to liabilities over the same period. This is a very large hit for banks; it amounts to four years worth of profits given that the industry return on assets is just $1 \%$. Although it would take time for the losses to be reflected in book values, investors would immediately price in the full $4 \%$ drop in market values. And since banks are levered ten to one, the $4 \%$ drop in assets would translate to a $40 \%$ drop in banks' stock prices.

Yet in practice we find that a 100-bps shock to interest rates induces only a $4.2 \%$ drop

\footnotetext{
${ }^{2}$ We understand narrow banking as allowing banks to invest only in short-term safe claims, precisely to avoid the interest-rate exposure that the literature associates with maturity transformation.

${ }^{3}$ Drechsler, Savov, and Schnabl (2017) present an alternative channel of monetary policy that does not rely on variation in banks' net worth.
} 
in bank stock prices, a value that is an order of magnitude smaller than that implied by the duration mismatch. We obtain this result by regressing the return on a portfolio of bank stocks on the change in the one-year rate around FOMC meetings. In addition to being small, this sensitivity is very similar to that of the overall market portfolio (which drops by $3.7 \%$ ), and is close to the median for the Fama-French 49 industries. Banks are thus no more exposed to interest rate shocks than the typical non-financial firm. ${ }^{4}$

To understand this result, we look at the interest rate sensitivity of banks' cash flows. We find that, consistent with their low equity sensitivity but in stark contrast to the textbook view, aggregate bank cash flows are insensitive to interest rate changes. Since 1955 net interest margins (NIM) have stayed in a narrow band between $2.2 \%$ and $3.8 \%$, even as the short rate has fluctuated widely and persistently between $0 \%$ and $16 \%$. Furthermore, yearly NIM changes have had a standard deviation of just $0.15 \%$, and zero correlation with changes in the short rate. Thus, fluctuations in NIM have been both extremely small and unrelated to changes in interest rates.

We show that the insensitivity of NIM is explained by banks' deposit franchise. We do so by breaking down NIM into its two components, interest income and interest expense (divided by assets in each case), and comparing the two components' interest rate sensitivties. We find that interest income has a low sensitivity to the short rate. This is expected because banks' assets are primarily long-term and fixed-rate, hence the income they generate is locked in for term. The surprising finding is that the sensitivity of interest expense is just as low, despite the fact that banks' liabilities are overwhelmingly of zero and near-zero maturity. The explanation for this apparent paradox is that having a deposit franchise gives banks substantial market power over retail deposits (Drechsler, Savov, and Schnabl 2017), which allows them to keep deposit rates low even when the market short rate rises. And since retail (core) deposits comprise over $70 \%$ of bank liabilities, this low sensitivity carries over to banks' overall interest expense. The deposit franchise thus allows banks to simultaneously have a large duration mismatch and a near-perfect match of the interest rate sensitivities of their income and expenses.

\footnotetext{
${ }^{4}$ We interpret the impact of interest rates on equity values as a discount rate shock that affects both non-financial firms and banks (Bernanke and Kuttner (2005)). The important result is that there is no additional effect for banks relative to non-financial firms.
} 
Of course, a deposit franchise does not come for free. To the contrary, banks pay high operating costs to maintain their deposit franchise. They invest in a network of retail outlets, in marketing their products, in servicing their customers, and in offering the latest financial technologies. These costs account for the large $2 \%$ to $3 \%$ drop from banks' NIM to their bottom-line return on assets (ROA). Yet while these costs are high, they do not vary with interest rates and are quite stable. Indeed, they resemble the operating expenses of nonfinancial firms. As a result, the insensitivity of NIM flows through to ROA.

We present a simple model that captures these findings. In the model, banks pay a fixed per-period operating cost to run their deposit franchise. This gives them market power, which allows them to pay a deposit rate that is only a fixed fraction of the market shortterm rate, as in Drechsler, Savov, and Schnabl (2017). The model shows that the deposit franchise functions like an interest rate swap in which the bank pays the fixed leg and receives the floating leg. The fixed leg is the operating cost the bank pays to obtain market power, while the floating leg is the interest spread it charges depositors by paying them a low deposit rate. The value of the deposit franchise can then be viewed as the net present value of this swap (the present value of the floating leg minus the fixed leg). As with any interest rate swap, this value is exposed to interest rate changes. In particular, an increase in interest rates causes the present value of the fixed leg to fall, and since the swap is short the fixed leg, the value of the deposit franchise rises. ${ }^{5}$ Thus, the deposit franchise has a positive exposure to interest rates; equivalently, it has negative interest rate duration.

Banks hedge their deposit franchise by taking the opposite exposure on their balance sheets. They do this by buying long-term fixed-rate assets (positive duration). When there is free entry into the deposit market, the average deposit spread banks can charge just cover their operating cost, and their net deposit rents are zero (i.e., the deposit franchise is fairly priced). In this case, banks earn very thin margins at very high leverage, so it is crucial for them to be tightly hedged. This requires them to perfectly match the sensitivities of their income and expenses to the short rate, so that their NIM and ROA are unexposed. Thus, the model explains why banks' aggregate interest income and expenses have the same

\footnotetext{
${ }^{5}$ We can also think of this result in terms of the forward value of the swap's cash flows. The forward value increases because the cash flows of the floating leg (the deposit spreads) rise relative to the cash flows of the fixed leg (the operating costs).
} 
sensitivity to the short rate, and why aggregate NIM and ROA are so stable.

An important insight from the model is that a fundamental part of banks' interest rate exposure - the exposure of the deposit franchise - does not appear on the balance sheet. This is because neither the deposit spread banks earn, nor the operating cost they pay, are capitalized. They do, however, figure prominently in banks' income and expenses. This is why our analysis examines banks' income and expenses, in combination with analyzing banks' net worth.

The model further predicts that income and expense rate sensitivities should match bankby-bank. We test this prediction in the cross section using quarterly data on U.S. commercial banks from 1984 to $2017 .{ }^{6}$ For each bank we estimate an interest expense sensitivity, which we call its interest expense beta, by regressing the change in its interest expense (divided by assets) on contemporaneous and lagged changes in the Fed funds rate, and then summing the coefficients. We compute its interest income beta analogously. The average expense and income betas are 0.354 and 0.371 , respectively, with substantial variation in the 0.1 to 0.6 range.

We find that estimated expense and income betas match up very strongly across banks. Their correlations are 51\% among all banks and 58\% among the largest 5\% of banks. In addition, the slopes from a regression of income betas on expense betas are 0.768 and 0.881 , respectively. The fact that these slopes are close to one shows that there is close to onefor-one matching, as predicted by the model. These results are confirmed in two-stage panel regressions with time fixed effects, which produce estimates that are more precise and even closer to one for the large banks (0.993 for large banks, 0.773 for all banks). The strong matching makes banks' profitability essentially unexposed: ROA betas (computed analogously to expense betas) are close to zero across the board, as predicted by the model.

Our estimates predict that a bank with an expense beta of one would have an income beta close to one. Although these betas are outside the range of variation in our sample, they have predictive power out of sample. In particular, they fit money market funds, which obtain funding at the Fed funds rate (expense beta of one) and only hold short-term assets (income beta of one), hence they do not engage in maturity transformation.

\footnotetext{
${ }^{6}$ We have posted the code for creating our sample and the sample itself on our websites.
} 
The insensitivity of banks' profits to interest rate shocks is confirmed by our analysis of banks' net worth. Following the methodology we used for the bank industry portfolio, we estimate firm-level "FOMC betas" for all publicly traded commercial banks. As in the aggregate, the average FOMC beta of banks is close to that of the market. More importantly, there is a flat relationship between banks' FOMC betas and their expense and income betas. This shows that there is no relationship between a bank's asset duration, as reflected in its income beta, and its net worth's exposure to interest rate risk. While this result is very puzzling from the vantage point of standard duration calculations, it is a clear and direct implication of our model.

We also directly test whether banks with low expense betas hold more long-term, fixedrate assets. The answer is yes: there is a strong negative relationship between a bank's interest expense beta and the estimated duration of its assets. The slope of this relationship is -3.4 years, which is large and close to the average duration of banks' assets. It again extrapolates to fit the duration of money market fund assets.

We consider two main alternative explanations for our matching results. One possibility is that banks with higher expense betas face more run (liquidity) risk, and in response hold more short-term assets as a buffer. Although this explanation does not predict one-for-one matching, it goes in the right direction. We address it by analyzing the shares of loans versus securities on banks' balance sheets. Since loans are far less liquid than securities, the liquidity risk explanation predicts that high expense-beta banks should hold more securities and fewer loans. Yet we find the exact opposite: it is low expense-beta banks that hold more securities and fewer loans. This result is consistent with our model because the average duration of securities is much higher than that of loans (8.4 years versus 3.8 years). Thus, liquidity risk is unlikely to explain our results. ${ }^{7}$

We also consider the possibility that the sensitivity matching we observe is the product of market segmentation. Perhaps banks with more market power over deposits also have more long-term lending opportunities. This explanation also does not predict one-for-one

\footnotetext{
${ }^{7}$ In addition to loans and securities, a small fraction of banks (about 13\%) make use of interest rate derivatives. In principle, banks can use these derivatives to hedge the interest rate exposure of their assets, yet the literature argues that they actually use them to increase it (Begenau, Piazzesi, and Schneider 2015). We show that our sensitivity matching results hold both for banks that do and do not use interest rate derivatives. Hence, derivatives use does not drive our results.
} 
matching. Nevertheless, we test it by checking if banks match the income betas of their securities holdings to their expense betas. Since securities are bought and sold in open markets, they are not subject to market segmentation. We once again find close matching, even when we focus narrowly on banks' holdings of Treasuries and agency MBS. This shows that banks actively match their interest income and expense sensitivities.

Finally, we provide direct evidence for the market power mechanism underlying the interest rate exposure of the deposit franchise in our model. We do so by exploiting three sources of geographic variation in market power in deposit provision. First, we use variation in local market concentration. We find that banks that raise deposits in more concentrated markets have lower expense betas and lower income betas, with a matching coefficient that is again close to one.

Second, we exploit branch-level variation in the rates banks pay on retail deposit products (interest checking, savings, and small time deposits) using data from the provider Ratewatch. These products are marketed directly to households in local markets and are thus the source of banks' market power. ${ }^{8}$ We regress changes in the average rates of these retail deposits by county on Fed funds rate changes and obtain a county-level retail deposit beta. We then average these county betas for each bank, weighting by the county's share of the bank's branches, to obtain a bank-level retail deposit beta. Again, we find that variation in banks' market power, as captured by their retail deposit betas, is strongly related to their overall expense betas, and that banks match this variation one-for-one with their income betas.

Third, we add bank-time fixed effects to the estimation of the county-level retail deposit betas, and thus estimate these betas using only differences in retail deposit rates across branches of the same bank. This purges them of any time-varying bank characteristics (e.g., loan demand), giving us a clean measure of local market power. Using the purged betas as an instrument for banks' overall expense betas, we again find one-for-one matching between income and expense sensitivities.

The rest of this paper is organized as follows. Section II discusses the related literature; Section III analyzes the aggregate time series; Section IV presents the model; Section V describes the data; Section VI contains our main sensitivity matching results; Section VII

\footnotetext{
${ }^{8}$ They are also well below the deposit insurance limit and hence immune to credit and run risk.
} 
looks at the asset side of bank balance sheets; Section VIII shows our results on market power; and Section IX concludes.

\section{Related literature}

Banks issue short-term deposits and make long-term loans. This dual function underlies modern banking theory (Diamond and Dybvig 1983, Diamond 1984, Gorton and Pennacchi 1990, Calomiris and Kahn 1991, Diamond and Rajan 2001, Kashyap, Rajan, and Stein 2002, Hanson, Shleifer, Stein, and Vishny 2015). Central to this literature is the liquidity risk that arises from issuing run-prone deposits. Brunnermeier, Gorton, and Krishnamurthy (2012) and Bai, Krishnamurthy, and Weymuller (2016) provide quantitative assessments of this liquidity risk. Our paper instead focuses on the interest rate risk that arises from maturity transformation. Liquidity risk and interest rate risk are distinct since assets can be exposed to one but not the other. For instance, a floating-rate bond has liquidity risk but no interest rate risk (its duration is zero), whereas a Treasury bond has interest rate risk but no liquidity risk (it can be resold easily). A broader distinction is that liquidity risk is concentrated in financial crises whereas interest rate risk is first-order at all times.

Other explanations for why banks engage in maturity transformation rely on the presence of a term premium. ${ }^{9}$ In Diamond and Dybvig (1983), an implicit term premium arises because households demand short-term claims but banks' productive projects are long-term. In a recent class of dynamic general equilibrium models, maturity transformation in the financial sector varies with the magnitude of the term premium and effective risk aversion (He and Krishnamurthy 2013, Brunnermeier and Sannikov 2014, 2016, Drechsler, Savov, and Schnabl 2018). In Di Tella and Kurlat (2017), as in our paper, deposit rates are relatively insensitive to interest rate changes (due to a net worth constraint rather than market power). This makes banks less averse to interest rate risk than other agents and induces them to maintain a maturity mismatch in order to earn the term premium. The result is a very large equity exposure: a 1\% increase in interest rates causes banks' net worth to drop by $31 \%$.

\footnotetext{
${ }^{9}$ The term premium has declined and appears to have turned negative in recent years (see https://www.newyorkfed.org/research/data_indicators/term_premia.html). At the same time, banks' maturity mismatch has remained unchanged.
} 
This is about the same as the textbook duration calculation but an order of magnitude larger than what we find empirically.

In contrast to this literature, our paper offers a risk-management rather than a risktaking explanation for banks' maturity mismatch. Under the risk-management explanation, maturity mismatch reduces banks' risk instead of increasing it. It also gives the strong quantitative prediction of one-for-one matching between between the interest sensitivities of income and expenses. We find this prediction to be borne out in the data. ${ }^{10}$

Consistent with the risk-management explanation, Bank of America's (2016) annual report reads, "Our overall goal is to manage interest rate risk so that movements in interest rates do not significantly adversely affect earnings and capital." Appendix A provides further discussion of bank risk management taken directly from the annual reports of the largest U.S. banks. ${ }^{11}$ For formal models of bank risk management, see Froot, Scharfstein, and Stein (1994), Freixas and Rochet (2008), and Nagel and Purnanandam (2015).

The empirical banking literature has looked at banks' sensitivity to interest rate shocks. In a sample of 15 banks, Flannery (1981) finds that bank profits have a surprisingly low exposure and frame this as a puzzle. Flannery (1983) finds the same result using a sample of 60 small banks. Purnanandam (2007) argues that banks use interest rate derivatives to reduce the sensitivity of lending policy to interest rate shocks. Flannery and James (1984a) and English, den Heuvel, and Zakrajsek (2012) examine the cross section of banks' stock price exposures, but without comparing banks to other firms to see if they are special. The exposures in English, den Heuvel, and Zakrajsek (2012) are somewhat larger than ours because they include unscheduled emergency FOMC meetings. Nevertheless, they remain much smaller than predicted and only slightly larger than the exposure of non-financial firms. $^{12}$

Other papers estimate banks' interest rate risk exposure from balance sheet data. Bege-

\footnotetext{
${ }^{10}$ We do not argue that our theory represents the only reasons why banks engage in the lending. We view our model as complimentary to existing models of why banks do informationally sensitive lending (e.g., Diamond (1984)).

${ }^{11}$ Our explanation is also consistent with case studies of bank interest rate risk management (e.g., Backus, Klapper, and Telmer (1994), Esty, Tufano, and Headley (1994).

12 Bernanke and Kuttner (2005) argues that the exposure of non-financial firms is due to an increase in the equity risk premium. Nakamura and Steinsson (2018) argues that the exposure comes from improved growth expectations.
} 
nau, Piazzesi, and Schneider (2015) and Begenau and Stafford (2018) find that bank balance sheets are heavily exposed to interest rates. Rampini, Viswanathan, and Vuillemey (2016) finds that banks hedge more of their interest rate risk if their net worth is larger. Our paper shows that banks' balance sheet exposure is hedged by the deposit franchise. ${ }^{13}$

Our paper connects with Drechsler, Savov, and Schnabl (2017) to create the following picture of the impact of interest rates on banks. Banks invest heavily in building a deposit franchise, which gives them market power. They exploit this market power by charging higher deposit spreads when interest rates rise. This makes deposits resemble long-term debt and leads banks to hold long-term assets so that their NIM and net worth are hedged. Yet, as Drechsler, Savov, and Schnabl (2017) show, to charge these higher spreads banks have to cut their deposit supply (like any monopolist), and must therefore contract their balance sheets. Thus, monetary policy exerts a powerful impact on banks' credit supply, even as NIM and net worth are hedged.

Under this framework banks with more market power have both a bigger maturity mismatch and more sensitive credit supply. This can explain the finding of Gomez, Landier, Sraer, and Thesmar (2016) that banks with a bigger income gap (a measure of maturity mismatch) contract lending by more when interest rate rise. Moreover, our results suggest that banks should become less willing to hold long-term assets as their deposits flow out. This can shed light on the finding of Haddad and Sraer (2015) that the income gap negatively predicts bond returns.

A canonical example of interest rate risk in the financial sector comes from the Savings and Loans (S\&L) crisis of the 1980s. An unprecedented rise in interest rates inflicted severe losses on S\&Ls, which were subject to a duration mismatch by regulation (White 1991). The rise in interest rates also triggered deposit outflows from commercial banks to money market funds, thereby leading to disintermediation in the banking sector and creating demand for securitization. We draw two important lessons from this historical episode. First, our data shows that unlike S\&Ls commercial banks saw no decline in NIM during this period because

\footnotetext{
${ }^{13}$ This point relates to the debate about whether bank balance sheets should be marked to market. Our analysis implies that for mark-to-market accounting to properly capture banks' interest rate risk, the deposit franchise would have to be capitalized on the balance sheet. Otherwise, as long as income from the deposit franchise is booked only as it accrues over time, it is consistent to do the same on the asset side.
} 
they were able to keep their deposit rates low. And second, as White (1991) points out, the rise in interest rates occurred right after deposit rates were deregulated, making it difficult for S\&Ls to anticipate the effect of such a large shock on their funding costs. Thus, when it comes to banks' interest rate risk exposure, the S\&L crisis is in some ways the exception that proves the rule.

The deposits literature has documented the low sensitivity of deposit rates to market rates, a key ingredient in our paper (Hannan and Berger 1991, Neumark and Sharpe 1992, Driscoll and Judson 2013, Yankov 2014, Drechsler, Savov, and Schnabl 2017). A subset of this literature (Flannery and James 1984b, Hutchison and Pennacchi 1996, Janosi, Jarrow, and Zullo 1999, O'Brien 2000) estimates the effective duration of deposits, finding it to be higher than their contractual maturity, consistent with a low interest rate sensitivity. ${ }^{14}$ Consistent with low interest rate sensitivity, Adams, Hunt, Palmer, and Zaliauskas (2019) conduct a large-scale field experiment in the U.K. and find that most households don't move savings accounts to other banks even if they are informed about significantly higher deposit rates elsewhere, Nagel (2016) and Duffie and Krishnamurthy (2016) extend the low sensitivity finding to a wider set of bank instruments. Brunnermeier and Koby (2016) argue that deposit rates become fully insensitive when nominal rates turn negative, and that this impacts bank profitability and undermines the effectiveness of monetary policy.

The deposits literature has also examined the relationship between deposit funding and bank assets. Kashyap, Rajan, and Stein (2002) emphasize the synergies between the liquidity needs of depositors and bank borrowers. Gatev and Strahan (2006) show that banks experience inflows of deposits in times of stress, which in turn allows them to provide more liquidity to their borrowers. Hanson, Shleifer, Stein, and Vishny (2015) argue that banks are better suited to holding fixed-rate assets than shadow banks because deposits are more stable than wholesale funding. Egan, Hortaçsu, and Matvos (2017) examine the effect of deposit competition on financial fragility. Berlin and Mester (1999) show that deposits allow banks to smooth out aggregate credit risk. Kirti (2017) finds that banks with more floating-rate liabilities extend more floating-rate loans to firms. Our paper focuses on banks' exposure

\footnotetext{
${ }^{14}$ These papers focus on the contribution of deposit rents to bank valuations. A recent paper in this area is Egan, Lewellen, and Sunderam (2016), which finds that deposits are the main driver of bank value.
} 
to interest rate risk and provides an explanation for the co-existence of deposit-taking and maturity transformation.

\section{Aggregate findings}

In this section we analyze the aggregate exposure of banks to changes in interest rates. We first document the extent to which banks engage in maturity transformation by estimating the durations of their assets and liabilities. We estimate an asset's duration using its repricing maturity, which is defined as the minimum of the time until the asset's interest rate resets and the time until the asset matures. ${ }^{15}$ Repricing maturity is a useful proxy for asset duration and, importantly, one that is available from from public data. We provide details on the estimation in Appendix B.

Figure 1 plots the time series of estimated durations of aggregate bank assets and liabilities for the period 1997 to 2017. The average asset duration in the sample is 4.2 years, rising slightly in the late 1990s before leveling off in the mid-2000s. The average liabilities duration is 0.4 years, declining slightly toward the end of the sample. Thus, the aggregate banking sector exhibits a duration mismatch of about 4 years, which has been stable throughout most of the sample.

A duration mismatch of 4 years is economically large. It implies that a $1 \%$ level shock to interest rates would cause the value of banks' assets to decline by $4 \%$ relative to liabilities. The ten-to-one leverage of banks amplifies this number to a $40 \%$ decline in equity values. Thus, one way to test if maturity transformation exposes banks to interest rate risk is by estimating the sensitivity of their equity prices to interest rate shocks. We do so by regressing the returns of an industry portfolio of bank stocks on changes in the one-year Treasury rate around Federal Open Market Committee (FOMC) meetings. For comparison, we also estimate this sensitivity for other industries and for the market portfolio. ${ }^{16}$

\footnotetext{
${ }^{15}$ For example, the repricing maturity of a floating-rate bond that pays quarterly is one quarter, regardless of its maturity, while the repricing maturity of a fixed-rate bond is the time remaining until maturity.

${ }^{16}$ We report the regression results in Appendix Table A.1. We use the 49 Fama-French industry portfolios, available from Ken French's website. We use a one-day-window around FOMC meetings. The sample starts in January 1994 (when the FOMC began making announcements) and ends in June 2007 (before the onset of the 2007-2009 financial crisis). We focus on the 108 scheduled meetings over this period (the 5 unscheduled ones are contaminated by other types of interventions). The results are unaffected if we use other maturities,
} 
Figure 2 displays the results. The coefficient for banks is -4.24 , hence bank stocks drop by $4.24 \%$ for every $1 \%$ positive shock to the one-year rate. This number is an order of magnitude smaller than predicted by the duration mismatch. Moreover, banks' sensitivity is very similar to that of the overall market portfolio $(-3.71)$, and ranks only $20^{\text {th }}$ among the 49 industries. Thus, in spite of their large duration mismatch, banks are no more exposed to interest rate shocks than the typical non-financial firm.

This result implies that banks have an asset whose interest-rate exposure offsets that of their duration mismatch, yet does not appear on their balance sheets. Another way to infer this is by looking at their cash flows. Banks' duration mismatch implies that an increase in interest rates should cause the rate the bank pays on its liabilities to rise relative to the average rate it earns on its assets, and hence cause their difference, the net interest margin (NIM), to fall.

We find that this is not what happens. Panel A of Figure 3 plots banks' aggregate NIM (interest income minus interest expense, divided by assets) from 1955 to $2017 .{ }^{17}$ It also plots the short-term rate (the Fed funds rate), which has varied very widely and persistently over the decades, from $2 \%$ in the 1950 s to over $16 \%$ in the early 1980 s then back to $0 \%$ after the 2008 financial crisis. On top of these decades-long fluctuations, the short rate has gone through the peaks and troughs of multiple business cycles, each measuring between three and five percentage points. This shows there has been a lot of risk in interest rates.

Despite this, aggregate bank NIM has never strayed outside a narrow band between $2.2 \%$ and $3.8 \%$. Moreover, movements within this band have been very slow and gradual, and have no obvious connection to interest rates. Formally, NIM changes have an annual standard deviation of just $0.15 \%$, and zero correlation with the Fed funds rate. To complete the picture, the figure also plots banks' return on assets (ROA, net income divided by assets), which is a standard measure of profitability. It shows that ROA is just as insensitive to interest rates as NIM. Overall, the lack of exposure of banks' cash flows to interest rates is consistent with the low exposure of their equity.

The asset that reconciles banks' low cash flow exposure with their high balance sheet

or if we control for slope changes.

${ }^{17}$ The data is from the Historical Statistics on Banking from the Federal Deposit Insurance Corporation (FDIC). The sample starts in 1955, the year the Fed funds rate becomes available. 
exposure is the deposit franchise. We can hone in on its impact by breaking out the two components of NIM: interest income and interest expense (divided by assets). These are shown in Panel B of Figure 3. Interest income is close to a moving average of past shortterm interest rates, which is exactly as expected given the long-term (high-duration) nature of banks' assets. The rates on these assets are set at origination and remain locked in until the assets roll off, which makes interest income slow-moving and relatively insensitive to the short rate.

The surprising feature in Panel B of Figure 3 is that interest expense is just as insensitive to the short rate as interest income. This is where the deposit franchise comes in. Deposits make up over $70 \%$ of banks' liabilities, and it is their zero and near-zero maturities that are responsible for the low overall duration of banks' liabilities. Yet, as the figure indicates, the rates banks pay on deposits are much lower and smoother than the economy's shortterm rate. As Drechsler, Savov, and Schnabl (2017) show, this is due to market power in retail deposit markets. Market power allows banks to keep deposit rates low even when market interest rates rise. Consequently, banks can have both a large duration mismatch and insensitive cash flows at the same time, i.e. they can engage in maturity transformation without interest rate risk.

To further highlight the importance of the deposit franchise, we construct a portfolio of Treasury bonds that has the same duration mismatch as banks, but no deposit franchise. ${ }^{18}$ Each year, the portfolio invests the proceeds from maturing bonds into new ten-year zerocoupon Treasury bonds that it holds to maturity. This gives it a duration of 5.5 years. To match the 4.2-year average duration of bank assets in Figure 1, the portfolio further invests $23.6 \%$ of assets at the Fed funds rate (this is close to the average share of short-term assets across banks, see Figure 8 below). On the liabilities side, the portfolio borrows $60 \%$ at the Fed funds rate and $40 \%$ at the one-year Treasury rate, matching the target liabilities duration of 0.4 years.

Panel A of Figure 4 plots the NIM of the Treasury portfolio. It is calculated in the same way as banks' NIM, hence an asset's interest income is booked at its yield to maturity as

\footnotetext{
${ }^{18}$ We thank Adi Sunderam for the suggestion. Thanks, Adi.
} 
of the purchase date. ${ }^{19}$ The Treasury portfolio NIM behaves exactly as predicted by its duration mismatch: it falls sharply whenever the short rate rises and jumps up when the short rate falls. Persistent shocks are especially powerful: interest rates rose steadily from the beginning of the sample until the 1980s, causing the Treasury portfolio's NIM to be negative almost the whole time. Afterward, as rates began their secular decline, it turned positive. Thus, the Treasury portfolio loses money in the whole first half of the sample, highlighting the extreme risk of having a large duration mismatch without a deposit franchise.

Panel B of Figure 4 highlights this point further. Whereas banks' interest expense is very low and smooth with respect to the Fed funds rate, the interest expense of the Treasury portfolio closely tracks the Fed funds rate. This is why its NIM crashes whenever the Fed funds rate rises. Thus, Figure 4 makes it clear why the deposit franchise allows banks to do maturity transformation without exposing their bottom lines to interest rate risk. ${ }^{20}$

\section{Model}

We provide a simple model of a bank's investment problem to explain our aggregate findings and obtain cross-sectional predictions. Time is discrete and the horizon is infinite. The bank funds itself by issuing risk-free deposits. Its problem is to invest in assets so as to maximize the present value of its future profits, subject to the requirement that it remain solvent so that its deposits are indeed risk free. For simplicity we assume the bank does not issue any equity. Though it is straightforward to incorporate equity, the bank is able to avoid losses and therefore does not need to issue equity.

To raise deposits the bank operates a deposit franchise at a cost of $c$ per deposit dollar. This cost is due to the investment the bank has to make in branches, salaries, advertising,

\footnotetext{
${ }^{19}$ This means that interest income ignores fluctuations in the bond's price and books income only when the bond's payments are realized. An alternative approach is to book valuation changes as income when they occur, rather than waiting for the cash flows to be realized. The problem with this approach is that it requires estimating the large but unobservable value of the deposit franchise and its fluctuations.

${ }^{20}$ Begenau and Stafford (2018) suggest that the low interest exposure of banks' NIM may be an artifact of book accounting. Figure 4 shows that this is not the case. The NIM of the Treasury portfolio is also calculated according to book accounting rules, yet it has an extremely large interest rate exposure. Moreover, if the Treasury portfolio accurately replicated a bank, then banks' equity would be highly exposed to interest rate changes, with a coefficient of $-40 \%$ in our equity regressions instead of the observed low coefficient of $-4.24 \%$.
} 
and so on to attract and service its depositors. ${ }^{21}$ Importantly, the deposit franchise gives the bank market power, which allows it to pay a deposit rate of only

$$
\beta^{E x p} f_{t}
$$

where $0<\beta^{E x p}<1$ and $f_{t}$ is the economy's short rate process (i.e. the Fed funds rate). Drechsler, Savov, and Schnabl (2017) provide a model that micro-founds this deposit rate as an industry equilibrium among banks with deposit market power. The strength of a bank's market power is captured by the spread it is able to charge their depositors, $\left(1-\beta^{E x p}\right) f_{t}$. A bank with high market power has a low $\beta^{E x p}$ and charges a high spread, while a bank with low market power, such as one funded mostly by wholesale deposits, has a $\beta^{\text {Exp }}$ close to one and charges almost no spread. Note that deposits are short term. While adding long-term liabilities to the model is straightforward, they would not change the mechanism and hence we leave them out. Moreover, as Figure 1 shows, banks' liabilities are largely short term.

On the asset side, we assume that markets are complete and prices are determined according to the stochastic discount factor $m_{t}$. Like all investors, banks use this stochastic discount factor when valuing profits. ${ }^{22}$ Their problem is thus

$$
\begin{gathered}
V_{0}=\max _{I N C_{t}} E_{0}\left[\sum_{t=0}^{\infty} \frac{m_{t}}{m_{0}}\left(I N C_{t}-\beta^{E x p} f_{t}-c\right)\right] \\
\text { s.t. } E_{0}\left[\sum_{t=0}^{\infty} \frac{m_{t}}{m_{0}} I N C_{t}\right]=1 \\
\text { and } I N C_{t} \geq \beta^{E x p} f_{t}+c,
\end{gathered}
$$

where $I N C_{t}$ is the time- and state-contingent income stream generated by the bank's asset portfolio. Note that we normalize the bank's problem to one dollar of deposits, which is without loss of generality since the problem scales linearly in deposit dollars. Equation (3) gives the budget constraint: the present value of future income must equal its current value of one dollar. Equation (4) is the solvency constraint: the bank must generate enough income

\footnotetext{
${ }^{21}$ Note that we assume that the marginal cost is constant. This assumption distinguishes the model from commonly used models of incomplete passthrough in the industrial organization literature, which assume variation in marginal costs.

${ }^{22}$ This is a basic distinction between our framework and the literature which typically models banks as separate agents with distinct risk preferences or beliefs.
} 
each period to pay its interest expenses, $\beta^{\operatorname{Exp}} f_{t}$, and operating costs, $c$.

The bank faces two solvency risks. The first is that its interest expenses rise with the short rate $\left(\beta^{E x p}>0\right)$, so it must ensure that its income stream is sufficiently positively exposed to $f_{t}$. Otherwise it will become insolvent when $f_{t}$ is high. This means that a sufficient fraction of the bank's portfolio must resemble short-term bonds, whose interest payments rise with the short rate. This condition echoes the standard concern that banks should not be overly maturity-mismatched, i.e., that a large-enough fraction of their assets should be short term. Yet, there is an important difference. The standard concern is based on the short maturity of deposits, which suggests a high sensitivity to the short rate. However, due to market power the bank's deposit sensitivity $\beta^{E x p}$ can be well below one, in which case so can its portfolio share of short-term assets.

The second solvency risk the bank faces is due to its operating $\operatorname{costs} c$, which are insensitive to the short rate. To cover them, the bank's income must be insensitive enough to $f_{t}$. Otherwise the bank will become insolvent when $f_{t}$ is low. Thus, the bank must hold sufficient long-term fixed-rate assets, which produce an income stream that is insensitive to the short rate. Put another way, when $f_{t}$ is low the bank's deposit franchise generates only a small deposit spread, yet continues to incur the same level of operating costs. To hedge against this low-rate scenario, the bank must hold sufficient long-term assets.

We can highlight the contribution of the deposit franchise by decomposing the value of the bank's future profits into a balance sheet component and a deposit franchise component:

$$
V_{0}=E_{0}\left[\sum_{t=0}^{\infty} \frac{m_{t}}{m_{0}}\left(I N C_{t}^{\star}-f_{t}\right)\right]+E_{0}\left[\sum_{t=0}^{\infty} \frac{m_{t}}{m_{0}}\left[\left(1-\beta^{E x p}\right) f_{t}-c\right]\right] .
$$

The first term captures the balance sheet component: the assets generate income of $I N C_{t}^{\star}$ and the liabilities, which are short-term, incur expenses of $f_{t}$. The second term is the deposit franchise. It generates income given by the deposit spread $\left(1-\beta^{E x p}\right) f_{t}$ and incurs expenses given by the fixed operating $\operatorname{costs} c$. Thus, the deposit franchise can be viewed as an interest rate swap in which the bank pays the fixed rate $c$ and receives the floating rate $\left(1-\beta^{E x p}\right) f_{t}{ }^{23}$ Thus, the deposit franchise has a negative duration. As for any pay-fixed

\footnotetext{
${ }^{23}$ Jarrow and Van Deventer (1998) also point out the analogy to interest rate swaps when valuing deposit
} 
swap, the value of the deposit franchise rises with interest rates. ${ }^{24}$

The bank can hedge this exposure by taking the opposite exposure through its balance sheet. A complete hedge is necessary when excess deposit rents are zero, as is the case under free ex-ante entry into the banking industry. ${ }^{25}$ In this case, the bank can generate just enough income to cover its expenses period by period. We obtain the following.

Proposition 1. Under ex-ante free entry, $V_{0}=0$, and the bank's income stream is given by:

$$
I N C_{t}^{\star}=\beta^{E x p} f_{t}+c .
$$

Hence, the bank matches the interest sensitivities of its income and expenses:

$$
\text { Income beta } \equiv \beta^{I n c}=\frac{\partial I N C_{t}^{\star}}{\partial f_{t}}=\beta^{\text {Exp }} \equiv \text { Expense beta. }
$$

This matching makes the bank fully hedged to any shock to current or expected future interest rates:

$$
\frac{\partial}{\partial E_{t}\left[f_{t+s}\right]} V_{t}=0 \text { for every } t, s \geq 0 \text {. }
$$

When there are no excess rents, the present value of future deposit spreads is equal to the present value of the operating costs. The bank must therefore apply its whole income stream to satisfying the solvency constraint, leading to the simple prediction that the bank matches the interest sensitivities of its income and expenses. We test this prediction in the following sections by analyzing the cross section of banks. ${ }^{26}$

It is worth pointing out that the bank can implement this strategy in various ways because asset markets are complete. Probably the simplest way for the bank to implement equation (6) is through holding standard assets. It can do so by investing a share $\beta^{E x p}$ of its assets in short-term bonds, and the remainder $\left(1-\beta^{E x p}\right)$ in long-term fixed-rate bonds. Alternatively, liabilities and credit card balances under imperfect competition.

${ }^{24}$ Formally, the value of the deposit franchise simplifies to $\left(1-\beta^{E x p}\right)-c P_{0}^{\text {consol }}$, where $P_{0}^{\text {consol }}=$ $E_{0}\left[\sum_{t=0}^{\infty} \frac{m_{t}}{m_{0}}\right]$ is the price of a consol bond with one dollar face value. Higher interest rates (lower discount factors $m_{t} / m_{0}$ for $\left.t>0\right)$ cause $P_{0}^{\text {consol }}$ to fall, hence the value of the deposit franchise rises.

${ }^{25}$ If we add bank equity to the model and it is small compared to assets, as in practice, banks will still hedge most of their interest rate risk.

${ }^{26}$ Note that given the tight matching in each period, the bank is fully hedged to all shocks to the short rate or to expectations of its future path, including any changes in the term premium. 
banks could use derivatives or a more sophisticated trading strategies as long as they satisfies equation (6).

In practice, it is likely that banks will try to implement this strategy using standard assets. The reason is that more complicated strategies likely generate require an implementation costs, possibly due to increased monitoring need. Any arbitrarily implementation cost would break the equivalence in favor of the simplest strategy. Indeed, the aggregate evidence is consistent with implementation through standard assets. The simply strategy predicts both a constant NIM and ROA, as shown in Figure 3, because banks match both interest income and interest expense. In contrast, strategies that rely on derivatives or the sale of assets also generate a constant ROA but do not necessarily lead to a constant NIM because capital gains do not enter NIM.

Finally, the model could be extended to allow for bank assets to have default risk. This would lead to imperfect hedging since deposits do not hedge default risk. This extension would allow for an analysis of bank default risk, bank bailouts, and bank risk management. To keep the focus in this paper on maturity transformation and interest-rate risk, we have abstracted from these important features of banks. ${ }^{27}$

\section{Data}

Bank data. Our bank data is from the U.S. Call Reports provided by Wharton Research Data Services. We use data from January 1984 to December 2017. The data contain quarterly observations of the income statements and balance sheets of all U.S. commercial banks. The data contain bank-level identifiers that can be used to link to other datasets.

Branch-level deposits. Our data on deposits at the branch level is from the Federal Deposit Insurance Corporation (FDIC). The data cover the universe of U.S. bank branches at an annual frequency from June 1994 to June 2017. The data contain information on branch characteristics such as the parent bank, address, and location. We match the data to the bank-level Call Reports using the FDIC certificate number as the identifier.

\footnotetext{
${ }^{27}$ Bank bailouts would not affect the results as long as they are efficient, i.e., there would be no rents to bank equity holders (Philippon and Schnabl 2013).
} 
Retail deposit rates. Our data on retail deposit rates are from Ratewatch, which collects weekly branch-level deposit rates by product from January 1997 to December 2017. The data cover $54 \%$ of all U.S. branches as of 2013. Ratewatch reports whether a branch actively sets its deposit rates or whether its rates are set by a parent branch. We limit the analysis to active branches to avoid duplicating observations. We merge the Ratewatch data with the FDIC data using the FDIC branch identifier.

Fed funds data. We obtain the monthly time series of the effective Federal funds rate from the H.15 release of the Federal Reserve Board. We convert the series to the quarterly frequency by taking the last month in each quarter.

\section{Income and expense sensitivity matching}

\section{VI.A Methodology}

There are two approaches to analyze whether banks hedge their interest rate risk. The "present-value approach" estimates the impact of interest rates on the market value of bank equity. The "income-approach" estimates the impact of interest rates on banks' income and expenses. The two approaches give consistent answers because the value of bank equity is the present value of future income minus the present value of future expenses.

The two approaches are best illustrated with an example. Consider the case of a bank portfolio that consists of a fixed-rate 4-year maturity bond with face value of 1 paying a coupon of $C \%$, and a liability that is a floating rate 4-year maturity bond with face value of 1 paying a coupon that equals the short rate $r_{t}$ in year $t$. This yields a duration mismatch of about 4 years. Assume the fixed-rate bond has a price of 1 at the outset and, by construction, the floating rate bond is always worth 1 . For simplicity, assume forward rates are equal at all maturities at the outset and that an interest rate shock increases them in parallel at all maturities.

What is the impact of an increase in the interest by $\Delta r$ under the present-value approach? The floating-rate liability's price remains fixed at 1 , as always. The fixed-rate bond's price drops immediately on impact. The drop in its price is equal to the present value of a 4 -year 
annuity paying $\Delta r$, the amount that would be needed to keep it valued at par. This is approximately $4 \Delta r$. Thus, the present-value approach would show that the bank's equity value drops by approximately $4 \Delta r$, which makes sense since its duration mismatch is 4 .

How about the income approach? The income approach follows the future income and expenses of the assets and liabilities. By definition, the fixed-rate bond's cash flows do not change, so there is no increase in interest income. In contrast, the interest expense owed on the floating rate liability increases by $\Delta r$ for each of the 4 years, i.e., the increase in future interest expenses is given by a 4-year annuity paying $\Delta r$. Combining the asset and liability cash flows, the decrease in the bank's net future cash flows is given by a 4-year annuity paying $\Delta r$, which is exactly the same conclusion we found using the present-value approach.

An important difference between the two approaches is that we do not add banks' unrealized capital gains or losses when analyzing future income and expenses under the income approach. The capital loss, which is the present value of a 4-year $\Delta r$ annuity, is exactly measuring the change in future net income. Adding the capital loss on top of the change in future income would be double-counting. In contrast, under the present value approach the effect on bank equity is equal to the capital loss. Put differently, the only difference between the two approaches is that the income approach measures the impact on income over four years, while the present value approach measures the entire impact immediately.

In our cross-sectional analysis, we start by using the income approach. The reason is that we want to analyze income and expenses separately and we observe both variable in bank call reports. However, we cannot do the same with the present value approach because we do not separately observe the present value of banks' future income and expenses but only the net amount. ${ }^{28}$ Having analyzed income and expenses separately, we then move to analyzing the net effect on bank income and expenses. For this analysis we use both the income and present-value approach since we observe the relevant variables for both approaches, namely NIM and ROA for the income approach and bank equity for the present-value approach. ${ }^{29}$

\footnotetext{
${ }^{28}$ To be clear, this is not just because banks do not mark all their holdings to market prices. It is because a huge part of the banks' value, its deposit franchise/market power, is not an asset that appears in any explicit portfolio or balance sheet. The same is true for banks' operating expenses, which are an important part of their liabilities and do not appear on banks' balance sheets.

${ }^{29}$ This approach mirrors our analysis of the aggregate data. Figure 2 uses the present value approach applied to bank equity and Figure 3 uses the income approach examining bank income and expenses separately.
} 


\section{VI.B Results based on income approach}

\section{VI.B.1 Interest expense beta}

We implement the income approach by estimating the interest sensitivity of banks' expenses and income to interest rate changes. We start with the analysis of the expense side by running the following time-series OLS regression for each bank $i$ :

$$
\Delta \text { IntExp } p_{i t}=\alpha_{i}+\sum_{\tau=0}^{3} \beta_{i, \tau}^{E x p} \Delta F e d F u n d s_{t-\tau}+\varepsilon_{i t}
$$

where $\Delta$ IntExp $i t$ is the change in bank $i$ 's interest expenses rate from $t$ to $t+1$ and $\Delta$ FedFunds $s_{t}$ is the change in the Fed funds rate from $t$ to $t+1$. The interest expense rate is total quarterly interest expense (including interest expense on deposits, wholesale funding, and other liabilities) divided by quarterly average assets and then annualized (multiplied by four). We allow for three lags of the Fed funds rate changes to capture the cumulative effect of Fed funds rate changes over a full year. ${ }^{30}$ Our estimate of bank $i$ 's expense beta is the sum of the coefficients in (9), i.e. $\beta_{i}^{E x p}=\sum_{\tau=0}^{3} \beta_{i, \tau}^{E x p}$. To calculate an expense beta, we require a bank to have at least five years of data over our sample, 1984 to 2017. This yields 15,385 banks.

The top panel of Figure 5 plots a histogram of banks' interest expense betas and Table 1 provides summary statistics. The average expense beta is 0.354 , which means that interest expenses rise by 35 bps for every 100 bps increase in the Fed funds rate. The estimate is similar but slightly larger for the largest $5 \%$ of banks by assets, whose average expense beta is 0.425 . There is significant variation across banks, with a standard deviation of $0.102 .^{31}$

Panel A of Table 1 presents a breakdown of banks' characteristics by whether their expense beta is below or above the median for the full sample of banks. The characteristics

\footnotetext{
${ }^{30}$ We choose the one-year estimation window based on the impulse responses of interest income and interest expense rates to changes in the Fed funds rate. For both interest income and interest expense, the impulse responses take about a year to build up and then flattens out. Our results are robust to including more lags.

${ }^{31}$ The low average expense beta suggests that banks see a large increase in revenues from their liabilities when interest rates go up. The average size of the banking sector from 1984 to 2017 is $\$ 7.768$ trillion, which implies an increase in annual revenues of $(1 \%-0.354 \%) \times \$ 7,768=\$ 50$ billion from a 100 bps increase in the Fed funds rate. The revenue increase is permanent as long as the Fed funds rate remains at the higher level. It is large compared to the banking sector's average annual net income of $\$ 70.2$ billion over this period.
} 
are averaged over time for each bank. The table shows that differences in banks' expense betas are not explained by the repricing maturity of their liabilities, which is similar across the two groups (0.450 versus 0.411 years). ${ }^{32}$ This is because repricing maturity does not capture banks' ability to keep their deposit rates low and insensitive to the short rate.

\section{VI.B.2 Cross-sectional analysis}

We compute interest income betas as in (9), but with interest income as the dependent variable. Interest income includes all interest earned on loans, securities, and other assets. Our model predicts that income betas and expense betas should match across banks. This strong quantitative prediction is unique to our theory, giving us a powerful test.

Table 1 shows summary statistics for interest income betas and the bottom panel of Figure 5 plots their distribution. The average income beta is 0.371 with a standard deviation of 0.153 . The estimate for the largest $5 \%$ of banks is 0.424 . As Figure 5 shows, the distributions of expense and income betas are very similar with nearly identical means. Moreover, as Table 1 shows, income betas are significantly lower for low-expense beta banks than highexpense beta banks (0.308 versus 0.434). Overall, income and expense betas line up well, both among all banks and the largest 5\%, indicating of tight matching.

The top two panels of Figure 6 provide a graphical representation of the relationship between income and expense betas. Each panel shows a bin scatter plot which groups banks into 100 bins by expense beta and plots the average expense and income beta within each bin. The top left panel includes all banks, while the top right panel focuses on the largest $5 \%$ of banks by assets.

The plots show a close alignment of the sensitivities of banks' interest income and expense. For all banks, the slope is 0.768 , while for the largest $5 \%$ it is 0.881 . These numbers are close to one, especially for large banks, as predicted. The raw correlations between income and expense betas are high: $51 \%$ for all banks and $58 \%$ for large banks. ${ }^{33}$ Expense betas thus explain a large proportion of the variation in income betas across banks.

We further examine the impact of this tight matching on the interest sensitivity of bank

\footnotetext{
${ }^{32}$ It is reflected in the somewhat higher proportion of core deposits among low-expense beta banks.

${ }^{33}$ The bin scatter plot looks noisier for large banks because there are $95 \%$ fewer observations in each bin.
} 
profitability. As in the aggregate analysis, we measure profitability as ROA (net income divided by assets). ROA can be derived from NIM (interest income minus interest expense) by subtracting loan losses and non-interest expenses (e.g. salaries and rent) and adding non-interest income (e.g. fees). We estimate ROA betas in the same way as expense and income betas (see (9)), except we use changes of seasonally adjusted ROA. ${ }^{34}$

The bottom panels of Figure 6 show that bank profitability is largely unexposed to interest rate changes. ROA betas are close to zero, both among all banks and large banks. Their relationship with expense betas among all banks is flat even though the matching coefficient for this group is a bit below one. This indicates that non-interest items provide just the right offset to make profitability unexposed. Among large banks, ROA betas are slightly lower for high-expense beta banks (the slope of the relationship is -0.189). However, the relationship is noisy and as the panel regressions below show (see Section VI.B.3), a more precise estimate is very close to zero. Thus, the tight matching of interest expense and income betas effectively insulates bank profitability from interest rate changes.

\section{VI.B.3 Panel analysis}

In this section we use panel regressions to estimate whether the interest income and interest expense have the same exposure to changes in the interest rate. In the language of asset pricing, where this analysis is common, changes in the interest rate (and its lags) are our risk factor and we want to test whether banks income and expenses have the same exposure to the risk factor. If so, then their difference, the net income, will be hedged to the factor. To implement this, the procedure simply projects changes in interest expenses and interest income on the risk factor and examines if they have the same exposure, i.e, if their relative slope is 1 .

This procedure is the panel equivalent of the cross-sectional analysis shown in Figure 6. The main difference is that the cross-sectional analysis summarizes the interest-rate exposures of income and expenses using the sum of their coefficients on the Fed funds rate and

\footnotetext{
${ }^{34}$ The seasonality is due to the fact that banks tend to book certain non-interest income and expenses in the fourth quarter. Our results are robust to ignoring it. The panel regressions reported below include time fixed effects which also take out any seasonality.
} 
its lags, whereas the panel regression utilizes the data more completely by comparing the full fitted values of income and expenses using the realized values of the Fed funds rate and its lags. The panel regressions also allows us to control for common time trends using time fixed effects, thereby identifying matching from the cross-sectional variation. Finally, panel regressions also implicitly give more weight to banks that have more observations, leading to more precise estimates. ${ }^{35}$

We implement the panel analysis in two stages. The first stage estimates a bank-specific effect of Fed funds rate changes on interest expense using the following OLS regression:

$$
\Delta \text { IntExp } \operatorname{Ex}_{i, t}=\alpha_{i}+\eta_{t}+\sum_{\tau=0}^{3} \beta_{i, \tau} \Delta F e d F u n d s_{t-\tau}+\epsilon_{i, t}
$$

where $\Delta I n t \operatorname{Exp}_{i, t}$ is the change in the interest expense rate of bank $i$ from from time $t$ to $t+1, \Delta$ FedFunds $s_{t}$ is the change in the Fed funds rate from $t$ to $t+1$, and $\alpha_{i}$ and $\eta_{t}$ are bank and time fixed effects. Unlike the cross-sectional regression where we simply summed the lag coefficients, here we utilize them fully to construct the fitted value $\widehat{\triangle I n t E x} p_{i, t}$. This fitted value captures the predicted change in bank $i$ 's interest expense rate following a given Fed funds rate change.

The second stage regression tests for matching by asking if banks with a higher predicted change in interest expense see a higher interest income change. Specifically, we run the following OLS regression:

$$
\Delta \operatorname{IntInc}_{i, t}=\lambda_{i}+\theta_{t}+\delta \widehat{\operatorname{IntEx}} p_{i, t}+\varepsilon_{i, t}
$$

where $\Delta \operatorname{Int} I n c_{i, t}$ is the change in bank $i$ 's interest income rate from time $t$ to $t+1, \widehat{\Delta \operatorname{IntEx}} p_{i, t}$ is the predicted change in its interest expense rate from the first stage, and $\lambda_{i}$ and $\theta_{t}$ are bank and time fixed effects. The coefficient of interest is $\delta$, which captures the matching of income and expense rate changes. It is the analog to the slope coefficient in the cross-sectional

\footnotetext{
${ }^{35}$ We note that the procedure tests whether the sensitivities of banks' interest incomes and interest expenses to the interest rate match in the cross-section. It is not mean to test-and indeed cannot say-whether a bank first chooses the interest-sensitivity of its interest expenses and then matches this sensitivity with its choice of assets, or the order is the opposite (or these choices happen simultaneously). The purpose is to test if in fact this hedging occurs across the cross-section of banks.
} 
test. In some specifications, we replace the time fixed effects with an explicit control for the Fed funds rate change and its three lags, $\sum_{\tau=0}^{3} \gamma_{\tau} \Delta F e d F u n d s_{t-\tau}$. The value of $\sum_{\tau=0}^{3} \gamma_{\tau}$ then gives the estimated interest income sensitivity of a bank with zero interest expense sensitivity. It is the analog to the intercept in the cross-sectional test.

Since our estimation procedure is done in two stages, we need to correct for the fact that the second-stage regressors were themselves estimated. We address this issue by using a block bootstrap. In a block bootstrap, samples of data are generated by drawing blocks of the data with replacement. The coefficients in question are estimated within the generated samples and their distribution gives the correct standard error. Sampling the data in blocks gives the generated samples the same correlation structure (within a block) as in the data. We take a block to be the cross-section of banks in a given quarter, thereby capturing the cross-sectional correlations within a quarter. All of our results are now presented using these block-bootstrap standard errors with 10,000 iterations. We note that the standard errors derived from the block-bootstrap are similar to standard errors computed when clustering by time and bank. ${ }^{36}$

Table 2 presents the panel regression results. Columns (1) and (2) include all banks, first with the Fed funds rate changes as controls and then with time fixed effects. The matching coefficients, 0.773 and 0.774 , respectively, are again close to one and very similar to the crosssectional estimates. ${ }^{37}$ This shows that the matching is not driven by some type of common time series variation. The sum of the coefficients on Fed funds rate changes, $\sum_{\tau=0}^{3} \gamma_{\tau}$, is very small (0.091, showing that a bank with zero interest expense sensitivity has a near-zero interest income sensitivity.

Columns (3) to (8) report results for the largest $10 \%, 5 \%$, and $1 \%$ of banks. Here the coefficients are almost exactly one with 0.977 for the top 10\%, 0.993 for the top 5\%, and 0.933 for the top $1 \%$. None of the estimates are more than one and a half standard errors from one, hence we cannot reject the strong hypothesis of one-for-one matching. This is despite the fact that the bootstrapped standard errors are quite small. The high statistical

\footnotetext{
${ }^{36}$ Appendix Tables A.3 and A.4 present standard errors using the block-boostrap and clustering by bank and times for the main results in Tables 2 and 3.

${ }^{37} \mathrm{~A}$ coefficient of 0.773 implies that the sensitivity of NIM is $(0.773-1)=-0.227$. Hence, by construction we find a coefficient of -0.227 if we estimate regression (11) using the change in NIM as the outcome variable.
} 
power allows us to provide a relatively precise estimate even for the smallest sub-sample of the largest $1 \%$ of banks. Moreover, the coefficients are almost unchanged when we include time fixed effects. The direct effect of Fed funds rate changes is small and insignificant, which shows that a bank with insensitive interest expenses is expected to have insensitive interest income, i.e. to hold only long-term fixed-rate assets.

Extrapolating these estimates in the other direction, a bank whose interest expense rises one-for-one with the Fed funds rate is predicted to hold only short-term assets. This describes money market funds, which obtain funding at rates close to the short rate and do not engage in maturity transformation. The ability of our estimates to capture the behavior of money market funds out of sample shows a high degree of external validity.

Table 3 presents results for the interest sensitivity of banks' ROA. We use the same twostage procedure but replace the change in interest income in equation (11) with the change in ROA. The coefficients are extremely close to zero (ranging from -0.016 to 0.056) and statistically insignificant across all sub-samples. They are unchanged whether we control for Fed funds rate changes (odd-numbered columns) or include time fixed effects (even-numbered columns). These results imply that non-interest income and expenses are largely insensitive to interest rate changes, consistent with our model. ${ }^{38}$

Taken together, Tables 2 and 3 provide strong evidence that banks match the interest rate sensitivities of their income and expenses one for one. This holds despite the fact that there is large cross-sectional variation in each of these sensitivities. As a consequence of this matching, banks' profitability is largely insulated from interest rate changes.

\section{VI.C Results based on present-value approach}

We complement the result based on the income approach using the present-value approach. The present value approach tests for matching by examining the effect on interest rates on the market value of bank equity. To implement this approach, we obtain the daily stock returns of all publicly listed banks and use them to compute FOMC betas as we did in Figure $2 .{ }^{39}$

\footnotetext{
${ }^{38}$ In the robustness Section VI.D we show directly that the main categories of banks' operating costs are insensitive to interest rate changes.

${ }^{39}$ We thank Anna Kovner for providing the list of publicly listed banks. The analysis is at the level of the bank holding company because banks are publicly listed through their holding company.
} 
Specifically, we regress each bank's stock return on the change in the one-year Treasury rate over a one-day window around scheduled FOMC announcements between January 1994 and June 2007. We then merge the FOMC betas with the interest expense and income betas. The merged sample contains 597 publicly listed banks. The average FOMC beta is -2.10 , which is similar to the industry-level FOMC beta in Figure 2.

Figure 7 presents the results as bin scatter plots of FOMC betas against interest expense and income betas, and against asset and liabilities duration (using repricing maturity as a proxy). While the relationships are noisy due to the high volatility of stock returns, the standard errors are small enough to detect meaningful effects. For instance, given banks' ten-to-one leverage, under the standard duration calculation FOMC betas should decline by 10 for every additional year of asset duration.

Contrary to the prediction of the duration calculation, the relationship between FOMC betas and all four sorting variables is flat. If anything, FOMC betas rise toward zero as asset duration increases and income betas fall, but the effects are small and insignificant. ${ }^{40}$ Figure 7 thus confirms our result for NIM and ROA, which showed that interest rate exposure is equally low throughout the distribution of banks. This result is consistent with our framework where banks are able to avoid interest rate risk by matching the sensitivities of their income and expenses.

\section{VI.D Robustness}

Operating costs and fee income. In our model banks' operating costs are insensitive to interest rate changes and hence resemble a long-term fixed-rate liability. As we noted above, the results in Figure 6 and Tables 2 and 3 are consistent with this assumption. Here we provide direct evidence for it by analyzing the interest rate sensitivity of the main components of banks' non-interest expenses and income.

Banks have substantial operating expenses and fee income. We analyze the six main categories: salaries, rent, deposit fee income, total non-interest income, loan loass provisions, and trading income. For each category, we estimate interest rate betas as in Equation (9).

\footnotetext{
${ }^{40}$ English, den Heuvel, and Zakrajsek (2012) similarly find that banks with a larger maturity gap have a dampened exposure to monetary policy.
} 
The results are presented as bin scatter plots in Figure A.2, and are constructed in the same manner as Figure 6. The figures shows that for all categories the betas are close to zero for both the full sample and the largest $5 \%$ of banks. Moreover, they exhibit no correlation with banks' interest expense betas. These findings show that non-interest income and expenses are largely insensitive to changes in interest rates, consistent with the model.

Interest rate derivatives. Banks can use interest rate derivatives to hedge their assets. In doing so, they would be giving up the term premium (essentially, whoever is on the other side would be the one engaging in maturity transformation). While our matching results imply that there is no need to do so, it is useful to look at derivatives hedging directly.

The Call Reports contain information on the notional amounts of derivatives used for non-trading (e.g., hedging) purposes since 1995. They do not, however, contain information on the direction and term of the derivatives contracts, making it impossible to precisely calculate exposures. We therefore take the simple approach of rerunning our matching tests separately for banks that do and do not use interest rate derivatives.

Consistent with prior studies (e.g. Purnanandam 2007, Rampini, Viswanathan, and Vuillemey 2016), we find that the overwhelming majority of banks (86.9\%) do not use any interest rate derivatives. This is not surprising under our framework because banks do not need derivatives to hedge. Larger banks are somewhat more likely to use interest rate derivatives, yet even among the top 10\%, only 37.7\% report nonzero notional amounts.

Appendix Table A.5 presents the regression results. Columns 1 and 2 include all banks with non-missing derivatives amounts since 1995. The matching coefficients are slightly larger than one. Columns 3 and 4 show nearly identical coefficients for banks with zero derivatives amounts as for the full sample. The coefficients for the derivatives users in columns 5 and 6 are also similar, albeit slightly smaller. Overall, the results are consistent for banks that use and banks that do not use interest-rate derivatives.

Asymmetry. We examine whether there is an asymmetry in banks' responses to Fed funds rate increases and decreases. ${ }^{41}$ We do so by allowing for separate betas for Fed funds rate increases and decreases in the cross-sectional analysis described in Section VI.B.2. Appendix

\footnotetext{
${ }^{41}$ Neumark and Sharpe (1992) find evidence of an asymmetric response of deposit rates using data from the 1980s. Kahn, Pennacchi, and Sopranzetti (2005) find that an asymmetric response for personal loans and car loans using data from the 1990s.
} 
Table A.6 reports the coefficients. We find that banks are slightly faster to reduce interest expenses relative to raising them during the six months after a Fed funds rate change. However, this effect disappears when considering the impact of Fed funds rate changes over a one-year horizon. The cumulative one-year change in interest expenses for Fed funds rate increases and decreases is almost identical at 39 bps and 34 bps, respectively. Thus, there is no asymmetry when considering the cumulative adjustment over a one-year period. ${ }^{42}$

The short delay has a negligible effect on bank profitability. The coefficients in TableA.6 imply that the increase in bank profits during the first year of a 100 bps change is only 4.4 bps higher for a Fed funds rate increase relative to a decrease. The difference is even smaller for Fed funds rate changes that go beyond one year because the asymmetry only affects profitability during the first year. Given that the Fed funds rate is highly persistent, this implies that asymmetry has a limited effect on bank profitability and on our main matching results. The first-order effect of Fed funds rate changes on bank profitability is due to the partial adjustment of deposit rates to the Fed funds rate, i.e., it comes from the fact that expense betas are far less than 1.

We also test directly whether asymmetry has an economically important effect on our main results from Table 2. Specifically, we augment the main specification in Table 2 by allowing for separate coefficients on Fed funds rate increases and decreases. Appendix Table A.7 presents the results. We find that all coefficients are quantitatively and qualitatively similar. Thus, our results are robust to allowing for asymmetry in the adjustment to Fed funds rate increases and decreases.

Bank holding companies. Our main analysis uses commercial bank data from the Call Reports. As a simple robustness check, we rerun Table 2 using regulatory data at the bank holding company level, which is available since 1986. Append Table A.8 presents the results. The matching coefficients are very close to one. The results hold for the full sample, the top $10 \%$, the top $5 \%$, and even the top $1 \%$ of bank holding companies. Hence, our matching results are independent of whether we use commercial bank data or bank holding company

\footnotetext{
${ }^{42}$ Yankov (2014) finds a similar short-lived asymmetry in the response of deposit rate to Fed funds rate changes. He finds an even shorter delay of 4 weeks when adjusting to Fed funds rate increases relative to decreases. This delay is even shorter than the one found in our analysis, presumably because Yankov is only examining interest rates paid on new deposit accounts, while we examine interest rates paid on all deposit accounts.
} 
data.

\section{Sensitivity matching and bank assets}

In this section we analyze how banks implement sensitivity matching by looking at the characteristics of their assets.

\section{VII.A Asset duration}

Our model predicts that banks with low expense betas can implement sensitivity matching by holding assets with higher duration. We test this prediction using repricing maturity as a proxy for duration. ${ }^{43}$ The left panel of Figure 8 shows a bin scatter plot of the average repricing maturity of banks' loans and securities against their interest expense betas. The relationship is strongly downward sloping. Hence, as predicted by the model, banks with low expense betas hold assets with substantially higher estimated duration than banks with high expense betas. The slope of the relationship is -3.406 years, which is on the order of the average duration of bank assets. As a result, while a bank with an expense beta of 0.1 has a predicted duration of 4.7 years, a bank with an expense beta of 1 is predicted to have a duration of around 1.6 year. This again describes the structure of money market funds, which are not in our sample but are nevertheless in line with our estimates. ${ }^{44}$

The right panel in Figure 8 looks at a related measure, banks' share of short-term assets, defined as those that reprice within a year. As predicted by the model, there is a significant positive relationship: banks with high expense betas have more short-term assets than banks with low expense betas (the slope is 0.382 ). Overall, Figure 8 shows that expense betas explain large differences in maturity transformation across banks.

We provide a formal test of the relationship between expense betas and repricing maturity

\footnotetext{
${ }^{43}$ Specifically, we use the repricing maturity of banks' loans and securities, for which we have detailed data since 1997. The remaining categories are mostly short-term, including cash and Fed funds sold and repurchases bought under agreements to resell.

${ }^{44}$ Money market funds only hold very short-term assets. Kacperczyk and Schnabl (2013) estimate that assets held by prime money market funds have an average maturity of 34 days.
} 
by running panel regressions of the form

$$
\text { RepricingMaturity }{ }_{i, t}=\alpha_{t}+\delta \beta_{i}^{E x p}+\gamma X_{i, t}+\epsilon_{i, t},
$$

where RepricingMaturity ${ }_{i, t}$ is the average repricing maturity of bank $i$ 's loans and securities at time $t, \beta_{i}^{E x p}$ is its interest expense beta, $\alpha_{t}$ are time fixed effects, and $X_{i, t}$ are a set of controls. The controls we consider are the wholesale funding share (large time deposits plus Fed funds purchased and repo), the equity ratio, and size (log assets). As before, we block-bootstrap the standard errors by quarter with 10,000 iterations.

Panel A of Table 4 presents the regression results for the sample of all banks. From column 1 , the univariate coefficient on the interest expense beta is -3.387 , which is similar to the slope in Figure 8 and highly significant. The coefficient remains stable and actually increases slightly as we add in the control variables in columns (2) to (4). Column (5) runs a horse race between all right-hand variables. The coefficient on the interest expense beta is -4.345 , hence its explanatory power for repricing maturity is even stronger once we control for bank characteristics.

Panel B of Table 4 repeats this analysis for the largest 5\% of banks. Even though this sample has only 446 banks over 83 quarters (and bootstrapped standard errors), the relationship between interest expense betas and repricing maturity is strong and clear. We find that the univariate coefficient is -3.054 , which is similar to the full sample. The effect rises to -3.436 in the specification with all controls (column (5)). This estimate, which applies to large banks, suggests that the aggregate banking sector would not engage in any maturity transformation if its interest expenses rose one-for-one with the short rate.

\section{VII.B Asset composition}

We can get a better understanding of how banks obtain duration by looking at the composition of their assets. From Appendix Table A.2, which summarizes the repricing maturity of different asset categories, a primary way to obtain duration is by investing in securities, which in aggregate have an average repricing maturity of 8.4 years versus 3.8 years for loans. ${ }^{45}$

\footnotetext{
${ }^{45}$ The higher repricing maturity of securities is due to the fact that many are linked to mortgages.
} 
Given these large differences, and given our results on duration, we expect banks with low expense betas to hold a larger share of securities.

Table 5 presents the results of panel regressions similar to (12) but with banks' securities share as the dependent variable. Looking first at the sample of all banks in Panel A, there is a strong and significant negative relationship between interest expense beta and the securities share. The stand-alone coefficient in column (1) is -0.310 while the multivariate one in column (5) is -0.215 . These numbers are large relative to the average securities share in Table 1, which is 0.245, and their sign is as predicted. Panel B repeats the analysis for the largest $5 \%$ of banks. The coefficients are -0.178 in column (1) and -0.147 in column (5), and again highly significant. By contrast, except for size, the control variables either lose their significance or see their signs flip. Thus, there is a robust negative relationship between interest expense betas and banks' securities holdings, which shows that banks with low expense betas obtain duration by holding more securities. ${ }^{46}$

This result is especially useful because it allows us to rule out an alternative explanation for our sensitivity matching results. It is possible that banks with high expense betas face more liquidity (or run) risk. Combined with the assumption that short-term assets act as a liquidity buffer, this could explain why banks with high expense betas hold assets with lower duration (thought it does not necessarily predict one-for-one matching). However, under this explanation these banks should hold more securities because securities are liquid and can be sold easily during a run, unlike loans. The fact that we see the opposite- high-expense beta banks hold fewer securities - shows that liquidity risk does not drive our results.

\section{VII.C Sensitivity matching within the securities portfolio}

Our model predicts that banks actively match the interest sensitivities of their income and expenses in order to manage their interest rate risk. Yet another possibility is that the matching is incidental. For instance, it may arise from market segmentation if banks with more market power over deposits also happen to face more long-term lending opportunities. Along these lines, Scharfstein and Sunderam (2014) find that banks have market power over

\footnotetext{
${ }^{46}$ Replacing the securities share with the loans share of assets yields an almost identical coefficient but with the opposite sign. This is not surprising given that securities and loans account for $81 \%$ of bank assets.
} 
lending. Although market segmentation does not explain why we see one-for-one matching, we nevertheless test it further.

We do so by looking at the interest rate sensitivity of banks' securities holdings. Securities are by definition traded in an open market and hence unaffected by market segmentation. Thus, under the market segmentation interpretation we should not see matching between banks' expense betas and the income betas of their securities holdings. To implement this idea, we rerun our main matching test using the two-stage procedure in equations (10)(11), but with banks' securities interest income as the second-stage outcome variable. While we no longer expect a coefficient of one (one-for-one matching applies only to the bank as a whole), our model still predicts positive matching between expense betas and securities income betas.

Table 6 presents the results for the sample of all banks. As columns (1) and (2) show, there is strong evidence of matching between securities interest income and interest expense. The coefficients are 0.584 and 0.571 , respectively, and highly significant. Columns (3) to (8) look at various sub-categories of securities. Since banks sometimes retain some selforiginated securities, we get a cleaner test by looking only at Treasury securities and agency MBS, which are among the most liquid securities in existence. Columns (3) and (4) show that there is matching even within this category. Columns (5) to (8) show the same for mortgage-backed securities (MBS) and other securities.

Table 7 repeats the analysis of Table 6 for the largest $5 \%$ of banks. The results are qualitatively the same. The matching coefficients are somewhat larger across the board, suggesting that large banks are even more likely to match the sensitivity of their interest expenses using securities. Overall, the results in Tables 6 and 7 support the view that banks actively match the interest rate exposures of their income and expenses.

\section{Market power and sensitivity matching}

Our model predicts that banks with more market power in retail deposit markets have lower interest expense betas, and that they match these with lower interest income betas. We use geographic variation in market power to test these predictions. Specifically, we first examine 
whether variation in market power generates differences in expense betas, and then whether banks match these differences with their income betas.

We use three sources of geographic variation in market power that are progressively more restrictive. We embed each source within the same two-stage empirical framework we used in Section VI (see (10) and (11)). Specifically, we run

$$
\begin{aligned}
\Delta \text { IntExp } \operatorname{Ex}_{i, t} & =\alpha_{i}+\eta_{t}+\sum_{\tau=0}^{3}\left(\beta_{\tau}^{0}+\beta_{\tau} \times M P_{i, t}\right) \Delta F e d F u n d s_{t-\tau}+\epsilon_{i, t} \\
\Delta \text { IntInc }_{i, t} & =\lambda_{i}+\theta_{t}+\delta \Delta \widehat{\operatorname{IntEx}} p_{i, t}+\varepsilon_{i, t} .
\end{aligned}
$$

where $\Delta I n t E x p_{i, t}$ is the change in the interest expense rate of bank $i$ from from time $t$ to $t+1, \Delta$ FedFundst is the change in the Fed funds rate from $t$ to $t+1, \alpha_{i}$ are bank fixed effects, and $\eta_{t}$ are time fixed effects. The difference with the earlier regressions is that we now parameterize the sensitivity coefficients to be functions of a given proxy for market power, $M P_{i, t}$. In the first stage, we are interested in the relationship between market power and

interest expense sensitivity, given by $\sum_{\tau=0}^{3} \beta_{\tau}$. In the second stage, we are interested in the matching coefficient $\delta$. We again bootstrap the standard errors with 10,000 iterations and cluster them at the quarter level.

\section{VIII.A Market concentration}

Our first source of variation in market power is local market concentration. We use the FDIC data to calculate a Herfindahl (HHI) index for each zip code by computing each bank's share of the total branches in the zip code and summing the squared shares. We then create a bank-level HHI by averaging the zip-code HHIs of each bank's branches, using the bank's deposits in each zip code as weights. The resulting bank HHIs have a mean of 0.478 and a standard deviation of 0.270 , indicating substantial geographic variation.

Figure 9 shows that there is a negative relationship between market concentration and interest expense betas. Banks operating in zip codes with zero concentration have an average interest expense beta of 0.37 versus 0.29 for those in highly concentrated zip codes. Note that even though there is substantial variation, interest expense betas are well below one 
everywhere. Hence banks appear to have significant market power in all areas, which allows them to justify the high costs of operating a deposit franchise.

The first two columns of Table 8 present the results of the two-stage estimation. Column (1) controls for Fed funds rate changes directly, while column (2) includes time fixed effects. The first-stage estimates in the top panel show that market concentration is significantly negatively related to the sensitivity of banks' interest expenses, as predicted. The first-stage coefficients are -0.074 and -0.093 in columns (1) and (2), respectively, which is similar to the slope of the cross-sectional regression line in Figure 9.

The bottom panel of Table 8 shows that the variation in expense sensitivity induced by market concentration is matched on the income side. The second-stage coefficients are 1.154 and 1.218 in columns (1) and (2), respectively, which is a bit higher than our earlier estimates but still not significantly different from one. As column (1) shows, the direct effect of Fed funds rate changes is zero, indicating that a bank with zero expense sensitivity is predicted to have zero income sensitivity, i.e. hold only long-term fixed-rate assets.

To ensure that our results are robust to alternative definitions of a local deposit market, we rerun the same analysis with a county-level HHI instead of a zip-code-level one. The results are in columns (3) and (4). The first-stage estimates are almost identical to the zipcode-level ones, and the matching coefficients are now even closer to one. Thus, the results in Table 8 support the market power mechanism of our model.

\section{VIII.B Retail deposit betas}

Banks in our model derive market power from the retail deposits they sell to households. In this section we use data on retail deposits to obtain variation in market power. Because retail deposits are government-insured, and hence immune to runs, they also allow us to further show that our results cannot be explained by liquidity risk.

The Ratewatch data contains the rates offered on new accounts of different retail deposit products at branches throughout the U.S.. To obtain variation in market power, we regress 
these rates on the Fed funds rate, allowing for separate coefficients by county:

$$
\text { DepRate }_{b, i, c, t}=\alpha_{b}+\gamma_{i}+\delta_{c}+\eta_{t}+\sum_{c} \beta_{c} \times \text { FedFunds } s_{t}+\varepsilon_{b, i, c, t}
$$

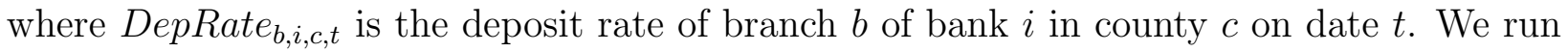
(15) separately for the three most common products in our data: interest checking accounts with less than $\$ 2,500, \$ 25,000$ money market deposit accounts, and $\$ 10,000$ 12-month CDs. These products are representative of the three main types of retail (core) deposits: checking, savings, and small time deposits. They are also well below the deposit insurance limit.

The county-level coefficients $\beta_{c}$ are the counterpart to the market power parameter $\beta^{E x p}$ in the model. By capturing the sensitivities of local deposit rates to the Fed funds rate, they provide a measure of local market power. We use them to construct a bank-level measure by averaging them across each bank's branches (using branch deposits as weights), and finally by averaging across the three products for each bank.

The first two columns of Table 9 present the results. The first-stage coefficients are highly significant and equal to 0.491 and 0.514 in columns (1) and (2), respectively. This shows that retail deposit betas strongly predict banks' overall interest expense sensitivities. The second stage shows the matching. The coefficients are 1.212 and 1.189 in columns (1) and (2), respectively, again a bit higher than one but not statistically different from one. Thus, variation in retail deposit betas generates variation in expense sensitivities, which banks in turn match with their income sensitivities.

As our third source of variation in market power, we go a step further and isolate withinbank variation in retail deposit betas. We do so by including bank-time fixed effects in the estimation of the retail deposit betas (equation (15)). The resulting estimates are identified by comparing branches of the same bank located in different areas. This purges the retail deposit betas of any time-varying bank-level characteristics so that they capture only differences in local market power.

The results are presented in columns (3) and (4) of Table 9. As the first-stage estimates show, the within-bank retail deposit betas have a significant and sizable impact on banks' overall interest expense sensitivity. This is true even though they are constructed in a way 
that ignores all bank-level variation in deposit rates across banks and only use variation within banks.

The second-stage estimates show that variation in within-bank retail deposit betas also produces strong matching between interest expense and interest income sensitivities. The matching coefficients are 0.892 to 0.895 in columns (3) and (4), respectively, which is again very close to one. These results show that differences in market power create variation in expense betas that banks match one-for-one on the income side.

\section{Conclusion}

The conventional view is that by borrowing short and lending long banks expose their bottom lines to interest rate risk. We argue that the opposite is true: banks reduce their interest rate risk through maturity transformation. They do so by matching the interest rate sensitivities of their income and expenses even as they maintain a large maturity mismatch. On the expense side, banks obtain a low sensitivity by exercising market power in retail deposit markets. On the income side, they obtain a low sensitivity by holding long-term fixed-rate assets. This sensitivity matching produces stable net interest margins (NIM) and return on assets (ROA) even as interest rates fluctuate widely.

Our results have important implications for monetary policy and financial stability. Monetary policy is thought to impact banks in part through the interest rate risk exposure created by their maturity mismatch. Our results show that by actively matching the sensitivities of their income and expenses banks are largely insulated from this effect. Banks' maturity mismatch is also a source of concern about financial stability. This has led to calls for narrow banking, the idea that deposit-issuing institutions should hold only short-term assets. Our

results imply that so long as banks have market power, narrow banking would not achieve its purpose and could actually reduce financial stability.

More broadly, our results provide an explanation for why deposit-taking and maturity transformation co-exists under one roof. Rather than viewing this co-existence as a source of risk and instability, this explanation highlights its unique stability. 


\section{References}

Adams, Paul D, Stefan Hunt, Christopher Palmer, and Redis Zaliauskas, 2019. Testing the effectiveness of consumer financial disclosure: Experimental evidence from savings accounts. Working Paper 25718 National Bureau of Economic Research.

Backus, David K, Leora F Klapper, and Chris Telmer, 1994. Derivatives at banc one (1994). Available at SSRN 102552.

Bai, Jennie, Arvind Krishnamurthy, and Charles-Henri Weymuller, 2016. Measuring liquidity mismatch in the banking sector. Journal of Finance forthcoming.

Bank of America, 2016. Bank of America corporation 2016 annual report. .

Begenau, Juliane, Monika Piazzesi, and Martin Schneider, 2015. Banks' risk exposures. Discussion paper, .

Begenau, Juliane, and Erik Stafford, 2018. Do banks have an edge?. Working paper.

Berlin, Mitchell, and Loretta J Mester, 1999. Deposits and relationship lending. Review of Financial Studies 12, 579-607.

Bernanke, Ben, and Mark Gertler, 1989. Agency costs, net worth, and business fluctuations. The American Economic Review 79, 14-31.

Bernanke, Ben S, Mark Gertler, and Simon Gilchrist, 1999. The financial accelerator in a quantitative business cycle framework. Handbook of Macroeconomics 1, 1341-1393.

Bernanke, Ben S, and Kenneth N Kuttner, 2005. What explains the stock market's reaction to federal reserve policy?. The Journal of Finance 60, 1221-1257.

Boivin, Jean, Michael T. Kiley, and Frederic S. Mishkin, 2010. How has the monetary transmission mechanism evolved over time?. vol. 3 of Handbook of Monetary Economics . pp. $369-422$ Elsevier.

Brunnermeier, Markus K, Gary Gorton, and Arvind Krishnamurthy, 2012. Risk topography. NBER Macroeconomics Annual 26, 149-176.

Brunnermeier, Markus K., and Yann Koby, 2016. The reversal interest rate: The effective lower bound of monetary policy. Working paper.

Brunnermeier, Markus K., and Yuliy Sannikov, 2014. A macroeconomic model with a financial sector. American Economic Review 104, 379-421.

— , 2016. The I theory of money. Working paper.

Calomiris, Charles W, and Charles M Kahn, 1991. The role of demandable debt in structuring optimal banking arrangements. The American Economic Review pp. 497-513. 
Cochrane, John H, 2014. Toward a run-free financial system. Across the great divide: New perspectives on the financial crisis 197, 214-15.

Di Tella, Sebastian, and Pablo Kurlat, 2017. Why are banks exposed to monetary policy?. Working paper.

Diamond, Douglas W, 1984. Financial intermediation and delegated monitoring. The Review of Economic Studies 51, 393-414.

— , and Philip H Dybvig, 1983. Bank runs, deposit insurance, and liquidity. The Journal of Political Economy 91, 401-419.

Diamond, Douglas W., and Raghuram G. Rajan, 2001. Liquidity risk, liquidity creation, and financial fragility: A theory of banking. Journal of Political Economy 109, 287-327.

Drechsler, Itamar, Alexi Savov, and Philipp Schnabl, 2017. The deposits channel of monetary policy. Quarterly Journal of Economics 132, 1819-1876.

— , 2018. A model of monetary policy and risk premia. The Journal of Finance 73, $317-373$.

Driscoll, John C, and Ruth A Judson, 2013. Sticky deposit rates. Federal Reserve Board Working Paper.

Duffie, Darrell, and Arvind Krishnamurthy, 2016. Passthrough efficiency in the fed's new monetary policy setting. in Designing Resilient Monetary Policy Frameworks for the Future. Federal Reserve Bank of Kansas City, Jackson Hole Symposium.

Egan, Mark, Ali Hortaçsu, and Gregor Matvos, 2017. Deposit competition and financial fragility: Evidence from the us banking sector. American Economic Review 107, 169-216.

Egan, Mark, Stefan Lewellen, and Adi Sunderam, 2016. The cross section of bank value. .

English, William B, Skander Van den Heuvel, and Egon Zakrajsek, 2012. Interest rate risk and bank equity valuations. .

Esty, Ben, Peter Tufano, and Jonathan Headley, 1994. Banc one corporation: Asset and liability management. Journal of Applied Corporate Finance 7, 33-52.

Flannery, Mark J, 1981. Market interest rates and commercial bank profitability: An empirical investigation. The Journal of Finance 36, 1085-1101.

- 1983. Interest rates and bank profitability: additional evidence: note. Journal of Money, Credit and Banking 15, 355-362.

Flannery, Mark J., and Christopher M. James, 1984a. The effect of interest rate changes on the common stock returns of financial institutions. The Journal of Finance 39, 1141-1153.

— 1984b. Market evidence on the effective maturity of bank assets and liabilities. 
Journal of Money, Credit and Banking 16, 435-445.

Freixas, Xavier, and Jean-Charles Rochet, 2008. Microeconomics of banking MIT press.

Friedman, Milton, 1960. A Program for Monetary Stability New York: Fordham University Press.

Froot, Kenneth A., David S. Scharfstein, and Jeremy C. Stein, 1994. A framework for risk management. Journal of Applied Corporate Finance 7, 22-33.

Gatev, Evan, and Philip E. Strahan, 2006. Banks' advantage in hedging liquidity risk: Theory and evidence from the commercial paper market. The Journal of Finance 61, 867-892.

Gomez, Matthieu, Augustin Landier, David Sraer, and David Thesmar, 2016. Banks exposure to interest rate risk and the transmission of monetary policy. Working Paper.

Gorton, Gary, and George Pennacchi, 1990. Financial intermediaries and liquidity creation. Journal of Finance 45, 49-71.

Haddad, Valentin, and David Sraer, 2015. The banking view of bond risk premia. Discussion paper, .

Hannan, Timothy H., and Allen Berger, 1991. The rigidity of prices: Evidence from the banking industry. The American Economic Review 81, 938-945.

Hanson, Samuel, Andrei Shleifer, Jeremy C. Stein, and Robert W. Vishny, 2015. Banks as patient fixed-income investors. Journal of Financial Economics 117, 449-469.

He, Zhiguo, and Arvind Krishnamurthy, 2013. Intermediary asset pricing. American Economic Review 103, 732-70.

Hutchison, David E, and George G Pennacchi, 1996. Measuring rents and interest rate risk in imperfect financial markets: The case of retail bank deposits. Journal of Financial and Quantitative Analysis 31.

Janosi, Tibor, Robert A Jarrow, and Ferdinando Zullo, 1999. An empirical analysis of the jarrow-van deventer model for valuing non-maturity demand deposits. The Journal of Derivatives 7, 8-31.

Jarrow, Robert A, and Donald R Van Deventer, 1998. The arbitrage-free valuation and hedging of demand deposits and credit card loans. Journal of Banking \& Finance 22, 249-272.

Kacperczyk, Marcin, and Philipp Schnabl, 2013. How safe are money market funds?. The Quarterly Journal of Economics 128, 1073-1122.

Kahn, Charles, George Pennacchi, and Ben Sopranzetti, 2005. Bank consolidation and the dynamics of consumer loan interest rates. The Journal of Business 78, 99-134. 
Kashyap, Anil K., Raghuram Rajan, and Jeremy C. Stein, 2002. Banks as liquidity providers: An explanation for the coexistence of lending and deposit-taking. The Journal of Finance $57,33-73$.

Kirti, Divya, 2017. Why do bank-dependent firms bear interest-rate risk? International Monetary Fund.

Kohn, Donald L, 2010. Focusing on bank interest rate risk exposure. Speech given at the Federal Deposit Insurance Corporation's Symposium on Interest Rate Risk Management, Arlington, Virginia.

Nagel, Stefan, 2016. The liquidity premium of near-money assets. The Quarterly Journal of Economics 131, 1927-1971.

— , and Amiyatosh Purnanandam, 2015. Bank risk dynamics and distance to default. Becker Friedman Institute for Research in Economics Working Paper, March, University of Chicago.

Nakamura, Emi, and Jón Steinsson, 2018. High-frequency identification of monetary nonneutrality: the information effect. The Quarterly Journal of Economics 133, 1283-1330.

Neumark, David, and Steven A. Sharpe, 1992. Market structure and the nature of price rigidity: Evidence from the market for consumer deposits. Quarterly Journal of Economics 107, 657-680.

O'Brien, James M, 2000. Estimating the value and interest rate risk of interest-bearing transactions deposits. .

Philippon, Thomas, and Philipp Schnabl, 2013. Efficient recapitalization. The Journal of Finance 68, 1-42.

Purnanandam, Amiyatosh, 2007. Interest rate derivatives at commercial banks: An empirical investigation. Journal of Monetary Economics 54, 1769-1808.

Rampini, Adriano A, S Viswanathan, and Guillaume Vuillemey, 2016. Risk management in financial institutions. Working paper.

Scharfstein, David, and Adi Sunderam, 2014. Market power in mortgage lending and the transmission of monetary policy. HBS Working Paper.

White, Lawrence J, 1991. The S\&L debacle: Public policy lessons for bank and thrift regulation Oxford University Press New York.

Yankov, Vladimir, 2014. In search of a risk-free asset. Federal Reserve Board Working Paper. 


\section{Table 1: Bank characteristics and expense beta}

This table provides summary statistics on bank characteristics. The sample in Panel A are all U.S. commercial banks from 1984 to 2017 (18,934 banks). Panel B restricts the sample to the largest $5 \%$ of banks. Interest expense betas are calculated by regressing the change in a bank's interest expense on the contemporaneous and three previous quarterly changes in the Fed funds rate. Interest income and ROA betas are calculated analogously. A bank must have at least 20 quarterly observations for its beta to be reported and the betas are winsorized at the $5 \%$ level (15,385 banks). The data on repricing maturities starts in 1997. Columns (2) and (3) report the sample mean and standard deviation. Columns (5) and (7) report averages for banks with above and below median expense beta.

Panel A: All banks

\begin{tabular}{|c|c|c|c|c|c|c|c|}
\hline & \multicolumn{3}{|c|}{ All } & \multicolumn{2}{|c|}{ Low beta } & \multicolumn{2}{|c|}{ High beta } \\
\hline & $\begin{array}{c}\text { Obs } \\
(1)\end{array}$ & $\begin{array}{c}\text { Mean } \\
(2)\end{array}$ & $\begin{array}{c}\text { St.Dev. } \\
\text { (3) }\end{array}$ & $\begin{array}{l}\text { Obs } \\
(4)\end{array}$ & $\begin{array}{c}\text { Mean } \\
(5)\end{array}$ & $\begin{array}{c}\text { Obs } \\
(6)\end{array}$ & $\begin{array}{c}\text { Mean } \\
(7)\end{array}$ \\
\hline \multicolumn{8}{|l|}{ Interest rate sensitivity } \\
\hline Interest expense beta & 15,385 & 0.354 & $(0.102)$ & 7,692 & 0.273 & 7,693 & 0.434 \\
\hline Interest income beta & 15,385 & 0.371 & $(0.153)$ & 7,692 & 0.308 & 7,693 & 0.434 \\
\hline ROA beta & 15,385 & 0.036 & $(0.168)$ & 7,692 & 0.030 & 7,693 & 0.041 \\
\hline \multicolumn{8}{|l|}{ Bank characteristics } \\
\hline Asset repricing maturity & 11,311 & 3.462 & $(1.638)$ & 5,701 & 3.695 & 5,162 & 3.208 \\
\hline Liabilities repricing maturity & 11,296 & 0.434 & $(0.234)$ & 5,697 & 0.450 & 5,161 & 0.411 \\
\hline Log assets & 18,934 & 4.249 & $(1.302)$ & 7,692 & 4.086 & 7,693 & 4.615 \\
\hline Loans/Assets & 18,934 & 0.568 & $(0.134)$ & 7,692 & 0.551 & 7,693 & 0.589 \\
\hline Securities/Assets & 18,934 & 0.245 & $(0.132)$ & 7,692 & 0.276 & 7,693 & 0.234 \\
\hline Core deposits/Assets & 18,933 & 0.727 & $(0.129)$ & 7,692 & 0.749 & 7,693 & 0.713 \\
\hline Equity/Assets & 18,933 & 0.103 & $(0.066)$ & 7,692 & 0.110 & 7,693 & 0.096 \\
\hline
\end{tabular}

Panel B: Top 5\%

\begin{tabular}{lcccccccc}
\hline \hline & \multicolumn{4}{c}{ All } & \multicolumn{3}{c}{ Low beta } & \multicolumn{3}{c}{ High beta } \\
& Obs & $\begin{array}{c}\text { Mean } \\
(1)\end{array}$ & $\begin{array}{c}\text { St.Dev. } \\
(2)\end{array}$ & $\begin{array}{c}\text { Obs } \\
(4)\end{array}$ & $\begin{array}{c}\text { Mean } \\
(5)\end{array}$ & $\begin{array}{c}\text { Obs } \\
(6)\end{array}$ & $\begin{array}{c}\text { Mean } \\
(7)\end{array}$ \\
\hline $\begin{array}{l}\text { Interest rate sensitivity } \\
\text { Interest expense beta }\end{array}$ & 810 & 0.425 & $(0.104)$ & 405 & 0.340 & 405 & 0.509 \\
$\quad$ Interest income beta & 810 & 0.424 & $(0.157)$ & 405 & 0.350 & 405 & 0.499 \\
$\quad$ ROA beta & 810 & 0.026 & $(0.158)$ & 405 & 0.041 & 405 & 0.011 \\
Bank characteristics & & & & & & & \\
$\quad$ Asset repricing maturity & 613 & 4.003 & $(2.033)$ & 300 & 4.333 & 268 & 3.420 \\
Liabilities repricing maturity & 613 & 0.427 & $(0.404)$ & 300 & 0.413 & 268 & 0.407 \\
Log assets & 946 & 7.631 & $(1.190)$ & 405 & 7.432 & 405 & 7.884 \\
Loans/Assets & 946 & 0.623 & $(0.117)$ & 405 & 0.616 & 405 & 0.625 \\
$\quad$ Securities/Assets & 946 & 0.196 & $(0.104)$ & 405 & 0.219 & 405 & 0.183 \\
$\quad$ Core deposits/Assets & 946 & 0.622 & $(0.193)$ & 405 & 0.670 & 405 & 0.580 \\
Equity/Assets & 946 & 0.089 & $(0.049)$ & 405 & 0.094 & 405 & 0.086 \\
\hline \hline
\end{tabular}




\section{Table 2: Interest sensitivity matching}

This table provides estimates of the matching of interest income and expense sensitivities. The results are from the following two-stage ordinary least squares regression:

$$
\begin{array}{rlr}
\Delta \text { IntExp }_{i, t} & =\alpha_{i}+\sum_{\tau=0}^{3} \beta_{i, \tau} \Delta F e d F u n d s_{t-\tau}+\epsilon_{i, t} & \text { [Stage 1] } \\
\Delta \text { IntInc } c_{i, t} & =\lambda_{i}+\sum_{\tau=0}^{3} \gamma_{\tau} \Delta \text { FedFund } s_{t-\tau}+\delta \Delta \widehat{\operatorname{IntEx}} p_{i, t}+\varepsilon_{i, t}, & \text { [Stage 2] }
\end{array}
$$

where $\Delta I n t E x p_{i, t}$ and $\Delta I n t I n c_{i, t}$ are the changes in interest expense and interest income rates of bank $i$ at time $t, \Delta F e d F u n d s_{t}$ is the change in the Fed funds rate, and $\widehat{\Delta \operatorname{IntEx}} p_{i, t}$ is the predicted value from the first stage. Columns (2), (4), (6), and (8) include time fixed effects. Top 10\% are the 10\% largest banks by average total assets over the sample. Top 5\% and top $1 \%$ are defined analogously. The data are quarterly and cover all U.S. commercial banks from 1984 to 2017 . Standard errors are block-bootstrapped by quarter with 10,000 iterations.

\begin{tabular}{|c|c|c|c|c|c|c|c|c|}
\hline & \multicolumn{2}{|c|}{ All banks } & \multicolumn{2}{|c|}{ Top $10 \%$} & \multicolumn{2}{|c|}{ Top 5\% } & \multicolumn{2}{|c|}{ Top 1\% } \\
\hline & (1) & $(2)$ & $(3)$ & (4) & $(5)$ & (6) & $(7)$ & $(8)$ \\
\hline$\triangle \widehat{\operatorname{IntExp}}$ & $\begin{array}{c}0.773^{* * *} \\
(0.033)\end{array}$ & $\begin{array}{c}0.774^{* * *} \\
(0.034)\end{array}$ & $\begin{array}{c}0.977^{* * *} \\
(0.070)\end{array}$ & $\begin{array}{c}0.980^{* * *} \\
(0.071)\end{array}$ & $\begin{array}{c}0.993^{* * *} \\
(0.081)\end{array}$ & $\begin{array}{c}0.994^{* * *} \\
(0.081)\end{array}$ & $\begin{array}{c}0.933^{* * *} \\
(0.110)\end{array}$ & $\begin{array}{c}0.944^{* * *} \\
(0.113)\end{array}$ \\
\hline$\sum \gamma_{\tau}$ & $\begin{array}{c}0.091^{* * *} \\
(0.031)\end{array}$ & & $\begin{array}{c}0.016 \\
(0.037)\end{array}$ & & $\begin{array}{l}-0.001 \\
(0.044)\end{array}$ & & $\begin{array}{c}0.006 \\
(0.062)\end{array}$ & \\
\hline Bank FE & Yes & Yes & Yes & Yes & Yes & Yes & Yes & Yes \\
\hline Time FE & No & Yes & No & Yes & No & Yes & No & Yes \\
\hline Obs. & $1,210,873$ & $1,210,873$ & 121,771 & 121,771 & 61,014 & 61,014 & 13,540 & 13,540 \\
\hline No. of banks & 18,615 & 18,615 & 1,855 & 1,855 & 924 & 924 & 185 & 185 \\
\hline No. of quarters & 135 & 135 & 135 & 135 & 135 & 135 & 135 & 135 \\
\hline$R^{2}$ & 0.087 & 0.117 & 0.102 & 0.132 & 0.093 & 0.122 & 0.091 & 0.126 \\
\hline
\end{tabular}

$\Delta$ Interest income rate 


\section{Table 3: The interest sensitivity of ROA}

This table provides estimates of the interest rate sensitivity of return on assets (ROA). The results are from the following two-stage ordinary least squares regression:

$$
\begin{array}{rrr}
\Delta \text { IntExp } p_{i, t} & =\alpha_{i}+\sum_{\tau=0}^{3} \beta_{i, \tau} \Delta F e d F u n d s_{t-\tau}+\epsilon_{i, t} & \text { [Stage 1] } \\
\Delta R O A_{i, t} & =\lambda_{i}+\sum_{\tau=0}^{3} \gamma_{\tau} \Delta F e d F u n d s_{t-\tau}+\delta \Delta \operatorname{IntEx} p_{i, t}+\varepsilon_{i, t}, & \text { [Stage 2] }
\end{array}
$$

where $\Delta$ IntExp $\operatorname{Ex}_{i, t}$ and $\Delta R O A_{i, t}$ are the changes in the interest expense rate and ROA of bank $i$ at time $t, \Delta F e d F u n d s_{t}$ is the change in the Fed funds rate, and $\widehat{\Delta \operatorname{IntEx}} p_{i, t}$ is the predicted value from the first stage. Columns (2), (4), (6), and (8) include time fixed effects. Top 10\% are the 10\% largest banks by average total assets over the sample. Top 5\% and top $1 \%$ are defined analogously. The data are quarterly and cover all U.S. commercial banks from 1984 to 2017 . Standard errors are block-bootstrapped by quarter with 10,000 iterations.

\begin{tabular}{|c|c|c|c|c|c|c|c|c|}
\hline & \multicolumn{2}{|c|}{ All banks } & \multicolumn{2}{|c|}{ Top $10 \%$} & \multicolumn{2}{|c|}{ Top 5\% } & \multicolumn{2}{|c|}{ Top 1\% } \\
\hline & (1) & $(2)$ & $(3)$ & (4) & $(5)$ & (6) & $(7)$ & (8) \\
\hline \multirow[t]{2}{*}{$\Delta \widehat{\operatorname{IntExp} p}$} & -0.016 & -0.012 & 0.003 & 0.015 & -0.010 & 0.002 & 0.035 & 0.056 \\
\hline & $(0.015)$ & $(0.016)$ & $(0.017)$ & $(0.018)$ & $(0.020)$ & $(0.022)$ & $(0.039)$ & $(0.038)$ \\
\hline \multirow[t]{2}{*}{$\sum \gamma_{\tau}$} & $0.042^{* * *}$ & & $0.041^{* *}$ & & $0.038^{*}$ & & 0.013 & \\
\hline & $(0.014)$ & & $(0.021)$ & & $(0.022)$ & & $(0.034)$ & \\
\hline Bank FE & Yes & Yes & Yes & Yes & Yes & Yes & Yes & Yes \\
\hline Time FE & No & Yes & No & Yes & No & Yes & No & Yes \\
\hline Obs. & $1,210,873$ & $1,210,873$ & 121,771 & 121,771 & 61,014 & 61,014 & 13,540 & 13,540 \\
\hline No. of banks & 18,615 & 18,615 & 1,855 & 1,855 & 924 & 924 & 185 & 185 \\
\hline No. of quarters & 135 & 135 & 135 & 135 & 135 & 135 & 135 & 135 \\
\hline$R^{2}$ & 0.027 & 0.035 & 0.020 & 0.041 & 0.017 & 0.045 & 0.012 & 0.078 \\
\hline
\end{tabular}

$\Delta$ Return on assets 


\section{Table 4: Maturity transformation and expense betas}

This table estimates the relationship between expense beta and asset duration. The proxy for duration is repricing maturity, calculated as the weighted average repricing maturity of loans and securities. The interest expense betas are estimated according to (9) and winsorized at the $5 \%$ level. The control variables are wholesale funding (sum of large time deposits, Fed funds purchased, and repos, divided by assets), equity ratio (equity divided by assets), and $\log$ total assets. Top 5\% of banks (Panel B) are the largest $5 \%$ by assets. The data are quarterly and cover all U.S. commercial banks with at least 5 years of data between 1997 to 2017. Standard errors are block-bootstrapped by quarter with 10,000 iterations.

Panel A: All banks

\begin{tabular}{lccccc}
\hline \hline & \multicolumn{5}{c}{ Repricing maturity } \\
\cline { 2 - 6 } & $(1)$ & $(2)$ & $(3)$ & $(4)$ & $(5)$ \\
\hline Interest expense beta & $-3.387^{* * *}$ & $-3.293^{* * *}$ & $-3.580^{* * *}$ & $-4.417^{* * *}$ & $-4.345^{* * *}$ \\
& $(0.079)$ & $(0.069)$ & $(0.083)$ & $(0.084)$ & $(0.073)$ \\
Wholesale funding ratio & & $-0.341^{* * *}$ & & & $-0.591^{* * *}$ \\
& & $(0.074)$ & & & $(0.082)$ \\
Equity ratio & & $-2.014^{* * *}$ & & $-1.389^{* * *}$ \\
& & & $(0.095)$ & & $(0.118)$ \\
log Assets & & & & $0.217^{* * *}$ & $0.209^{* * *}$ \\
& Yes & Yes & Yes & $(0.009)$ & $(0.009)$ \\
Time FE & 561,975 & 561,974 & 561,975 & 561,975 & Yes \\
\hline Obs. & 8,843 & 8,843 & 8,843 & 8,843 & 8,843 \\
No. of banks & 83 & 83 & 83 & 83 & 83 \\
No. of quarters & 0.146 & 0.146 & 0.149 & 0.162 & 0.164 \\
$R^{2}$ & & & & & \\
\hline \hline
\end{tabular}

Panel B: Top 5\%

\begin{tabular}{lccccc}
\hline \hline & \multicolumn{5}{c}{ Repricing maturity } \\
\cline { 2 - 6 } & $(1)$ & $(2)$ & $(3)$ & $(4)$ & $(5)$ \\
\hline Interest expense beta & $-3.054^{* * *}$ & $-3.124^{* * *}$ & $-3.150^{* * *}$ & $-3.360^{* * *}$ & $-3.436^{* * *}$ \\
& $(0.199)$ & $(0.222)$ & $(0.215)$ & $(0.248)$ & $(0.279)$ \\
Wholesale funding ratio & & $0.464^{* *}$ & & & $0.433^{* *}$ \\
& & $(0.200)$ & & & $(0.195)$ \\
Equity ratio & & & $-3.263^{* * *}$ & & $-2.982^{* * *}$ \\
& & & $(0.512)$ & & $(0.457)$ \\
log Assets & & & & $0.085^{* * *}$ & $0.063^{* * *}$ \\
& Yes & Yes & Yes & $(0.018)$ & $(0.016)$ \\
Time FE & 26,610 & 26,610 & 26,610 & 26,610 & Yes \\
\hline Obs. & 446 & 446 & 446 & 446 & 446 \\
No. of banks & 83 & 83 & 83 & 83 & 83 \\
No. of quarters & 0.044 & 0.044 & 0.052 & 0.046 & 0.054 \\
$R^{2}$ & & & & & \\
\hline \hline
\end{tabular}




\section{Table 5: Securities share and expense betas}

This table estimates the relationship between expense beta and the securities share of assets (the relationship between expense beta and the loan share has the same magnitude and opposite sign). The interest expense betas are estimated according to (9) and winsorized at the $5 \%$ level. The control variables are wholesale funding (sum of large time deposits, Fed funds purchased, and repos, divided by assets), equity ratio (equity divided by assets), and $\log$ total assets. Top 5\% of banks (Panel B) are the largest $5 \%$ by assets. The data are quarterly and cover all U.S. commercial banks with at least 5 years of data between 1997 to 2017. Standard errors are block-bootstrapped by quarter with 10,000 iterations.

Panel A: All banks

\begin{tabular}{lccccc}
\hline \hline & \multicolumn{5}{c}{ Securities/Assets } \\
\cline { 2 - 6 } & $(1)$ & $(2)$ & $(3)$ & $(4)$ & $(5)$ \\
\hline Interest expense beta & $-0.310^{* * *}$ & $-0.241^{* * *}$ & $-0.296^{* * *}$ & $-0.278^{* * *}$ & $-0.215^{* * *}$ \\
& $(0.005)$ & $(0.005)$ & $(0.005)$ & $(0.005)$ & $(0.005)$ \\
Wholesale funding ratio & & $-0.221^{* * *}$ & & & $-0.207^{* * *}$ \\
& & $(0.014)$ & & & $(0.015)$ \\
Equity ratio & & $0.150^{* * *}$ & & $0.109^{* * *}$ \\
& & & $(0.012)$ & & $(0.012)$ \\
log Assets & & & & $-0.007^{* * *}$ & $-0.004^{* * *}$ \\
& Yes & Yes & Yes & Yes & Yes \\
Time FE & $1,193,766$ & $1,193,762$ & $1,193,766$ & $1,193,766$ & $1,193,762$ \\
\hline Obs. & 15,385 & 15,385 & 15,385 & 15,385 & 15,385 \\
No. of banks & 136 & 136 & 136 & 136 & 136 \\
No. of quarters & 0.092 & 0.106 & 0.096 & 0.095 & 0.110 \\
$R^{2}$ & & & & & \\
\hline \hline
\end{tabular}

Panel B: Top 5\%

\begin{tabular}{lccccc}
\hline \hline & \multicolumn{5}{c}{ Securities/Assets } \\
\cline { 2 - 6 } & $(1)$ & $(2)$ & $(3)$ & $(4)$ & $(5)$ \\
\hline Interest expense beta & $-0.178^{* * *}$ & $-0.186^{* * *}$ & $-0.187^{* * *}$ & $-0.145^{* * *}$ & $-0.147^{* * *}$ \\
& $(0.007)$ & $(0.006)$ & $(0.007)$ & $(0.005)$ & $(0.005)$ \\
Wholesale funding ratio & & $0.030^{* *}$ & & & 0.019 \\
& & $(0.013)$ & & & $(0.012)$ \\
Equity ratio & & & $-0.244^{* * *}$ & & $-0.302^{* * *}$ \\
& & & $(0.019)$ & & $(0.020)$ \\
log Assets & & & & $-0.008^{* * *}$ & $-0.012^{* * *}$ \\
& Yes & Yes & Yes & $(0.001)$ & $(0.001)$ \\
Time FE & 60,710 & 60,708 & 60,710 & 60,710 & Yes \\
\hline Obs. & 810 & 810 & 810 & 810 & 810 \\
No. of banks & 136 & 136 & 136 & 136 & 136 \\
No. of quarters & 0.043 & 0.044 & 0.058 & 0.051 & 0.073 \\
$R^{2}$ & & & & & \\
\hline \hline
\end{tabular}




\section{Table 6: Sensitivity matching within the securities portfolio}

This table provides estimates of the matching of the sensitivities of interest expense and interest income from securities. The results are from the following two-stage ordinary least squares regression:

$$
\begin{array}{rlr}
\Delta \text { IntExp } \operatorname{Ex}_{i, t}=\alpha_{i}+\sum_{\tau=0}^{3} \beta_{i, \tau} \Delta \text { FedFund } s_{t-\tau}+\epsilon_{i, t} & \text { [Stage 1] } \\
\Delta \text { IntIncX } X_{i, t} & =\lambda_{i}+\sum_{\tau=0}^{3} \gamma_{\tau} \Delta \text { FedFund } s_{t-\tau}+\delta \Delta \operatorname{IntEx} p_{i, t}+\varepsilon_{i, t}, & \text { [Stage 2] }
\end{array}
$$

where $\operatorname{IntInc} X_{i, t}$ is the change in the rate of interest income from total securities (columns (1) and (2)), Treasuries and agency debt (columns (3) and (4)), mortgage-backed securities (columns (5) and (6)), and other securities (columns (7) and (8)), $\Delta$ IntExp E $_{i, t}$ is the change in the interest expense rate of bank $i$ at time $t, \Delta F e d F u n d s_{t}$ is the change in the Fed funds rate, and $\widehat{\triangle I n t E x} p_{i, t}$ is the predicted value from the first stage. Columns (2), (4), (6), and (8) include time fixed effects. The data are quarterly and cover all U.S. commercial banks from 1984 to 2017 (columns (1) and (2)) and 2001 to 2017 (columns (3) to (8)). Standard errors are block-bootstrapped by quarter with 10,000 iterations.

\begin{tabular}{|c|c|c|c|c|c|c|c|c|}
\hline & \multicolumn{2}{|c|}{ Total securities } & \multicolumn{2}{|c|}{ Treasuries \& agency debt } & \multicolumn{2}{|c|}{$\mathrm{MBS}$} & \multicolumn{2}{|c|}{ Other securities } \\
\hline & $(1)$ & $(2)$ & $(3)$ & $(4)$ & $(5)$ & $(6)$ & $(7)$ & $(8)$ \\
\hline$\triangle \widehat{\operatorname{IntEx} p}$ & $\begin{array}{c}0.584^{* * *} \\
(0.040)\end{array}$ & $\begin{array}{c}0.571^{* * *} \\
(0.040)\end{array}$ & $\begin{array}{c}0.429^{* * *} \\
(0.054)\end{array}$ & $\begin{array}{c}0.429 * * * \\
(0.053)\end{array}$ & $\begin{array}{c}0.478^{* * *} \\
(0.084)\end{array}$ & $\begin{array}{c}0.472^{* * *} \\
(0.083)\end{array}$ & $\begin{array}{c}0.506^{* * *} \\
(0.060)\end{array}$ & $\begin{array}{c}0.508^{* * *} * \\
(0.061)\end{array}$ \\
\hline$\sum \gamma_{\tau}$ & $\begin{array}{c}0.053 \\
(0.040)\end{array}$ & & $\begin{array}{c}0.103^{* *} \\
(0.045)\end{array}$ & & $\begin{array}{c}-0.010 \\
(0.080)\end{array}$ & & $\begin{array}{c}-0.113^{* * *} \\
(0.026)\end{array}$ & \\
\hline Bank FE & Yes & Yes & Yes & Yes & Yes & Yes & Yes & Yes \\
\hline Time FE & No & Yes & No & Yes & No & Yes & No & Yes \\
\hline Obs. & $1,198,067$ & $1,198,067$ & 392,677 & 392,677 & 348,469 & 348,469 & 378,341 & 378,341 \\
\hline No. of banks & 18,512 & 18,512 & 8,986 & 8,986 & 8,201 & 8,201 & 8,568 & 8,568 \\
\hline No. of quarters & 135 & 135 & 67 & 67 & 67 & 67 & 67 & 67 \\
\hline$R^{2}$ & 0.012 & 0.023 & 0.020 & 0.031 & 0.004 & 0.010 & 0.007 & 0.008 \\
\hline
\end{tabular}

$\Delta$ Securities interest income rate 


\section{Table 7: Sensitivity matching within the securities portfolio, top $5 \%$ of banks}

This table provides estimates of the matching of the sensitivities of interest expense and interest income from securities for the largest $5 \%$ of banks by assets. The results are from the following two-stage ordinary least squares regression:

$$
\begin{array}{rlr}
\Delta \text { IntExp } \operatorname{Ex}_{i, t} & =\alpha_{i}+\sum_{\tau=0}^{3} \beta_{i, \tau} \Delta \text { FedFund } s_{t-\tau}+\epsilon_{i, t} & \text { [Stage 1] } \\
\Delta \text { IntIncX } X_{i, t} & =\lambda_{i}+\sum_{\tau=0}^{3} \gamma_{\tau} \Delta F e d F u n d s_{t-\tau}+\delta \Delta \operatorname{IntEx} p_{i, t}+\varepsilon_{i, t}, & \text { [Stage 2] }
\end{array}
$$

where $\operatorname{IntInc} X_{i, t}$ is the change in the rate of interest income from total securities (columns (1) and (2)), Treasuries and agency debt (columns (3) and (4)), mortgage-backed securities (columns (5) and (6)), and other securities (columns (7) and (8)), $\Delta$ IntExp E $_{i, t}$ is the change in the interest expense rate of bank $i$ at time $t, \Delta F e d F u n d s_{t}$ is the change in the Fed funds rate, and $\widehat{\triangle I n t E x} p_{i, t}$ is the predicted value from the first stage. Columns (2), (4), (6), and (8) include time fixed effects. The data are quarterly and cover all U.S. commercial banks from 1984 to 2017 (columns (1) and (2)) and 2001 to 2017 (columns (3) to (8)). Standard errors are block-bootstrapped by quarter with 10,000 iterations.

\begin{tabular}{|c|c|c|c|c|c|c|c|c|}
\hline & \multicolumn{2}{|c|}{ Total securities } & \multicolumn{2}{|c|}{ Treasuries \& agency debt } & \multicolumn{2}{|c|}{ MBS } & \multicolumn{2}{|c|}{ Other securities } \\
\hline & $(1)$ & $(2)$ & $(3)$ & $(4)$ & $(5)$ & $(6)$ & $(7)$ & $(8)$ \\
\hline$\triangle \widehat{\operatorname{IntExp}}$ & $\begin{array}{c}0.902^{* * *} \\
(0.113)\end{array}$ & $\begin{array}{c}0.881^{* * *} \\
(0.114)\end{array}$ & $\begin{array}{c}0.539 * * * \\
(0.155)\end{array}$ & $\begin{array}{c}0.557^{* * *} \\
(0.157)\end{array}$ & $\begin{array}{c}0.827^{* * *} \\
(0.222)\end{array}$ & $\begin{array}{c}0.852^{* * *} \\
(0.231)\end{array}$ & $\begin{array}{c}0.807^{* * *} \\
(0.207)\end{array}$ & $\begin{array}{c}0.831^{* * *} \\
(0.205)\end{array}$ \\
\hline$\sum \gamma_{\tau}$ & $\begin{array}{c}-0.128^{* *} \\
(0.060)\end{array}$ & & $\begin{array}{c}0.114 \\
(0.083)\end{array}$ & & $\begin{array}{l}-0.176 \\
(0.108)\end{array}$ & & $\begin{array}{l}-0.143 \\
(0.091)\end{array}$ & \\
\hline Bank FE & Yes & Yes & Yes & Yes & Yes & Yes & Yes & Yes \\
\hline Time FE & No & Yes & No & Yes & No & Yes & No & Yes \\
\hline Obs. & 60,147 & 60,147 & 18,200 & 18,200 & 19,517 & 19,517 & 19,513 & 19,513 \\
\hline No. of banks & 918 & 918 & 449 & 449 & 458 & 458 & 461 & 461 \\
\hline No. of quarters & 135 & 135 & 67 & 67 & 67 & 67 & 67 & 67 \\
\hline$R^{2}$ & 0.013 & 0.027 & 0.027 & 0.037 & 0.015 & 0.034 & 0.012 & 0.017 \\
\hline
\end{tabular}

$\Delta$ Securities interest income rate 


\section{Table 8: Market power and interest sensitivity matching}

This table estimates the effect of market power on interest rate sensitivity matching. The results are from the following two-stage ordinary least squares regression:

$$
\begin{array}{rlrl}
\Delta \text { IntExp }_{i, t} & =\alpha_{i}+\phi X_{i, t}+\sum_{\tau=0}^{3}\left(\beta_{\tau}^{0}+\beta_{\tau} X_{i, t}\right) \Delta F e d F u n d s_{t-\tau}+\epsilon_{i, t} & \text { [Stage 1] } \\
\Delta \text { IntInc }_{i, t} & =\lambda_{i}+\sum_{\tau=0}^{3} \gamma_{\tau} \Delta \text { FedFund } s_{t-\tau}+\delta \Delta \text { IntEx }_{i, t}+\varepsilon_{i, t}, & & \text { [Stage 2] }
\end{array}
$$

where $X_{i, t}$ is bank $i$ 's market concentration, $\Delta \operatorname{Int} \operatorname{Exp}_{i, t}$ and $\Delta \operatorname{IntInc}_{i, t}$ are the changes in interest expense and interest income rates of bank $i$ at time $t, \Delta F e d F u n d s_{t}$ is the change in the Fed funds rate, and $\widehat{\Delta \text { IntEx }} p_{i, t}$ is the predicted value from the first stage. To calculate market concentration, we construct a Herfindahl index of bank branches at the zip code level (columns (1) and (2)) or county level (columns (3) and (4)), then average them across each bank's branches, using branch deposit as weights. Columns (2), and (4) include time fixed effects. The data are quarterly and cover all U.S. commercial banks from 1994 to 2017. Standard errors are block-bootstrapped by quarter with 10,000 iterations.

Stage 1: $\Delta$ Interest expense rate

\begin{tabular}{lccccc}
\hline \hline & \multicolumn{2}{c}{ Zip code } & & \multicolumn{2}{c}{ County } \\
\cline { 2 - 3 } \cline { 5 - 6 } & $(1)$ & $(2)$ & & $(3)$ & $(4)$ \\
\hline$\sum \beta_{\tau}$ & $-0.074^{* * *}$ & $-0.093^{* * *}$ & & $-0.054^{* *}$ & $-0.068^{* * *}$ \\
& $(0.023)$ & $(0.016)$ & & $(0.027)$ & $(0.022)$ \\
Bank FE & Yes & Yes & & Yes & Yes \\
Time FE & No & Yes & & No & Yes \\
\hline$R^{2}$ & 0.192 & 0.232 & & 0.191 & 0.231 \\
\hline \hline
\end{tabular}

Stage 2: $\Delta$ Interest income rate

\begin{tabular}{lccccc}
\hline \hline & \multicolumn{2}{c}{ Zip code } & & \multicolumn{2}{c}{ County } \\
\cline { 2 - 3 } \cline { 5 - 6 } & $(1)$ & $(2)$ & & $(3)$ & $(4)$ \\
\hline$\Delta$ IntExp & $1.154^{* * *}$ & $1.218^{* * *}$ & & $0.968^{* * *}$ & $1.048^{* * *}$ \\
& $(0.189)$ & $(0.160)$ & & $(0.284)$ & $(0.270)$ \\
$\sum \gamma_{\tau}$ & -0.022 & & 0.040 & \\
& $(0.073)$ & & & $(0.104)$ & \\
Bank FE & Yes & Yes & & Yes & Yes \\
Time FE & No & Yes & No & Yes \\
\hline Obs. & 698,002 & 698,002 & & 698,002 & 698,002 \\
No. of banks & 12,916 & 12,916 & & 12,916 & 12,916 \\
No. of quarters & 95 & 95 & & 95 & 95 \\
$R^{2}$ & 0.083 & 0.115 & 0.083 & 0.114 \\
\hline \hline
\end{tabular}




\section{Table 9: Retail deposit betas and interest sensitivity matching}

This table examines the effect of retail deposit betas on interest rate sensitivity matching. The results are from the following two-stage ordinary least squares regression:

$$
\begin{array}{rll}
\Delta \text { IntExp }_{i, t} & =\alpha_{i}+\phi X_{i, t}+\sum_{\tau=0}^{3}\left(\beta_{\tau}^{0}+\beta_{\tau} X_{i, t}\right) \Delta \text { FedFund } s_{t-\tau}+\epsilon_{i, t} & \text { [Stage 1] } \\
\Delta \text { IntInc } c_{i, t} & =\lambda_{i}+\sum_{\tau=0}^{3} \gamma_{\tau} \Delta \text { FedFund } s_{t-\tau}+\delta \Delta \text { IntEx } p_{i, t}+\varepsilon_{i, t}, & \text { [Stage 2] }
\end{array}
$$

where $X_{i, t}$ is bank $i$ 's retail deposit beta (columns (1) and (2)) and bank $i$ 's retail deposit beta using within-bank estimation (column (3) and (4)). Retail deposit betas are calculated at the county level using Ratewatch data for interest checking, $\$ 25 \mathrm{k}$ money market accounts and \$10k 12-month CDs, then averaged across branches for each bank-product (using branch deposits as weights) and finally across product for each bank. Retail deposit betas using within-bank estimation impose bank-time fixed effects in the first step of this estimation in order to purge the betas of any time-varying bank characteristics. Columns (2) and (4) include time fixed effects. The data are quarterly and cover all U.S. commercial banks from 1997 to 2017. Standard errors are Standard errors are block-bootstrapped by quarter with 10,000 iterations.

Stage 1: $\Delta$ Interest expense rate

\begin{tabular}{lccccc}
\hline \hline & \multicolumn{2}{c}{ Across-bank } & & \multicolumn{2}{c}{ Within-bank } \\
\cline { 2 - 3 } \cline { 5 - 6 } & $(1)$ & $(2)$ & & $(3)$ & $(4)$ \\
\hline$\sum \beta_{\tau}$ & $0.491^{* * *}$ & $0.514^{* * *}$ & & $0.172^{* * *}$ & $0.176^{* * *}$ \\
& $(0.054)$ & $(0.050)$ & & $(0.023)$ & $(0.022)$ \\
Bank FE & Yes & Yes & & Yes & Yes \\
Time FE & No & Yes & & No & Yes \\
\hline$R^{2}$ & 0.209 & 0.256 & 0.206 & 0.252 \\
\hline \hline
\end{tabular}

Stage 2: $\Delta$ Interest income rate

\begin{tabular}{lccccc}
\hline \hline & \multicolumn{2}{c}{ Across-bank } & & \multicolumn{2}{c}{ Within-bank } \\
\cline { 2 - 3 } \cline { 5 - 6 } & $(1)$ & $(2)$ & & $(3)$ & $(4)$ \\
\hline$\Delta$ IntExp & $1.212^{* * *}$ & $1.189^{* * *}$ & & $0.892^{* * *}$ & $0.895^{* * *}$ \\
& $(0.170)$ & $(0.168)$ & & $(0.239)$ & $(0.231)$ \\
$\sum \gamma_{\tau}$ & -0.045 & & 0.060 & \\
& $(0.058)$ & & & $(0.091)$ & \\
Bank FE & Yes & Yes & Yes & Yes \\
Time FE & No & Yes & No & Yes \\
\hline Obs. & 577,468 & 577,468 & & 533,954 & 533,954 \\
No. of banks & 11,042 & 11,042 & & 10,520 & 10,520 \\
No. of quarters & 83 & 83 & & 83 & 83 \\
$R^{2}$ & 0.087 & 0.122 & 0.086 & 0.119 \\
\hline \hline
\end{tabular}


Figure 1: Estimated duration of aggregate bank assets and liabilities

The figure plots the repricing maturity, a proxy for duration, of the assets and liabilities of the aggregate banking sector. The repricing maturity of assets is estimated by calculating the repricing maturity of loans and securities using the available data and assigning zero repricing maturity to cash and Fed funds sold. The repricing maturity of liabilities is calculated by assigning zero repricing maturity to transaction deposits, savings deposits, and Fed funds purchased, by assigning repricing maturity of five to subordinated debt, and by calculating the repricing maturity of time deposits using the available data. All other asset and liabilities categories (e.g. trading assets, other borrowed money), for which repricing maturity is not given, are left out of the calculation. The sample is from 1997 (when repricing maturity data becomes available) to 2017.

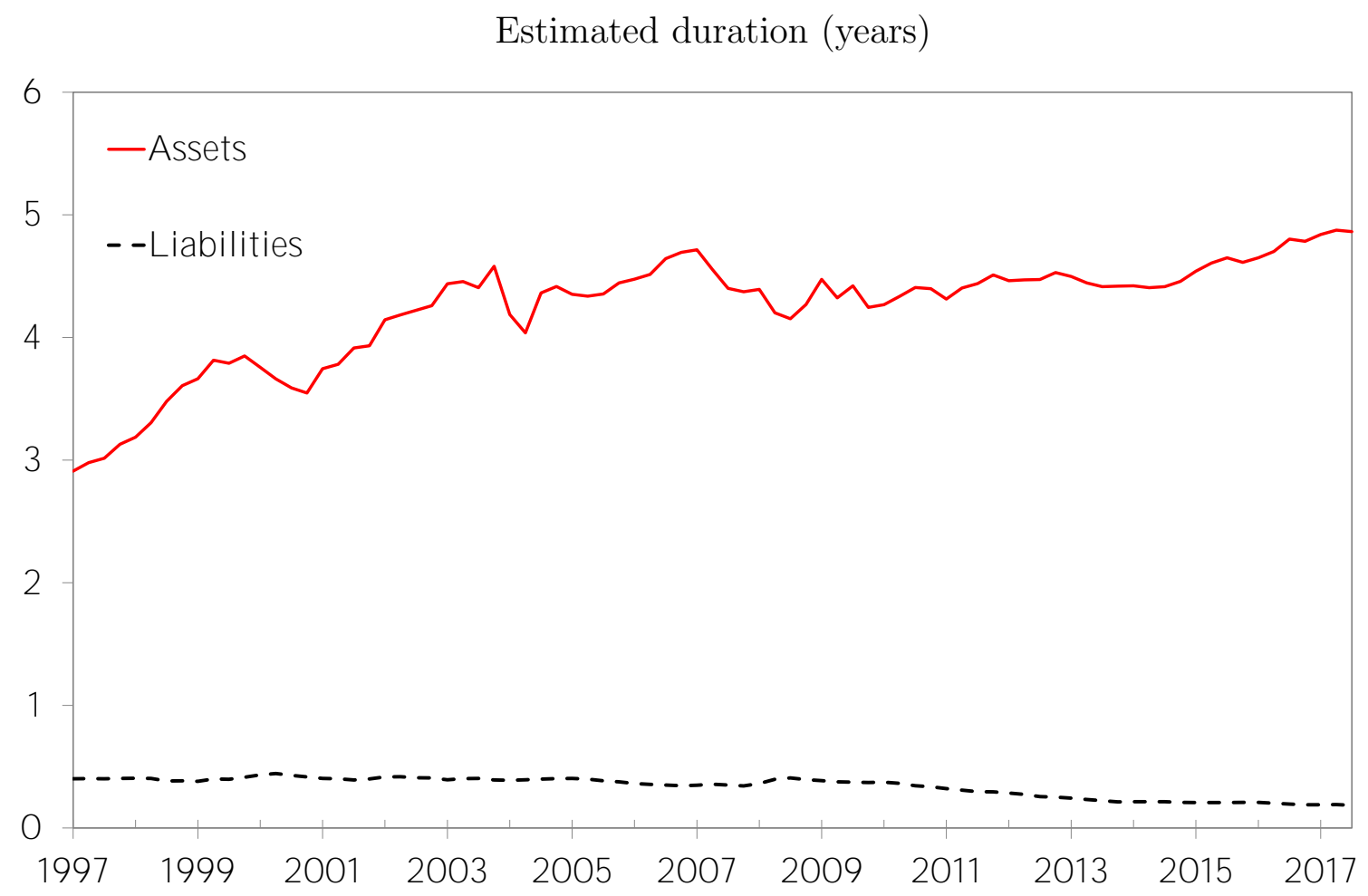




\section{Figure 2: Industry-level stock returns and interest rate changes}

The figure shows the sensitivity of bank and other industry stock portfolios to FOMC rate changes. The data are the returns of the Fama-French 49 industry portfolios and the CRSP value-weighted market portfolio, downloaded from Ken French's website. The figure plots the coefficients from regressions of these industry returns on the change in the one-year Treasury rate (obtained from the Fed's H.15 release) over a one-day window around FOMC meetings. The sample includes all scheduled FOMC meetings from January 1994 to June 2008 (there are 108 such meetings and 5 unscheduled ones).

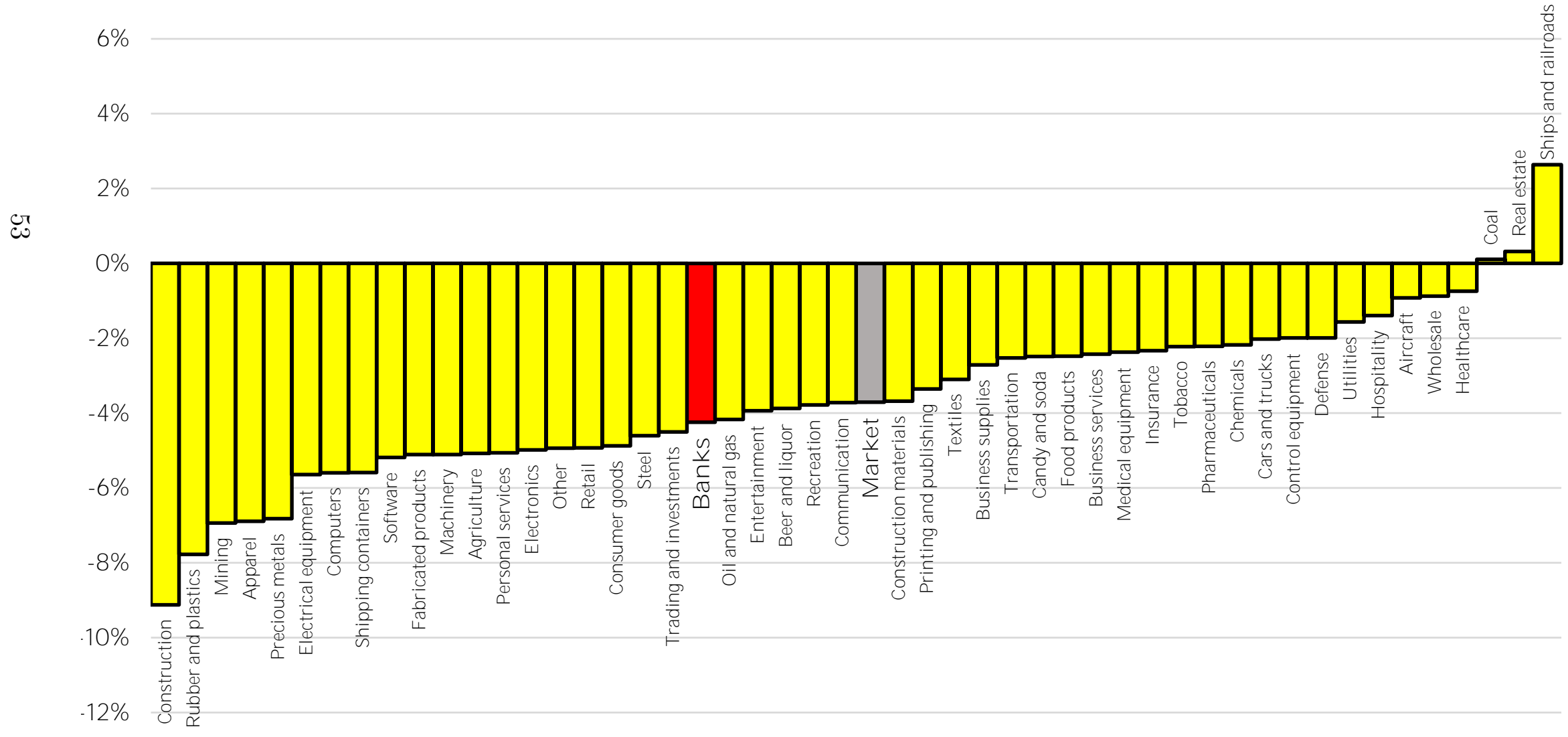




\section{Figure 3: Aggregate time series}

The figure plots the aggregate time series of net interest margin (NIM) and return on assets (ROA) in Panel A, and the interest income and interest expense rates in Panel B. Also shown is the Fed funds rate. The interest income and expense rates equal total interest income and expense divided by assets, respectively. The data are annual from FDIC, 1955 to 2017.

Panel A: NIM and ROA

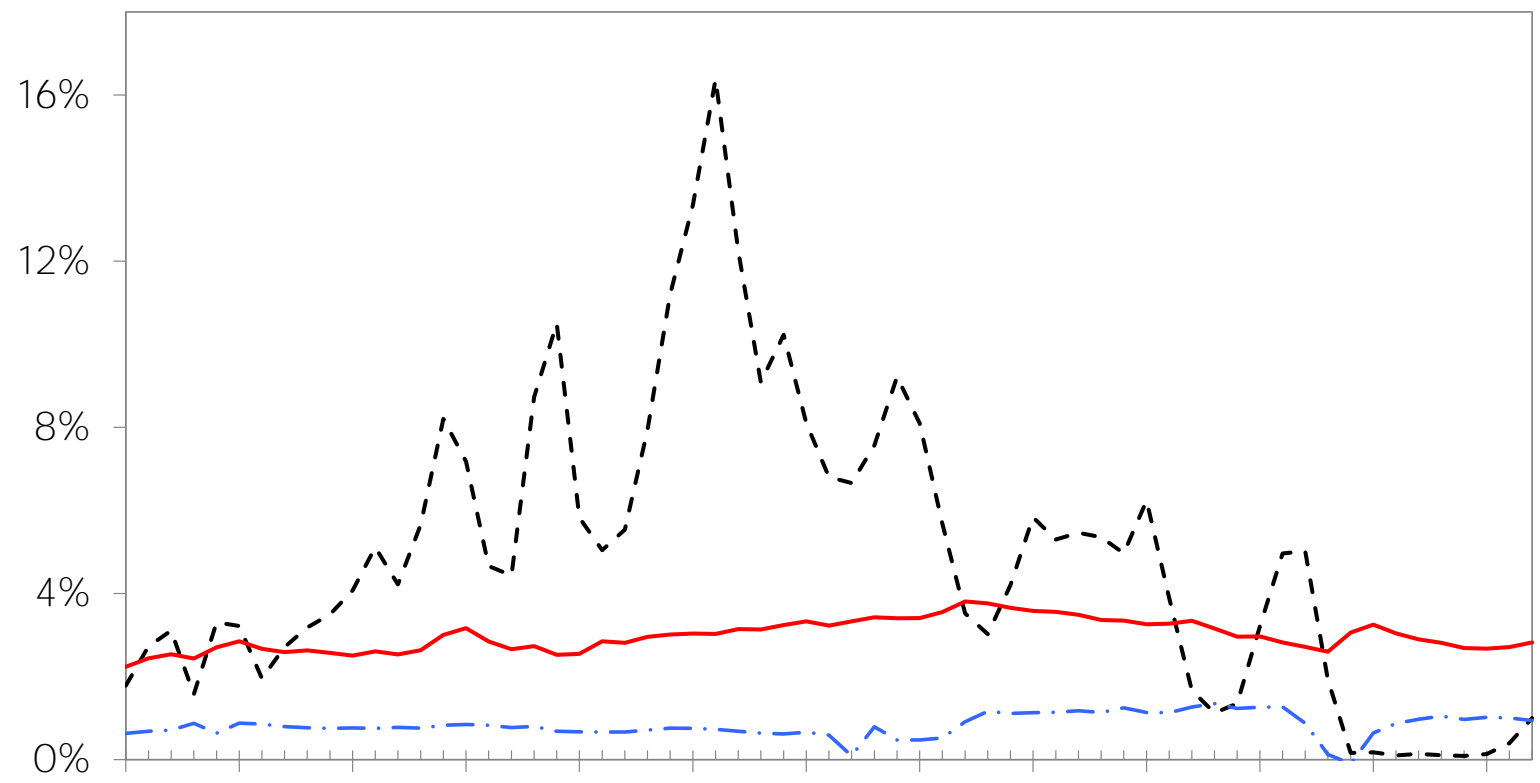

1955196019651970197519801985199019952000200520102015

- -Fed funds rate -Net interest margin (NIM) - Return on assets (ROA)

Panel B: Interest income and interest expense

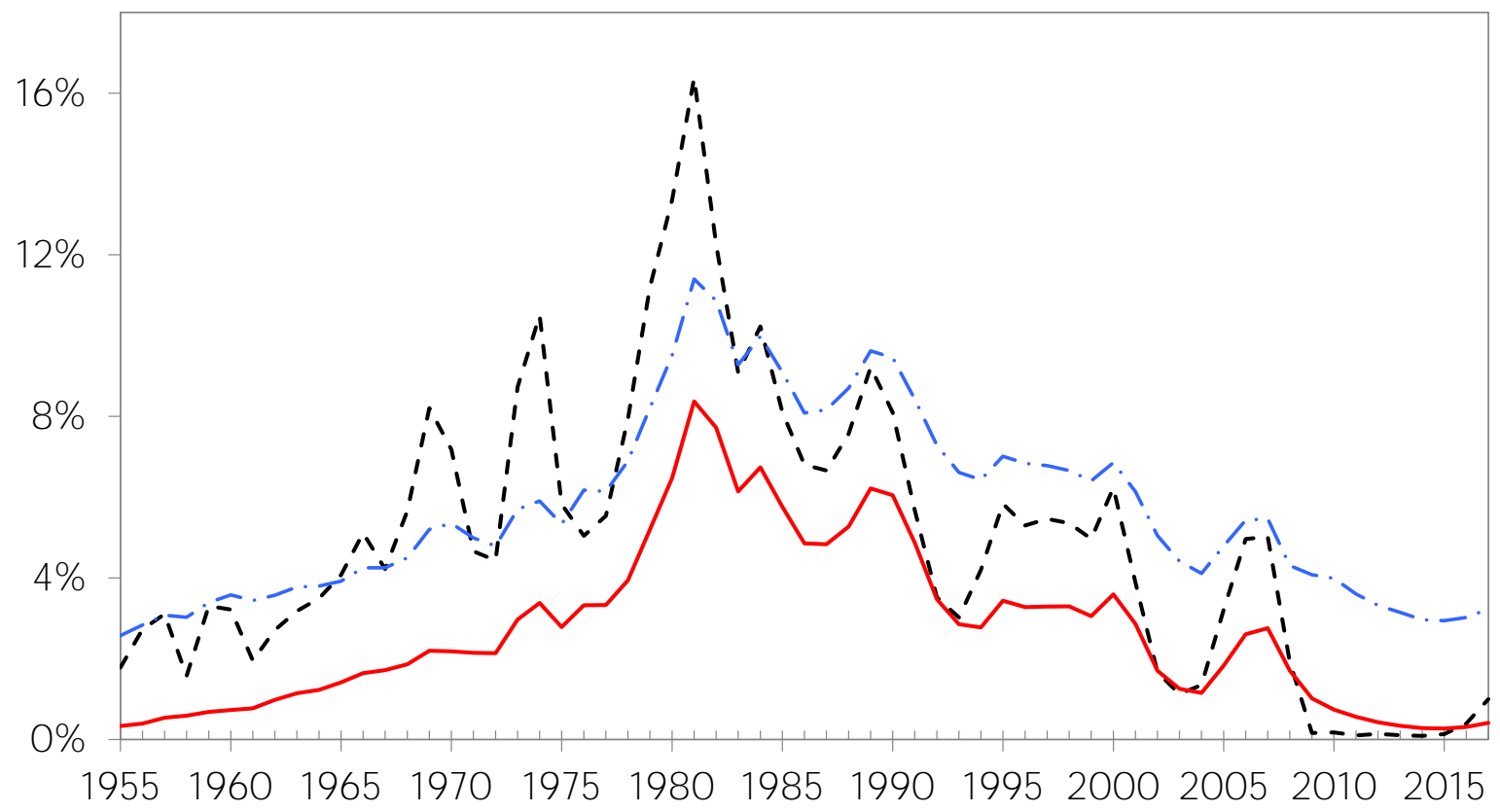

- -Fed funds rate -Interest expense - Interest income 


\section{Figure 4: Simulated Treasury portfolio net interest margin}

The figure plots the net interest margin (Panel A) and interest income and interest expense (Panel B) of a simulated portfolio of Treasury bonds with the same duration mismatch as banks. The simulated Treasury portfolio buys ten-year zero-coupon bonds and holds them to maturity. This gives it an asset duration of 5.5 years, hence to achieve the target asset duration of 4.2 years (see Table A.2), the portfolio also invests $23.6 \%$ at the Fed funds rate. The portfolio is funded by borrowing $40 \%$ at the 1-year Treasury rate and $60 \%$ at the Fed funds rate for a target liabilities duration of 0.4 years. The portfolio's net interest margin (NIM), interest income, and interest expense are computed using standard bank accounting. Also shown is the NIM of banks from Figure 3. The data are annual, from 1955 to 2017.

Panel A: Net interest margin (NIM)

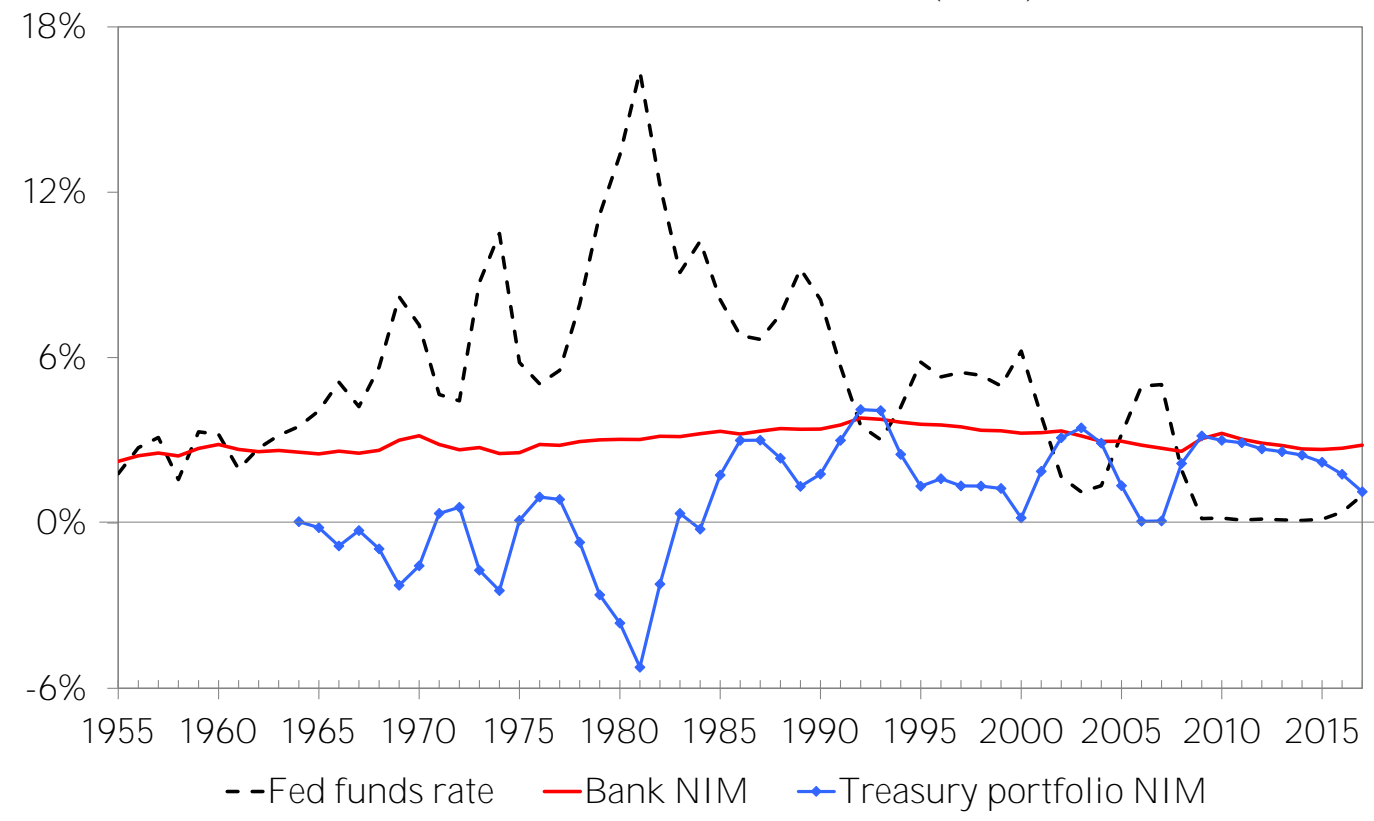

Panel B: Interest income and expense

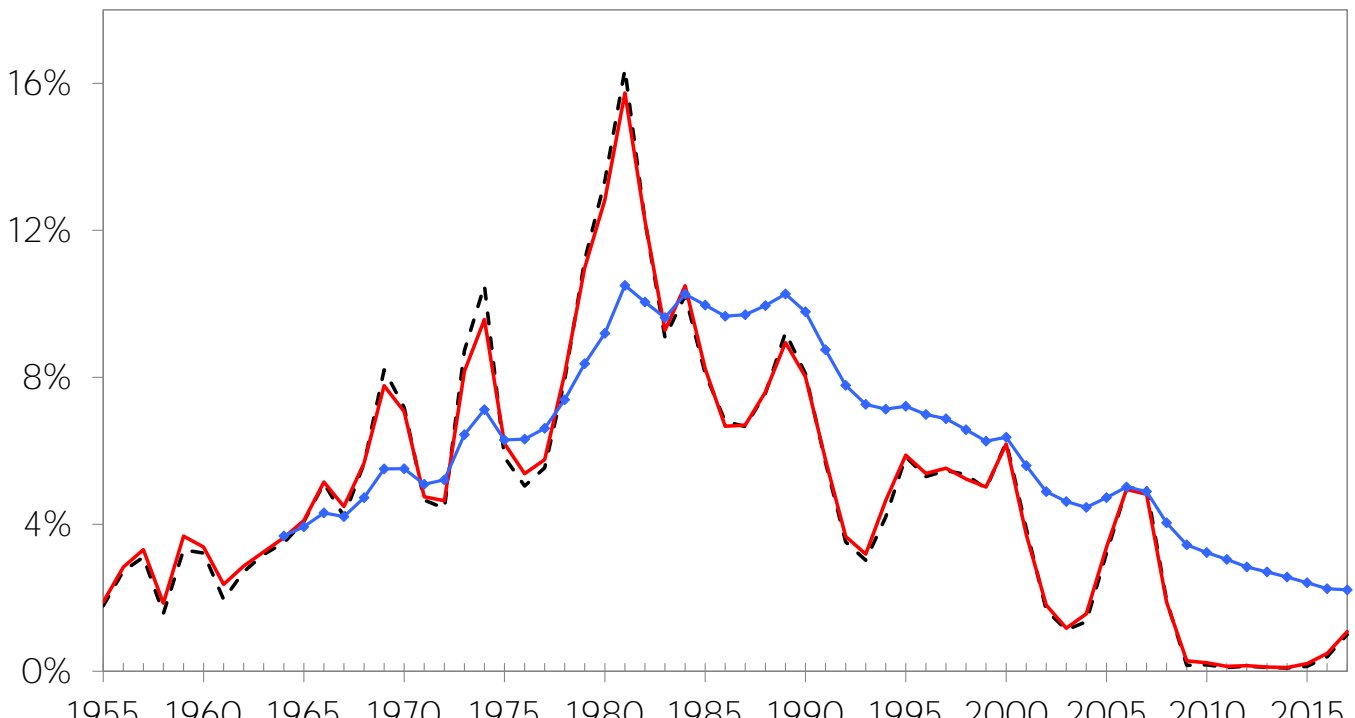

1955196019651970197519801985199019952000200520102015

- -Fed funds rate — Treasury portfolio interest expense $\rightarrow$-Treasury portfolio interest income 
Figure 5: The distributions of interest expense and income betas

The interest expense and income betas are calculated by regressing the change in a bank's interest expense or income rate on the contemporaneous and previous three quarterly changes in the Fed funds rate. The sample includes all banks with at least 20 quarterly observations from 1984 to 2017. For this figure, the betas are winsorized at the $1 \%$ level.
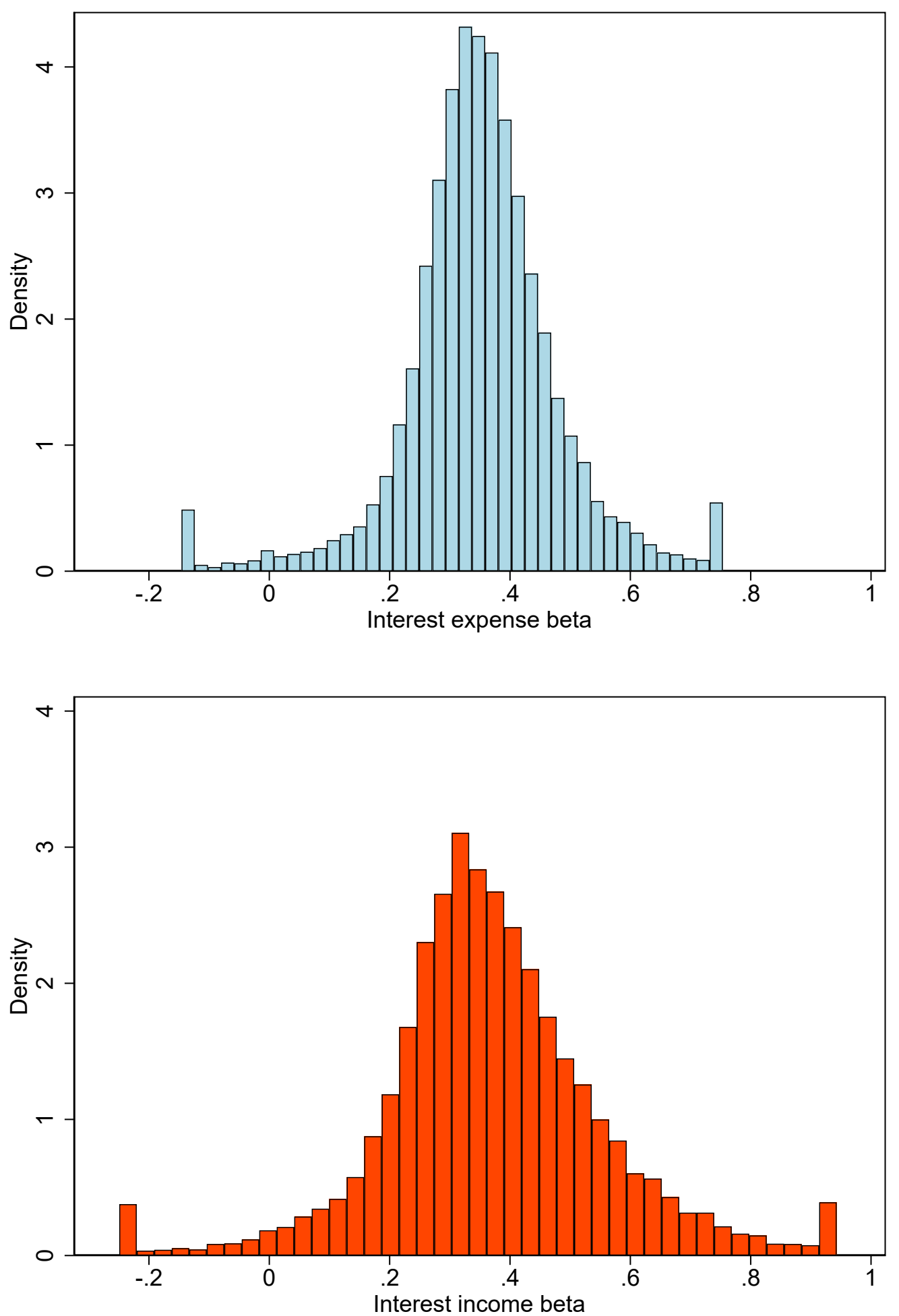


\section{Figure 6: Interest expense, interest income, and ROA matching}

This figure shows bin scatter plots of interest expense, interest income, and ROA betas for all banks and the largest five percent of banks. The betas are calculated by regressing the quarterly change in each bank's interest expense rate, interest income rate, or ROA on the contemporaneous and previous three changes in the Fed funds rate. Only banks with at least 20 quarterly observations are included. The betas are winsorized at the $5 \%$ level. The bin scatter plot groups banks into 100 bins by interest expense beta and plots the average income or ROA beta within each bin. The top $5 \%$ of banks are those whose average total assets over the sample are in the top fifth percentile. The sample is from 1984 to 2017.

All banks
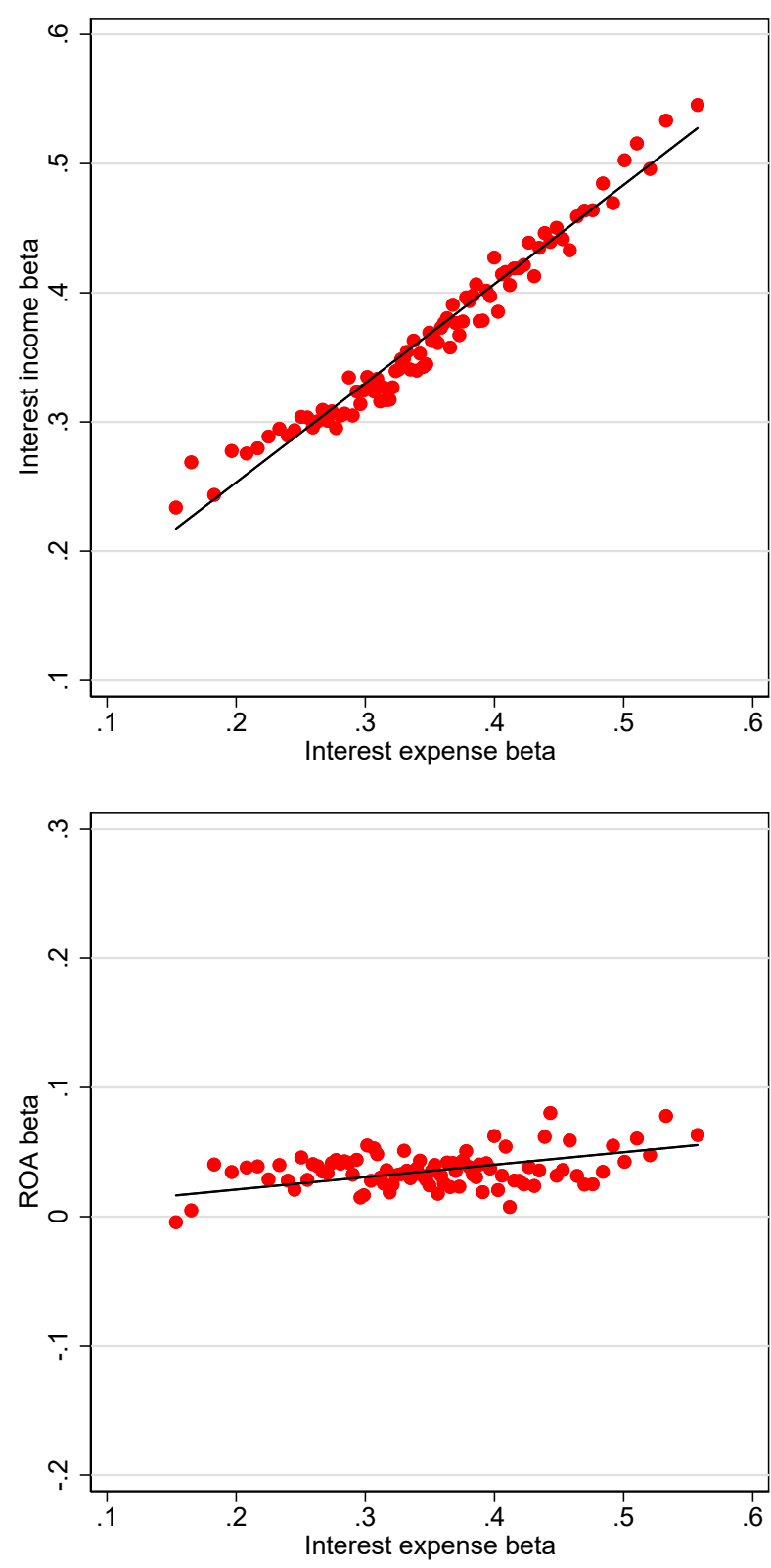

Top $5 \%$
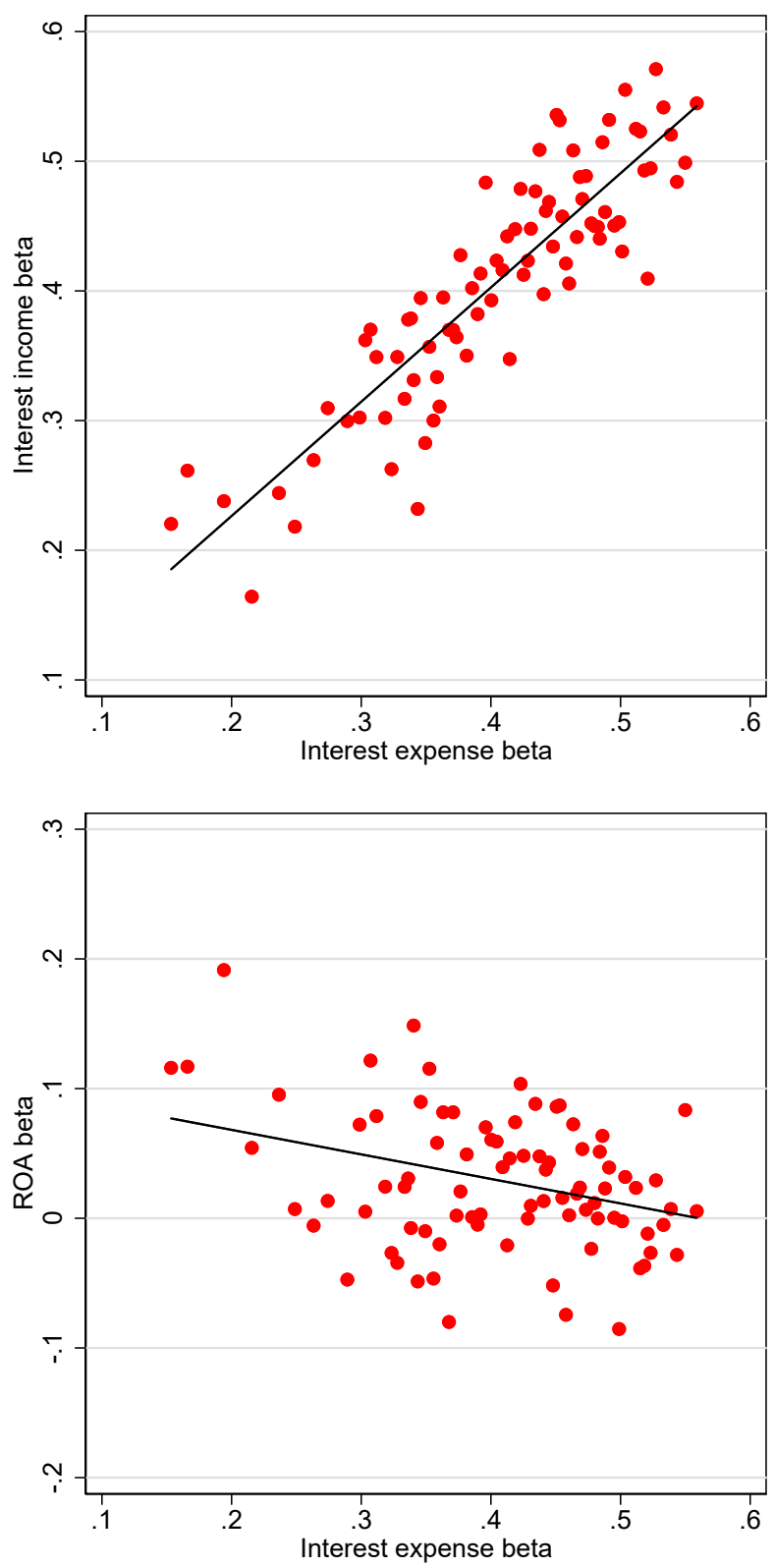


\section{Figure 7: Equity FOMC betas}

This figure shows bin scatter plots of banks' equity FOMC betas against their interest expense betas (top left), interest income betas (top right), asset duration (bottom left), and liabilities duration (bottom right). The FOMC betas are calculated by regressing the stock return of publicly listed banks on the change in the one-year Treasury rate over a one-day window around scheduled FOMC meetings. The expense and income betas are calculated by regressing the quarterly change in each bank's interest expense or income on the contemporaneous and previous three changes in the Fed funds rate. The proxy for duration is repricing maturity. The sample includes all publicly listed banks with at least 20 quarterly observations. The betas are winsorized at the 5\% level. The bin scatter plot groups the bank holding companies into 50 bins and plots the average FOMC beta within each bin. The sample is from January 1994 to June 2007.
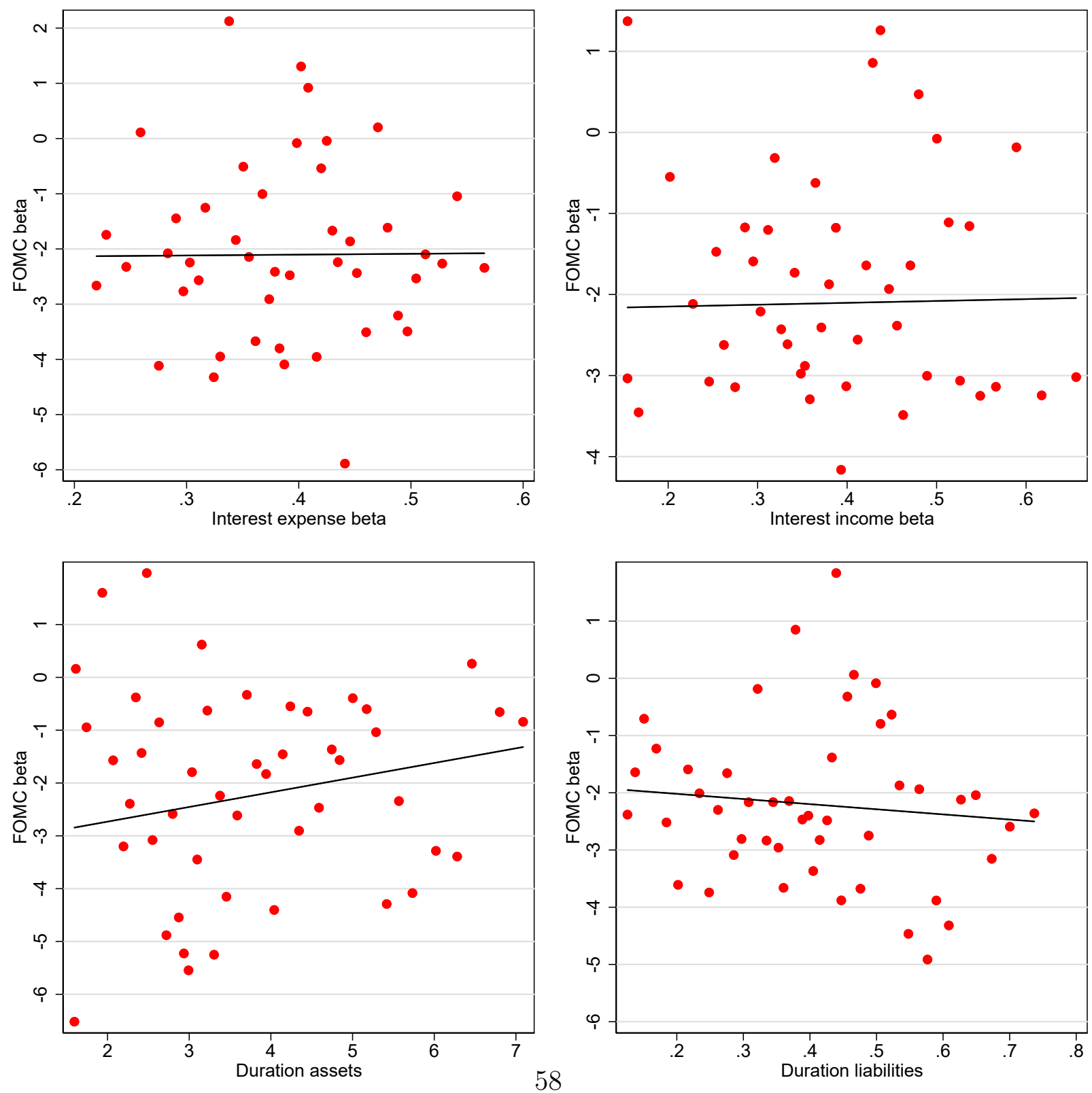


\section{Figure 8: Interest expense betas and asset duration}

This figure shows bin scatter plots of the repricing maturity and short term share of loans and securities against interest expense betas. Repricing maturity is calculated as a weighted average of the amounts reported within each interval (e.g. loans with repricing maturity of one to three years are assigned repricing maturity of two years). The short term share refers to loans and securities with repricing maturity of less than one year as a percentage of the total. The betas are calculated by regressing the quarterly change in each bank's interest expense rate on the contemporaneous and previous three changes in the Fed funds rate. Only banks with at least 20 quarterly observations are included and the betas are winsorized at the 5\% level. The bin scatter plot groups banks into 100 bins by interest expense beta and plots the average repricing maturity and short term share within each bin. The sample is from 1997 to 2017.
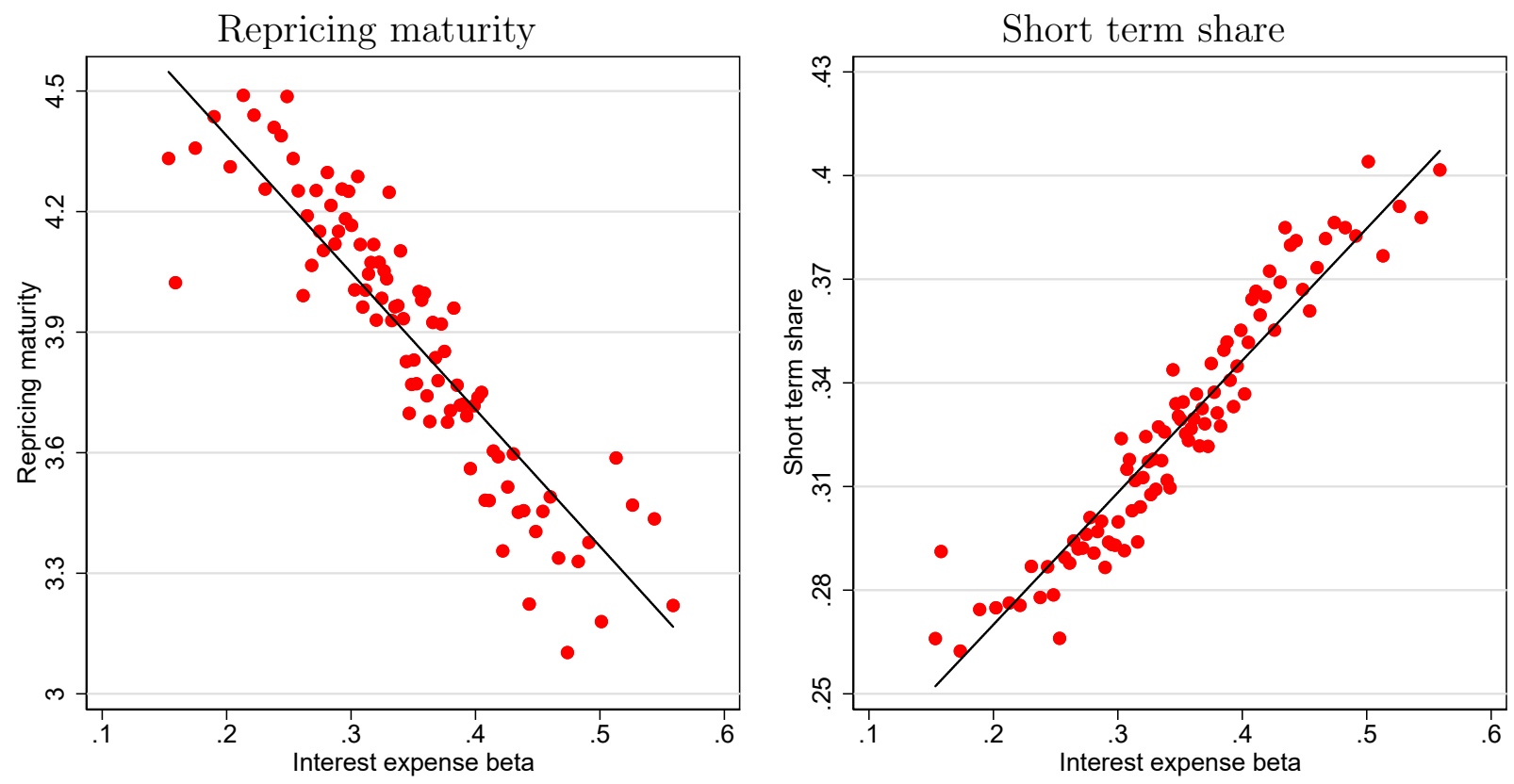


\section{Figure 9: Interest expense betas and market concentration}

This figure presents a bin scatter plot of interest expense betas against a bank Herfindahl (HHI) index. To calculate the bank HHI, we first calculate a zip-code HHI by computing each bank's share of the total branches in the zip code and summing the squared shares. We then create the bank HHI by averaging the zip-code HHIs of each bank's branches, using the bank's deposits in each zip code as weights. The betas are calculated by regressing the change in a bank's interest expense rate on the contemporaneous and previous three quarterly changes in the Fed funds rate. Only banks with at least 20 quarterly observations are included. The betas are winsorized at the 5\% level. The sample covers 1994 to 2017.

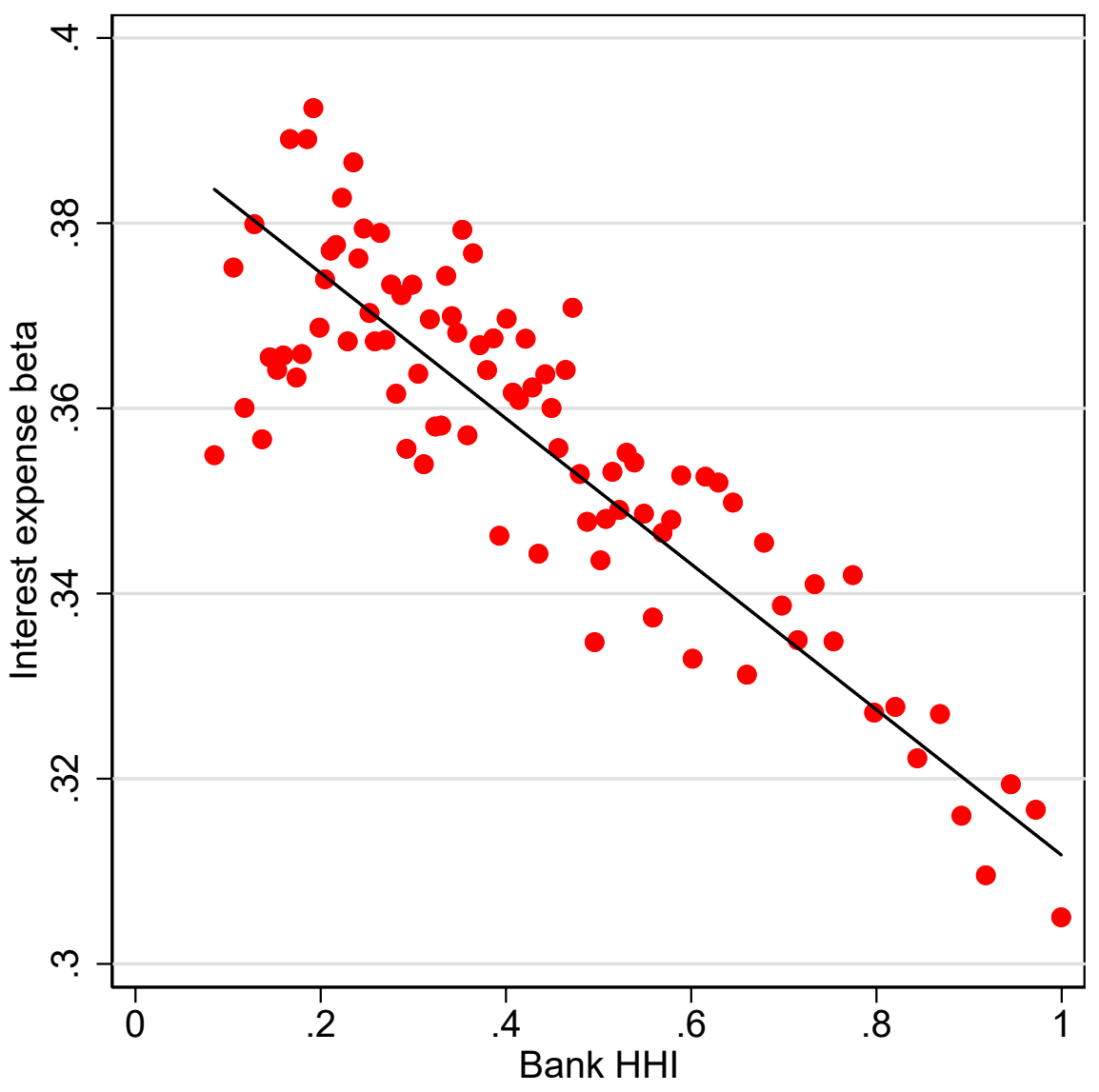




\section{Appendix}

This appendix contains supplementary material, tables, and figures.

\section{A Evidence from the annual reports of the three largest U.S. banks}

The annual reports of the largest U.S. banks provide strong evidence that banks hedge interest rates carefully and that the deposit franchise is central to this process.

Banks are not required to disclose their deposit betas but some banks do so on occasion. For instance, in 2016, Wells Fargo stated that it has an estimated deposit beta of 0.45 to 0.55 on its interest-bearing deposits. ${ }^{47} \mathrm{~S} \& \mathrm{P}$ reported that Bank of America also has an estimated deposit beta between 0.45 and 0.55. ${ }^{48}$ In 2017, J.P. Morgan reported a "deposit reprice beta" of 0.4 during the 2004 rate hiking cycle but stated that it expects its beta to be higher after 2016. ${ }^{49}$ We estimate similar betas for these banks in our data $(0.51,0.46$, and 0.49 , respectively). They are broadly in line with but slightly higher than the mean estimates in our data, reflecting the greater use of competitive wholesale funding by the largest banks. The importance of the deposit franchise for these betas is captured in the following statement from J.P. Morgan's 2016 annual report: "Our firm benefits greatly when rates rise, particularly short rates, which allow us to capture the full value of our significant deposit franchise" ${ }^{50}$

The annual reports also show that banks believe they have low exposure to interest rate risk and are either hedged to, or even slightly benefit from, unexpected interest rate increases. In 2016, Wells Fargo reported that a 100 bps level shift in interest rates would increase NIM by 5 to 15 bps (NIM in 2015 was 295 bps). ${ }^{51}$ J.P. Morgan and Wells Fargo report that a level shift in the yield curve would have a small, positive effect on net interest income.

\footnotetext{
${ }^{47}$ See Wells Fargo Investor Day, May 24, 2016, page 10. Available at https:// www08.wellsfargomedia.com/assets/pdf/about/investor-relations/presentations/2016/ corporate-treasury-presentation.pdf. Last accessed on March 19, 2018.

${ }^{48}$ See Nathan Stovall, "How much deposit costs increase is anyone's guess", February 13, 2017. Available at http: //www.bankingexchange.com/images/Dev_SNL/022217-Blog-HowMuchDeposit.pdf. Last accessed on March 19, 2018.

${ }^{49}$ See J.P. Morgan Chase, Investor Day, February 28, 2017, page 27. Available at https: //www.jpmorganchase.com/corporate/investor-relations/document/firm_overview_investor_ day_2017.pdf. Last accessed on March 19, 2018.

${ }^{50}$ See J.P. Morgan Chase Annual Report 2016, "Letter of the Chief Operating Officer", page 51. Available at https://www.jpmorganchase.com/corporate/investor-relations/document/2016-annualreport. pdf. Last accessed on March 19, 2018.

${ }^{51}$ See Wells Fargo Investor Day, May 24, 2016, page 10. Available at https:// www08.wellsfargomedia.com/assets/pdf/about/investor-relations/presentations/2016/ corporate-treasury-presentation.pdf.
} 
The annual reports make clear that the deposit franchise and the low deposit beta it provides are central to banks' business model. In February 2017, at the start of the most recent hiking cycle, an $\mathrm{S} \& \mathrm{P}$ industry report quotes a bank analyst as saying "We are all trying to figure out deposit betas and the banks are too."52 So far, it appears that deposit betas in the current cycle are not significantly different from past cycles. As The Wall Street Journal reported in October 2017, "the so-called deposit beta ... reached $34 \%$ in third quarter of 2017."53 A report in Barron's from August 2017 suggests that the largest U.S. banks have raised deposit rates by even less, increasing them by only 11 bps even as the Fed raised the Fed funds rate by 100 bps. ${ }^{54}$ These reports are consistent with the small uptick in interest expense seen at the end of the sample in Figure 3. Thus, even though it may be early to assess the full impact of the ongiong interest rate hiking cycle, deposit betas have so far remained stable.

\section{B Repricing maturity}

To calculate the repricing maturity of bank assets and liabilities, we follow the methodology of English, den Heuvel, and Zakrajsek (2012). Starting in 1997, banks report their holdings of five asset categories (residential mortgage loans, all other loans, Treasuries and agency debt, MBS secured by residential mortgages, and other MBS) broken down into six bins by repricing maturity interval (0 to 3 months, 3 to 12 months, 1 to 3 years, 3 to 5 years, 5 to 15 years, and over 15 years). To calculate the overall repricing maturity of a given asset category, we assign the interval midpoint to each bin (and 20 years to the last bin) and take a weighted average using the amounts in each bin as weights. For the "other MBS" category, banks only report two bins: 0 to 3 years and over 3 years. We assign repricing maturities of 1.5 years and 5 years to these bins, respectively. We compute the repricing maturity of a bank's assets as the weighted average of the repricing maturities of all of its asset categories, using their dollar amounts as weights. In some tests we include cash and Fed funds sold in the calculation, assigning them a repricing maturity of zero.

We follow a similar approach to calculate the repricing maturity of liabilities. Banks report the repricing maturity of their small and large time deposits by four intervals (0 to 3 months, 3 to 9 months, 1 to 3 years, and over 3 years). We assign the midpoint to each interval and 5 years to the last one. We assign zero repricing maturity to demandable

\footnotetext{
${ }^{52}$ See Nathan Stovall, "How much deposit costs increase is anyone's guess.", February 13, 2017. Available at http: //www . bankingexchange.com/images/Dev_SNL/022217-Blog-HowMuchDeposit.pdf

${ }^{53}$ Aaron Back in Wall Street Journal, "A Surprising Shake-Out Among Banks as Rates Rise", October 30, 2017.

${ }^{54}$ Teresa Rivas in Barron's, "Why Big Bank Deposit Betas Will Likely Stay Low For Now", August 15, 2017.
} 
deposits such as transaction and savings deposits. We also assign zero repricing maturity to wholesale funding such as repo and Fed funds purchased. We assume a repricing maturity of 5 years for subordinated debt. We compute the repricing maturity of liabilities as the weighted average of the repricing maturities of all of these categories.

Figure A.1 plots the distribution of asset and liabilities repricing maturity across banks, showing that it exhibits substantial variation. Table A.2 provides summary statistics for repricing maturity by asset category. We note in particular that securities have a substantially higher repricing maturity (5.7 years on average, 8.4 years in the aggregate) than loans (3.2 years on average, 3.8 years in the aggregate). 


\section{Table A.1: Bank equity and interest rate changes}

This table examines the effect of interest rate shocks on bank equity values on FOMC dates using the following OLS regression:

$$
R_{t}=\alpha_{0}+\beta \Delta y_{t}^{1 y r}+\epsilon_{t},
$$

where $\Delta y_{t}^{1 y r}$ is the change in one-year Treasury yield on FOMC meeting days (one-day change computed using end-of-day data). The outcome variables in Columns 1 and 2 are the one-day returns on the CRSP value-weighted banking sector index and market index, downloaded from Ken French's website. The FOMC meeting dates are from Kenneth Kuttner's website. The sample are all scheduled FOMC meeting dates from June 1994 to June 2007 (108 meetings).

\begin{tabular}{lcc}
\hline \hline & $(1)$ & $(2)$ \\
\hline$\Delta y^{1 y r}$ & $-4.243^{* *}$ & $-3.708^{* *}$ \\
& $(2.060)$ & $(1.546)$ \\
Constant & $0.203^{*}$ & $0.182^{* *}$ \\
& $(0.114)$ & $(0.087)$ \\
\hline Obs. & 108 & 108 \\
Industry & Banks & Market \\
$A d j-R^{2}$ & 0.025 & 0.037 \\
\hline \hline
\end{tabular}




\section{Table A.2: Repricing maturity by asset category}

This table reports summary statistics on repricing maturity and asset shares. Repricing maturity is computed as the weighted average by asset category. Asset shares are total amounts in each asset category as a share of total assets. The sample are all U.S. commercial banks from 1997 to 2017 and we include all assets with reported repricing maturities (95\%) of total assets). Columns (1) and (2) are for the average bank. Columns (3) and (4) are for the aggregate banking system.

\begin{tabular}{|c|c|c|c|c|}
\hline & \multicolumn{2}{|c|}{ Average bank } & \multicolumn{2}{|c|}{ Aggregate } \\
\hline & $\begin{array}{c}\text { Asset } \\
\text { Share }(\%) \\
(1)\end{array}$ & $\begin{array}{c}\text { Repricing } \\
\text { Maturity } \\
(2)\end{array}$ & $\begin{array}{c}\text { Asset } \\
\text { Share }(\%) \\
(3)\end{array}$ & $\begin{array}{c}\text { Repricing } \\
\text { Maturity } \\
\text { (4) }\end{array}$ \\
\hline Securities & 22.3 & 5.7 & 18.2 & 8.4 \\
\hline Gov't securities & 15.9 & 5.2 & 8.4 & 5.4 \\
\hline RMBS & 4.3 & 9.0 & 6.3 & 14.9 \\
\hline Other securities & 2.2 & 3.2 & 3.6 & 3.8 \\
\hline Loans & 61.6 & 3.2 & 56.2 & 3.8 \\
\hline Residential loans & 13.6 & 4.9 & 11.1 & 9.5 \\
\hline Other loans & 48.0 & 2.7 & 45.0 & 2.4 \\
\hline Cash & 11.0 & 0.0 & 11.8 & 0.0 \\
\hline Securities + Loans + Cash & 94.8 & 3.5 & 86.1 & 4.2 \\
\hline
\end{tabular}




\section{Table A.3: Interest sensitivity matching}

This table replicates Table 2. Standard errors in parentheses "( )" are computed using a block bootstrap method with 10,000 iterations. Standard errors in square brackets "[ ]" are clustered at the bank and quarter level.

$\Delta$ Interest income rate

\begin{tabular}{|c|c|c|c|c|c|c|c|c|}
\hline & \multicolumn{2}{|c|}{ All banks } & \multicolumn{2}{|c|}{ Top $10 \%$} & \multicolumn{2}{|c|}{ Top 5\% } & \multicolumn{2}{|c|}{ Top 1\% } \\
\hline & $(1)$ & $(2)$ & $(3)$ & $(4)$ & $(5)$ & $(6)$ & $(7)$ & $(8)$ \\
\hline \multirow[t]{3}{*}{$\triangle \widehat{\operatorname{lntEx} p}$} & $0.773^{* * *}$ & $0.774^{* * *}$ & $0.977 * * *$ & $0.980 * * *$ & $0.993^{* * *}$ & $0.994^{* * *}$ & $0.933^{* * *}$ & $0.944^{* * *}$ \\
\hline & $(0.033)$ & $(0.034)$ & $(0.070)$ & $(0.071)$ & $(0.081)$ & $(0.081)$ & $(0.110)$ & $(0.113)$ \\
\hline & {$[0.033]$} & {$[0.034]$} & {$[0.071]$} & {$[0.072]$} & {$[0.091]$} & {$[0.091]$} & {$[0.090]$} & {$[0.093]$} \\
\hline \multirow[t]{3}{*}{$\sum \gamma_{\tau}$} & $0.091 * * *$ & & 0.016 & & -0.001 & & 0.006 & \\
\hline & $(0.031)$ & & $(0.037)$ & & $(0.044)$ & & $(0.062)$ & \\
\hline & {$[0.030]$} & & {$[0.035]$} & & {$[0.045]$} & & {$[0.050]$} & \\
\hline Bank FE & Yes & Yes & Yes & Yes & Yes & Yes & Yes & Yes \\
\hline Time FE & No & Yes & No & Yes & No & Yes & No & Yes \\
\hline Obs. & $1,210,873$ & $1,210,873$ & 121,771 & 121,771 & 61,014 & 61,014 & 13,540 & 13,540 \\
\hline No. of banks & 18,615 & 18,615 & 1,855 & 1,855 & 924 & 924 & 185 & 185 \\
\hline No. of quarters & 135 & 135 & 135 & 135 & 135 & 135 & 135 & 135 \\
\hline$R^{2}$ & 0.087 & 0.117 & 0.102 & 0.132 & 0.093 & 0.122 & 0.091 & 0.126 \\
\hline
\end{tabular}




\section{Table A.4: Interest sensitivity of ROA}

This table replicates Table 3. Standard errors in parentheses "( )" are computed using a block bootstrap method with 10,000 iterations. Standard errors in square brackets "[ ]" are clustered at the bank and quarter level.

$\Delta$ Return on assets

\begin{tabular}{|c|c|c|c|c|c|c|c|c|}
\hline & \multicolumn{2}{|c|}{ All banks } & \multicolumn{2}{|c|}{ Top $10 \%$} & \multicolumn{2}{|c|}{ Top 5\% } & \multicolumn{2}{|c|}{ Top $1 \%$} \\
\hline & $(1)$ & $(2)$ & $(3)$ & $(4)$ & $(5)$ & $(6)$ & $(7)$ & $(8)$ \\
\hline \multirow[t]{3}{*}{$\Delta \widehat{\operatorname{IntExp}}$} & -0.016 & -0.012 & 0.003 & 0.015 & -0.010 & 0.002 & 0.035 & 0.056 \\
\hline & $(0.015)$ & $(0.016)$ & $(0.017)$ & $(0.018)$ & $(0.020)$ & $(0.022)$ & $(0.039)$ & $(0.038)$ \\
\hline & {$[0.015]$} & {$[0.016]$} & {$[0.016]$} & {$[0.018]$} & {$[0.020]$} & {$[0.022]$} & {$[0.065]$} & {$[0.065]$} \\
\hline \multirow[t]{3}{*}{$\sum \gamma_{\tau}$} & $0.042^{* * *}$ & & $0.041 * *$ & & $0.038^{*}$ & & 0.013 & \\
\hline & $(0.014)$ & & $(0.021)$ & & $(0.022)$ & & $(0.034)$ & \\
\hline & {$[0.013]$} & & {$[0.020]$} & & {$[0.022]$} & & {$[0.041]$} & \\
\hline Bank FE & Yes & Yes & Yes & Yes & Yes & Yes & Yes & Yes \\
\hline Time FE & No & Yes & No & Yes & No & Yes & No & Yes \\
\hline Obs. & $1,210,873$ & $1,210,873$ & 121,771 & 121,771 & 61,014 & 61,014 & 13,540 & 13,540 \\
\hline No. of banks & 18,615 & 18,615 & 1,855 & 1,855 & 924 & 924 & 185 & 185 \\
\hline No. of quarters & 135 & 135 & 135 & 135 & 135 & 135 & 135 & 135 \\
\hline$R^{2}$ & 0.027 & 0.035 & 0.020 & 0.041 & 0.017 & 0.045 & 0.012 & 0.078 \\
\hline
\end{tabular}




\section{Table A.5: Interest sensitivity matching and derivatives usage}

This table estimates the same regressions as in Table 2 for the sub-samples that do and do not use interest rate derivatives. Columns 1 and 2 provide results for all banks with non-missing derivatives data (this data starts in 1995). Columns 3 and 4 present results for banks that have zero exposure to derivatives. Columns 5 and 6 present results for banks that have nonzero exposure to derivatives. Standard errors are block-bootstrapped by quarter with 10,000 iterations.

$\Delta$ Interest income rate

\begin{tabular}{|c|c|c|c|c|c|c|}
\hline & \multicolumn{2}{|c|}{ All banks } & \multicolumn{2}{|c|}{ No derivatives } & \multicolumn{2}{|c|}{ Nonzero derivatives } \\
\hline & $(1)$ & $(2)$ & $(3)$ & $(4)$ & $(5)$ & $(6)$ \\
\hline$\triangle \widehat{\operatorname{IntExp}}$ & $\begin{array}{c}1.122^{* * *} \\
(0.064)\end{array}$ & $\begin{array}{c}1.130^{* * *} \\
(0.064)\end{array}$ & $\begin{array}{c}1.134^{* * *} \\
(0.062)\end{array}$ & $\begin{array}{c}1.142^{* * *} \\
(0.062)\end{array}$ & $\begin{array}{c}1.099 * * * \\
(0.097)\end{array}$ & $\begin{array}{c}1.110^{* * * *} \\
(0.098)\end{array}$ \\
\hline$\sum \gamma_{\tau}$ & $\begin{array}{l}-0.019 \\
(0.034)\end{array}$ & & $\begin{array}{l}-0.016 \\
(0.033)\end{array}$ & & $\begin{array}{l}-0.031 \\
(0.043)\end{array}$ & \\
\hline Bank FE & Yes & Yes & Yes & Yes & Yes & Yes \\
\hline Time FE & No & Yes & No & Yes & No & Yes \\
\hline Obs. & 647,121 & 647,121 & 479,480 & 479,480 & 167,641 & 167,641 \\
\hline No. of banks & 12,280 & 12,280 & 9,809 & 9,809 & 2,471 & 2,471 \\
\hline No. of quarters & 92 & 92 & 92 & 92 & 92 & 92 \\
\hline$R^{2}$ & 0.129 & 0.162 & 0.137 & 0.171 & 0.106 & 0.140 \\
\hline
\end{tabular}




\section{Table A.6: Asymmetry in expense betas}

This table presents quarterly expense beta coefficients from a specification that allows for separate coefficients for Fed funds rate increases and decreases. The results are from the following regression:

$$
\begin{aligned}
\Delta \text { IntInc } c_{i t}= & \alpha_{i}+\sum_{\tau=0}^{3} \beta_{i, \tau}^{E x p^{+}} \Delta \text { FedFund } s_{t-\tau} * \mathbb{1}\left(\text { FedFund } s_{t-\tau} \geq 0\right)+ \\
& \sum_{\tau=0}^{3} \beta_{i, \tau}^{E x p^{-}} \Delta \text { FedFund } s_{t-\tau} * \mathbb{1}\left(\text { FedFund } s_{t-\tau} \leq 0\right)+\varepsilon_{i t}
\end{aligned}
$$

where $\Delta \operatorname{Int} E x p_{i, t}$ and $\Delta \operatorname{IntInc_{i,t}}$ are the changes in interest expense and interest income rates of bank $i$ at time $t$, and $\Delta F F_{t}$ is the change in the Fed funds rate. The data are quarterly and cover all U.S. commercial banks from 1984 to 2017.

\begin{tabular}{lcccc}
\hline \hline & \multicolumn{2}{c}{$\beta^{E x p^{+}}$} & \multicolumn{2}{c}{$\beta^{E x p^{-}}$} \\
& $\mu$ & $\sigma$ & $\mu$ & $\sigma$ \\
\hline 1st Quarter & 0.020 & $(0.128)$ & 0.069 & $(0.083)$ \\
2nd Quarter & 0.125 & $(0.143)$ & 0.185 & $(0.087)$ \\
3rd Quarter & 0.148 & $(0.131)$ & 0.055 & $(0.069)$ \\
4th Quarter & 0.095 & $(0.121)$ & 0.033 & $(0.064)$ \\
& & & & \\
Cumulative & 0.386 & $(0.133)$ & 0.342 & $(0.096)$ \\
\hline \hline
\end{tabular}




\section{Table A.7: Matching regression with asymmetry in expense betas}

This table provides estimates of the matching of interest income and expense sensitivities. The results are from the following two-stage ordinary least squares regression:

$$
\begin{aligned}
& \Delta \text { IntExp } \operatorname{Exp}_{i, t}=\alpha_{i}+\sum_{\tau=0}^{3} \beta_{i, \tau}^{E x p^{+}} \Delta F F_{t-\tau} * \mathbb{1}\left(F F_{t-\tau} \geq 0\right)+\sum_{\tau=0}^{3} \beta_{i, \tau}^{E x p^{-}} \Delta F F_{t-\tau} * \mathbb{1}\left(F F_{t-\tau} \leq 0\right)+\epsilon_{i, t}[\text { Stage 1] } \\
& \Delta \text { IntInc }_{i, t}=\quad \lambda_{i}+\sum_{\tau=0}^{3} \gamma_{\tau} \Delta F F_{t-\tau}+\delta \Delta \widehat{\operatorname{IntEx}} p_{i, t}+\varepsilon_{i, t} \text {, [Stage 2] }
\end{aligned}
$$

where $\Delta$ IntExp $p_{i, t}$ and $\Delta I n t I n c_{i, t}$ are the changes in interest expense and interest income rates of bank $i$ at time $t, \Delta F F_{t}$ is the change in the Fed funds rate, and $\widehat{\Delta I n t E x} p_{i, t}$ is the predicted value from the first stage. Columns (2), (4), (6), and (8) include time fixed effects. Top $10 \%$ are the $10 \%$ largest banks by average total assets over the sample. Top 5\% and top $1 \%$ are defined analogously. The data are quarterly and cover all U.S. commercial banks from 1984 to 2017 . Standard errors are block-bootstrapped by quarter with 10,000 iterations.

\begin{tabular}{|c|c|c|c|c|c|c|c|c|}
\hline & \multicolumn{2}{|c|}{ All banks } & \multicolumn{2}{|c|}{ Top $10 \%$} & \multicolumn{2}{|c|}{ Top 5\% } & \multicolumn{2}{|c|}{ Top $1 \%$} \\
\hline & $(1)$ & $(2)$ & $(3)$ & $(4)$ & $(5)$ & $(6)$ & $(7)$ & $(8)$ \\
\hline$\triangle \widehat{\operatorname{IntExp}}$ & $\begin{array}{c}0.776^{* * *} \\
(0.028)\end{array}$ & $\begin{array}{c}0.767^{* * *} \\
(0.026)\end{array}$ & $\begin{array}{c}0.986^{* * *} \\
(0.054)\end{array}$ & $\begin{array}{c}0.992^{* * *} \\
(0.054)\end{array}$ & $\begin{array}{c}0.994^{* * *} \\
(0.065)\end{array}$ & $\begin{array}{c}0.998^{* * *} \\
(0.064)\end{array}$ & $\begin{array}{c}0.950^{* * *} \\
(0.089)\end{array}$ & $\begin{array}{c}0.966^{* * *} \\
(0.091)\end{array}$ \\
\hline$\sum \gamma_{\tau}$ & $\begin{array}{c}0.090^{* * *} \\
(0.027)\end{array}$ & & $\begin{array}{c}0.013 \\
(0.037)\end{array}$ & & $\begin{array}{l}-0.001 \\
(0.043)\end{array}$ & & $\begin{array}{l}-0.002 \\
(0.053)\end{array}$ & \\
\hline Bank FE & Yes & Yes & Yes & Yes & Yes & Yes & Yes & Yes \\
\hline Time FE & No & Yes & No & Yes & No & Yes & No & Yes \\
\hline Obs. & $1,210,873$ & $1,210,873$ & 121,771 & 121,771 & 61,014 & 61,014 & 13,540 & 13,540 \\
\hline No. of banks & 18,615 & 18,615 & 1,855 & 1,855 & 924 & 924 & 185 & 185 \\
\hline No. of quarters & 135 & 135 & 135 & 135 & 135 & 135 & 135 & 135 \\
\hline$R^{2}$ & 0.104 & 0.132 & 0.126 & 0.154 & 0.116 & 0.143 & 0.105 & 0.139 \\
\hline
\end{tabular}


Table A.8: Interest sensitivity matching for bank holding companies (BHC)

This table examines whether bank holding companies match the interest rate sensitivity of their income and expenses. The results are from the following two-stage ordinary least squares regression of interest income rates on interest expense rates:

$$
\begin{aligned}
& \Delta \text { IntExp } \operatorname{Exp}_{i, t}=\alpha_{i}+\sum_{\tau=0}^{3} \beta_{i, \tau} \Delta \text { FedFunds } s_{t-\tau}+\epsilon_{i, t} \quad \text { [Stage 1] } \\
& \Delta \text { IntInc }_{i, t}=\lambda_{i}+\sum_{\tau=0}^{3} \gamma_{\tau} \Delta F e d F u n d s_{t-\tau}+\delta \Delta \widehat{\operatorname{IntEx}} p_{i, t}+\varepsilon_{i, t} \text {. [Stage 2] }
\end{aligned}
$$

Columns (2), (4), (6), and (8) include time fixed effects. Top $10 \%$ are the $10 \%$ largest BHCs by average total assets over the sample. Top 5\% and top 1\% of BHCs are defined analogously. The data are quarterly and cover all U.S. BHCs from 1989 to 2015. Standard errors are block-bootstrapped by quarter with 10,000 iterations.

\begin{tabular}{|c|c|c|c|c|c|c|c|c|}
\hline & \multicolumn{2}{|c|}{ All banks } & \multicolumn{2}{|c|}{ Top $10 \%$} & \multicolumn{2}{|c|}{ Top 5\% } & \multicolumn{2}{|c|}{ Top 1\% } \\
\hline & $(1)$ & $(2)$ & $(3)$ & $(4)$ & $(5)$ & $(6)$ & $(7)$ & $(8)$ \\
\hline$\Delta \widehat{\operatorname{IntExp}}$ & $\begin{array}{c}0.975^{* * *} \\
(0.082)\end{array}$ & $\begin{array}{c}0.974^{* * * *} \\
(0.084)\end{array}$ & $\begin{array}{c}1.093^{* * *} * \\
(0.100)\end{array}$ & $\begin{array}{c}1.087^{* * * *} \\
(0.099)\end{array}$ & $\begin{array}{c}1.096^{* * *} \\
(0.133)\end{array}$ & $\begin{array}{c}1.083^{* * *} \\
(0.133)\end{array}$ & $\begin{array}{c}1.070^{* * *} * \\
(0.229)\end{array}$ & $\begin{array}{c}1.036^{* * *} \\
(0.219)\end{array}$ \\
\hline$\sum \gamma_{\tau}$ & $\begin{array}{c}0.005 \\
(0.036)\end{array}$ & & $\begin{array}{c}-0.085^{*} \\
(0.051)\end{array}$ & & $\begin{array}{l}-0.102 \\
(0.071)\end{array}$ & & $\begin{array}{l}-0.108 \\
(0.122)\end{array}$ & \\
\hline Bank FE & Yes & Yes & Yes & Yes & Yes & Yes & Yes & Yes \\
\hline Time FE & No & Yes & No & Yes & No & Yes & No & Yes \\
\hline Obs. & 142,239 & 142,239 & 17,587 & 17,587 & 9,092 & 9,092 & 1,703 & 1,703 \\
\hline No. of BHCs & 4,146 & 4,146 & 425 & 425 & 212 & 212 & 40 & 40 \\
\hline No. of quarters & 107 & 107 & 107 & 107 & 107 & 107 & 107 & 107 \\
\hline$R^{2}$ & 0.172 & 0.213 & 0.148 & 0.189 & 0.145 & 0.189 & 0.158 & 0.318 \\
\hline
\end{tabular}

$\Delta$ Interest income rate 


\section{Figure A.1: Estimated duration of bank assets and liabilities}

The figure plots the distribution of repricing maturity, a proxy for duration, of bank assets and liabilities. The repricing maturity of assets is estimated by calculating the repricing maturity of loans and securities using the available data and assigning zero repricing maturity to cash and Fed funds sold. The repricing maturity of liabilities is calculated by assigning zero repricing maturity to transaction deposits, savings deposits, and Fed funds purchased, by assigning repricing maturity of five to subordinated debt, and by calculating the repricing maturity of time deposits using the available data. All other asset and liabilities categories (e.g. trading assets, other borrowed money), for which repricing maturity is not given, are left out of the calculation. The sample is from 1997 to 2017. Repricing maturities are winsorized at the $1 \%$ level for this figure.

All banks

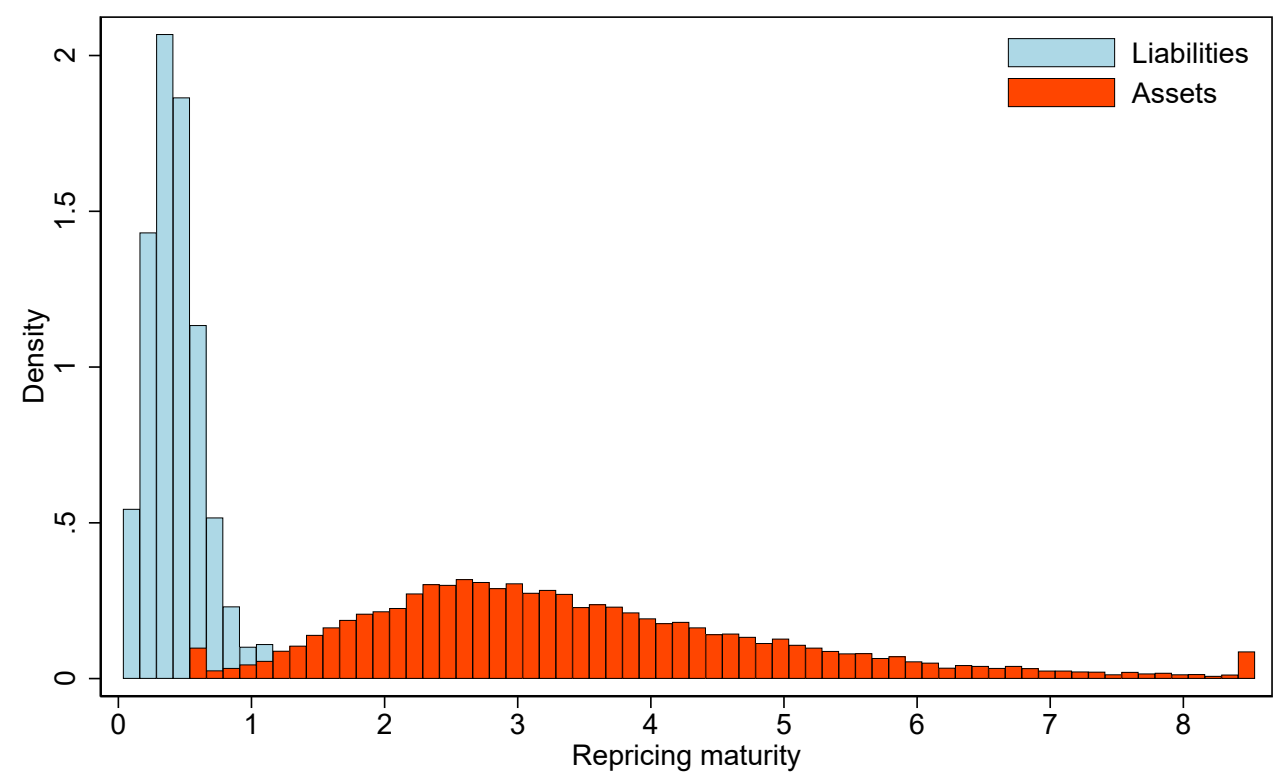

Top $5 \%$

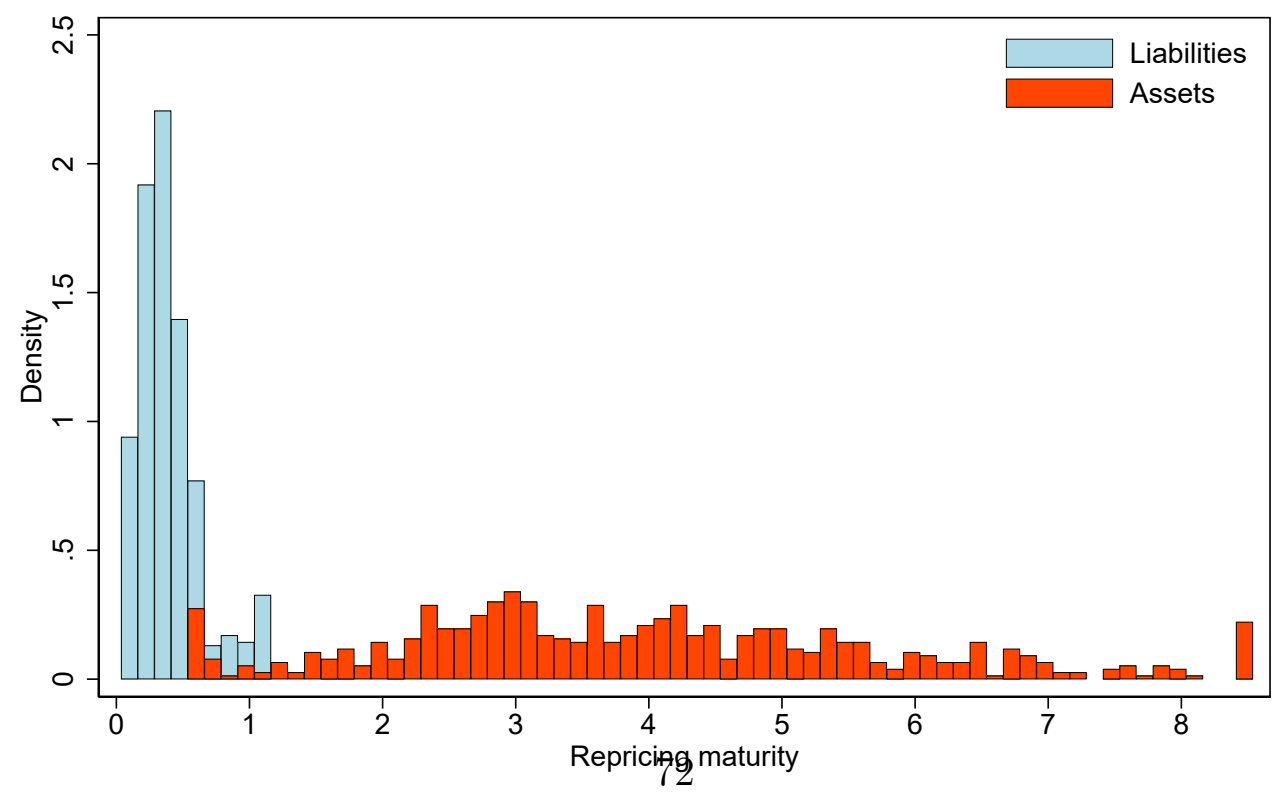




\section{Figure A.2: The interest rate sensitivity of operating costs and fee income}

This figure shows bin scatter plots of bank operating costs and deposit fee income by expense betas. The betas and scatterplots are constructed the same was as in Figure 6. The left column is for all banks and the right column for the top five percent of banks. The top panel provides information on total salaries, the middle panel on total rent, and the bottom panel on deposit fee income.

All banks

Top $5 \%$

Panel A: Total salaries
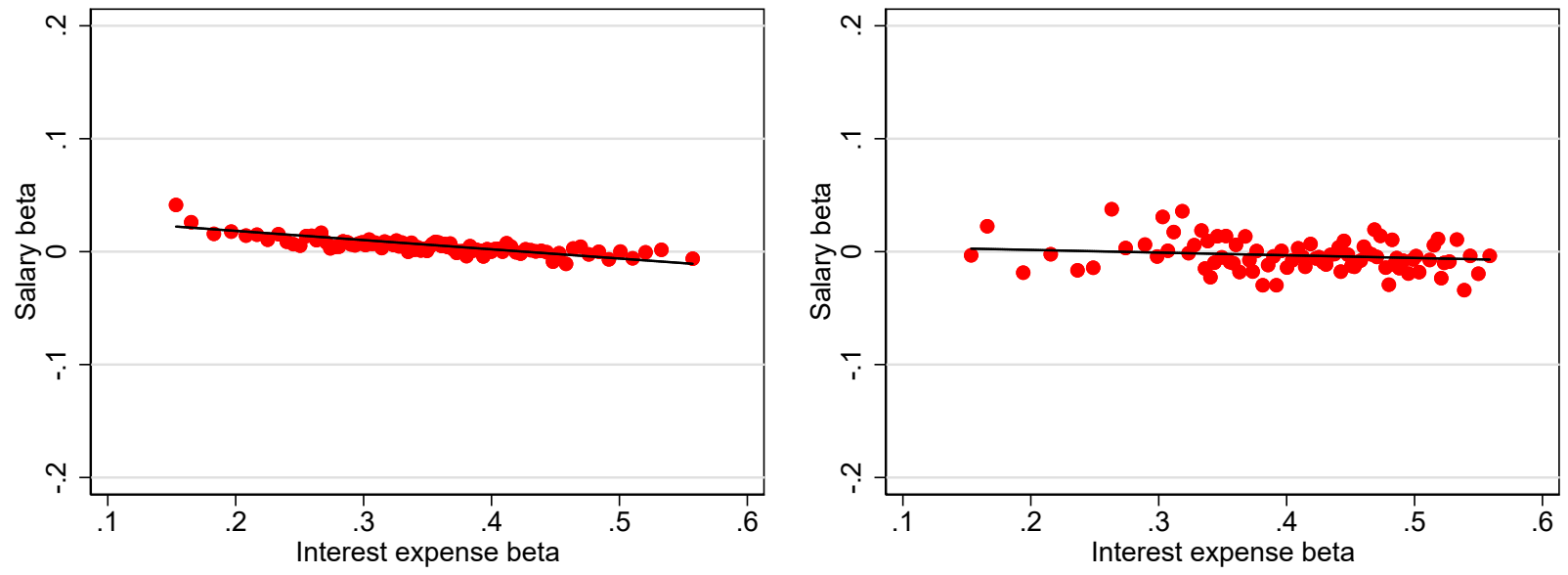

Panel B: Total rent
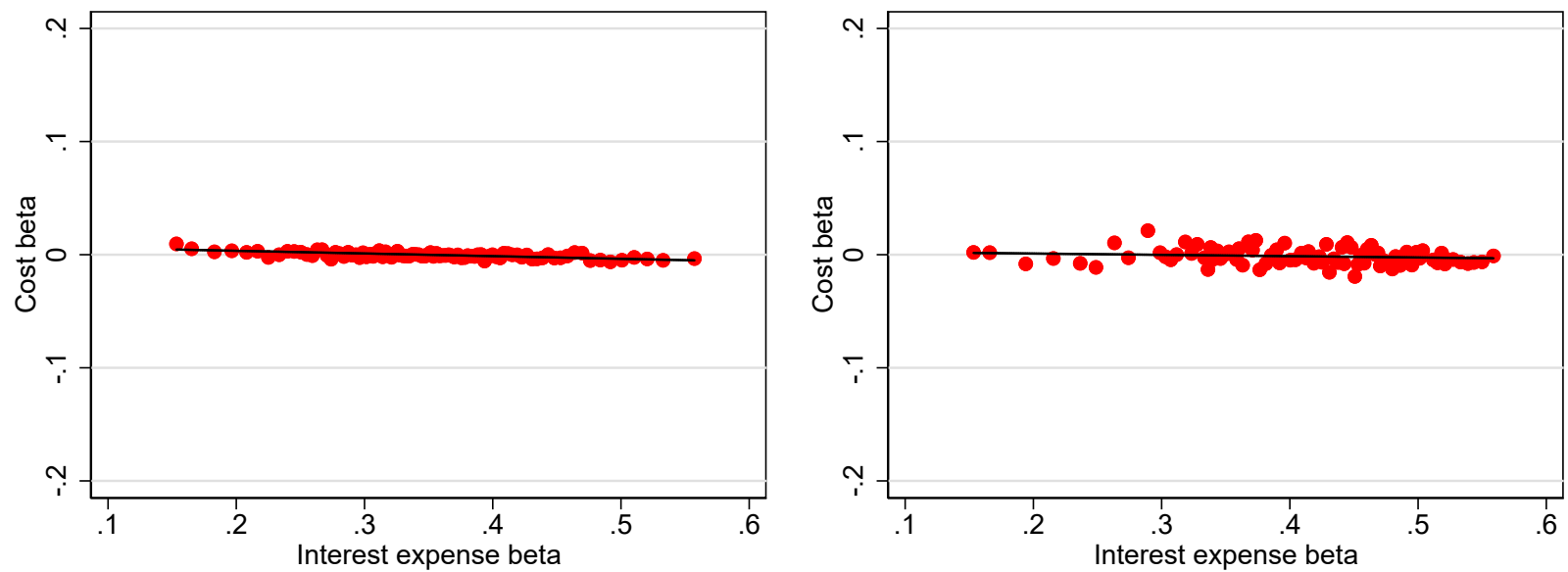

Panel C: Deposit fee income
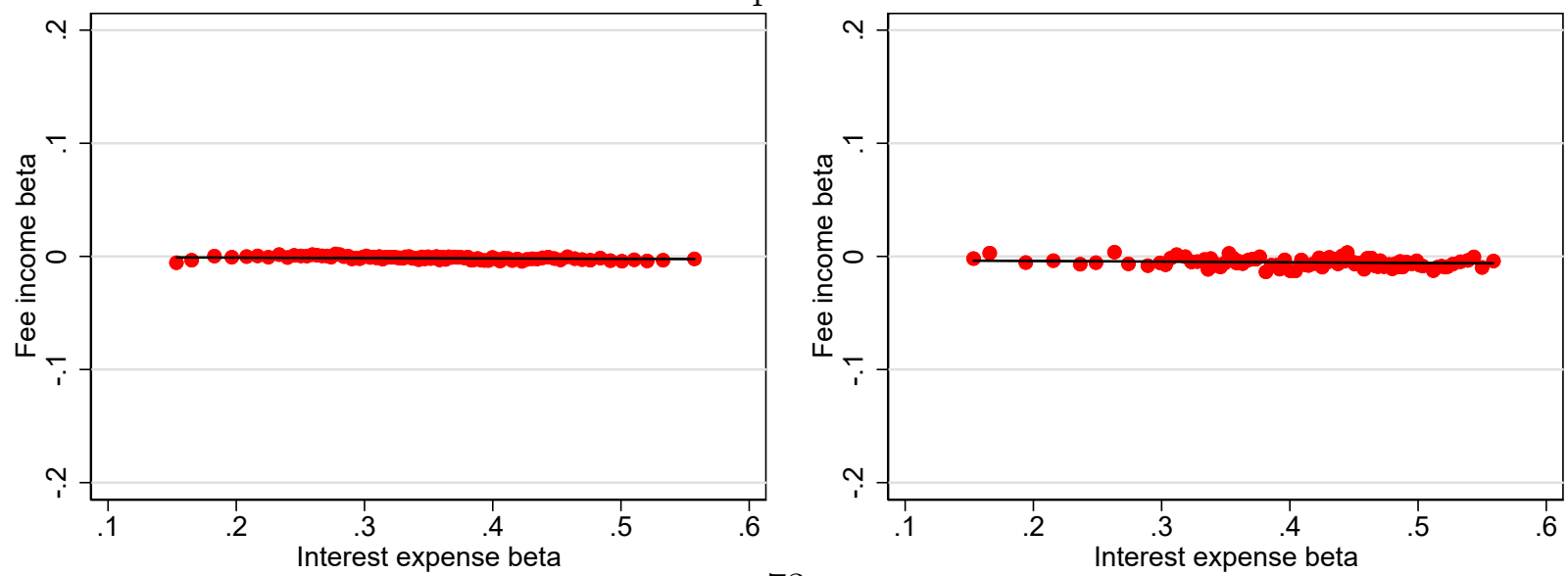
Figure A.2 The interest rate sensitivity of operating costs and fee income (cont.)

This figure shows bin scatter plots of bank operating costs and deposit fee income by expense betas. The betas and scatterplots are constructed the same was as in Figure 6. The left column is for all banks and the right column for the top five percent of banks. The top panel provides information on noninterest income, the middle panel on loan loss provision, and the bottom panel on trading revenue.

All banks

Top $5 \%$

Panel D: Noninterest income
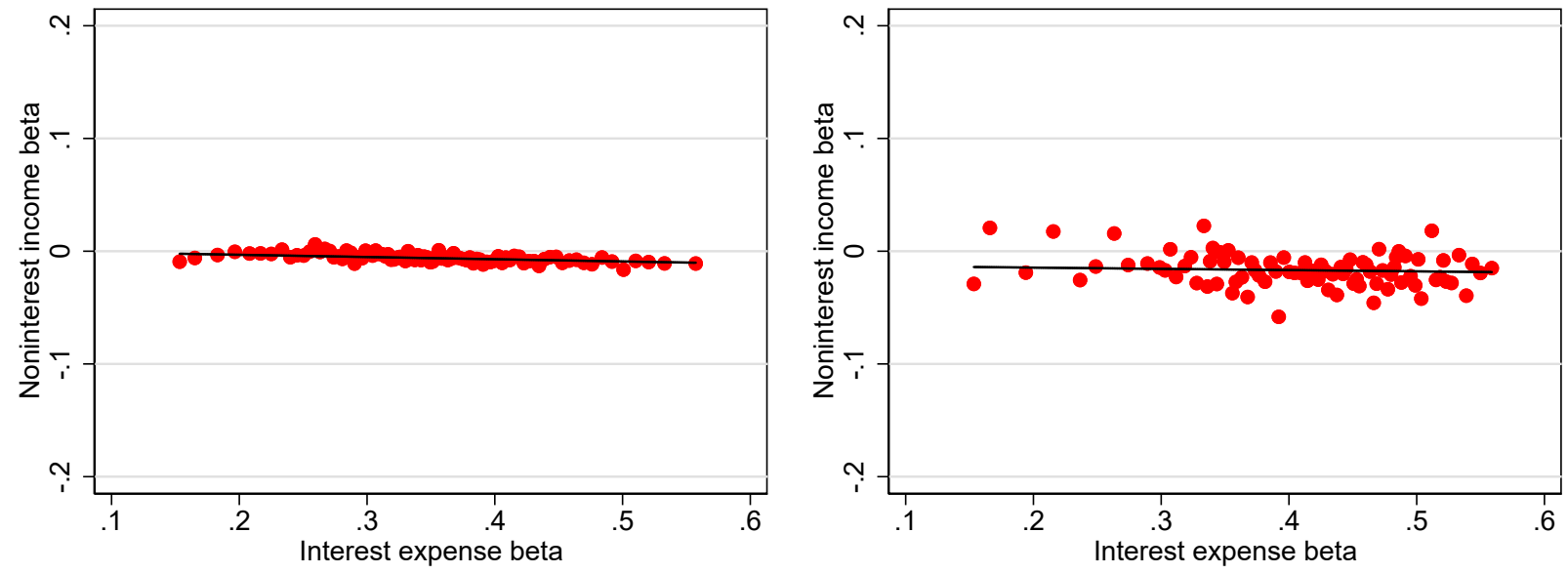

Panel E: Loan loss provision
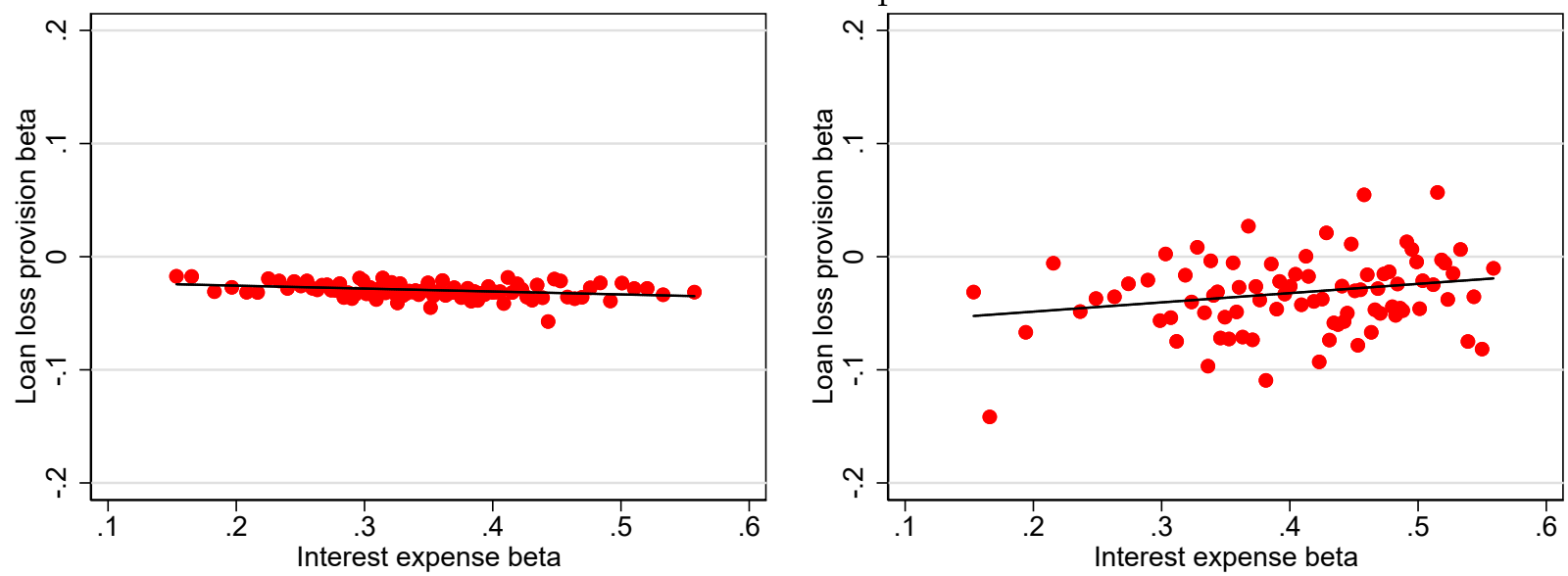

Panel F: Trading revenue
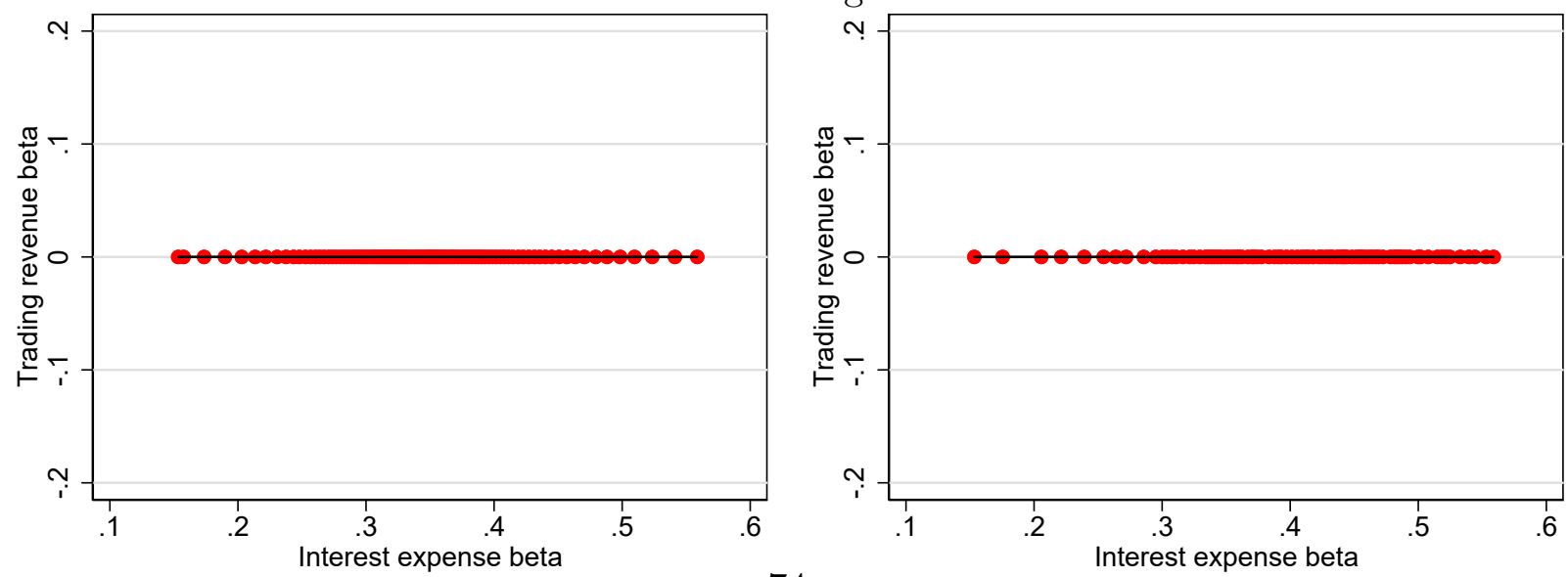